\title{
A Tecnologia Computacional Móvel na Sistematização da Assistência de Enfermagem: Avaliação de um Software-protótipo
}

Tese de Doutorado apresentada ao Programa de PósGraduação em Enfermagem Fundamental da Escola de Enfermagem de Ribeirão Preto - USP

Linha de pesquisa: Dinâmica de organização dos Serviços de Saúde e de Enfermagem.

Orientadora: Profa. Dra. Yolanda Dora Martinez Évora

Ribeirão Preto

2008 
Sperandio, Dircelene Jussara

A tecnologia computacional móvel na sistematização da assistência de enfermagem: avaliação de um softwareprotótipo. - Ribeirão Preto, 2008.

141p. : il. ; $29,7 \mathrm{~cm}$

Tese de Doutorado, apresentada à Escola de Enfermagem de Ribeirão Preto/USP - Departamento de Enfermagem Geral e Especializada.

Orientadora: Yolanda Dora Martinez Évora

1. Enfermagem. 2. Sistemas automatizados de Assistência junto ao Leito. 3. Avaliação. 4. Informática na Enfermagem. 5. Software. 


\section{FOLHA DE APROVAÇÃO}

Dircelene Jussara Sperandio

A Tecnologia Computacional Móvel na Sistematização da Assistência de Enfermagem: Avaliação de um Software-protótipo

Tese de Doutorado apresentada ao Programa de PósGraduação em Enfermagem Fundamental da Escola de Enfermagem de Ribeirão Preto - USP

Linha de pesquisa: Dinâmica de organização dos Serviços de Saúde e de Enfermagem.

Orientadora: Profa. Dra. Yolanda Dora Martinez Évora

Aprovado em:

Banca Examinadora

Prof. Dr.

Instituição:

Assinatura:

Prof. Dr.

Instituição:

Assinatura:

Prof. Dr.

Instituição:

Assinatura:

Prof. Dr.

Instituição:

Assinatura:

Prof. Dr.

Instituição:

Assinatura: 


\title{
DEDICATÓRIA
}

\author{
Dovalantino e Ana, \\ Meus pais, \\ Compartilho essa conquista \\ que foi possivel por me proporcionarem \\ amor e os caminhos para a construção \\ da minha vida e da minha história.
}

\section{Evandro,}

Meu irmão,

Presença constante na minha trajetória, inspiração e exemplo sempre valorizando e impulsionando a concretização dos meus ideais.

\author{
Pedro, \\ Pela dedicação ao nosso filho \\ $e$ compreensão \\ nos meus momentos de ausência \\ para a elaboração deste estudo.
}

\section{Julio,}

Protagonista do meu amor incondicional, seu nascimento e sua vida colorem meus caminhos e trouxeram luz a minha existência. 


\section{AGRADECIMENTOS}

Meus agradecimentos especiais, ao meu Deus, que me ilumina, protege e por ter colocado a minha família e estas pessoas no meu caminho.

Á Profa. Dra. Yolanda Dora Martinez Évora, que conduziu este estudo com dedicação, paciência e compartilhou sua sabedoria e conhecimento. Acima de tudo, pela amizade conquistada nestes anos, por acreditar em mim e indicar os caminhos.

A Fundação Padre Albino e as Faculdades Integradas Padre Albino, por apoiarem minha participação neste estudo que contribuiu para meu crescimento profissional.

A Profa. Dra. Dulce, Marcia, Maristela, Ilza e Maria Claudia pelo incentivo, colaboração e companheirismo que impulsionaram a concretização desta jornada.

A Mariane, Marisa e Antonio Marcio pelo carinho, dedicação, disponibilidade e eficiência que possibilitaram a elaboração desta pesquisa e a Soraya, Kamila, Ana Letícia, Cristiane, Solange, Karina, Juliano e Fábio pela dedicação e esmero nas atividades profissionais e pela nossa convivência sempre harmoniosa.

Aos discentes e docentes do Curso de Enfermagem-FIPA e em especial aos que participaram ativamente deste estudo, pela oportunidade de aprendermos e ensinarmos juntos.

Aos Serviços de Enfermagem dos Hospitais de Ensino: Emilio Carlos, Padre Albino e de Base por partilharem essa experiência e juntos contribuirmos para 0 crescimento da enfermagem como profissão.

Ao Professor Osvaldo, e demais docentes do Curso de Ciência da Computação do IMES-FAFICA pela confiança e participação no processo avaliativo deste estudo.

À Fundação de Amparo a Pesquisa-FAPESP pelo apoio financeiro na realização desta pesquisa.

$\grave{A}$ todas as pessoas que possibilitaram a concretização deste trabalho, meu compromisso de retribuir com mão amiga, o incentivo e apoio que sempre recebi $e$ continuo recebendo de vocês. 


\section{RESUMO}

SPERANDIO, D. J. A tecnologia computacional móvel na sistematização da assistência de enfermagem: avaliação de um Software-protótipo. Tese (Doutorado). 2008. 141p. Escola de Enfermagem de Ribeirão Preto, Universidade de São Paulo.

O propósito desta investigação foi avaliar o desempenho funcional e a qualidade técnica de um Software-protótipo desenvolvido para a sistematização da assistência de enfermagem. Foi elaborada uma versão deste ambiente computacional específica para aplicação em dispositivo de mão móvel com interface de rede sem fio integrada possibilitando aos enfermeiros acessar e documentar dados acerca de sinais vitais, balanço hidroeletrolítrico, evolução e prescrição de enfermagem a beira do leito com transmissão de dados em tempo real. Este estudo está alicerçado no Modelo do Processo de Avaliação segundo a ISO/IEC 9126, Parte 1: Modelo de qualidade, que versa sobre qualidade externa e interna de software e a especifica em seis características denominadas: funcionalidade, confiabilidade, usabilidade, eficiência, manutenibilidade e portabilidade, as quais são subdivididas em subcaracterísticas. Foi utilizado subsídio da NBR ISO/IEC 14598 que apresenta uma visão geral do processo de avaliação de software, suas orientações e requisitos. Este estudo descritivo/exploratório foi realizado em uma instituição de ensino superior de enfermagem e duas instituições hospitalares de ensino localizadas no interior do estado de São Paulo. Os avaliadores totalizaram um número de vinte e sete e foram constituídos por oito especialistas em informática; oito enfermeiros docentes e 11 enfermeiros, sendo sete do Hospital A e quatro do Hospital B. Considerando-se a característica de modularidade e adotando o referencial proposto por Pressman (2006), realizaram-se duas etapas de avaliação: teste de unidade modular e de validação. Inicialmente, a verificação concentrou-se em cada uma das doze unidades modulares, em seguida foram avaliados na forma integrada para se proceder ao teste de validação. O desenvolvimento destas duas etapas contou com a participação individual de cada um dos especialistas e ocorreu na presença da pesquisadora. Foi elaborado um instrumento de avaliação (Anexo I) a fim de documentar os dados coletados no teste de unidade modular e com base nas características e subcaracterísticas de qualidade foram desenvolvidos instrumentos específicos para aplicação do teste de validação junto aos especialistas em informática (Anexo II a) e enfermeiros docentes e enfermeiros (Anexo II b). Os resultados demonstraram que a incorporação da tecnologia da computação móvel advinda de rede sem fio às atividades assistenciais de enfermagem proporcionou um ambiente com mobilidade para as ações e facilitou a comunicação e a documentação da assistência prestada. A avaliação dos atributos de qualidade do Software-protótipo em questão foi mensurada pelos especialistas em informática, enfermeiros docentes e enfermeiros destacando-se duas características: usabilidade e eficiência. A usabilidade foi avaliada com $100 \%$ de respostas positivas pelos docentes e enfermeiros e com $80,4 \%$ de aprovação pelos especialistas em informática evidenciando que o Software-protótipo para a sistematização da assistência de enfermagem (SAE) apresenta facilidade para inserir e obter informações e apresenta-se como um sistema dinâmico para documentar a assistência prestada. A eficiência foi aprovada com $92,3 \%$ e $87,5 \%$ de respostas positivas pelos enfermeiros docentes e especialistas em informática, respectivamente, demonstrando que uma das vantagens desta ferramenta é 
armazenar, processar e disponibilizar informações sobre a SAE de forma mais eficiente que a realizada manualmente.

Palavras-chaves: enfermagem; sistemas automatizados de assistência junto ao leito; avaliação; informática na enfermagem; software. 


\begin{abstract}
SPERANDIO, D. J. The mobile computational technology in the systematization of nursing care: evaluation of a software-prototype. Thesis (Doctorate). 2008. 141p. College of Nursing at Ribeirão Preto, University of São Paulo.
\end{abstract}

The purpose of this investigation was to evaluate the functional performance and the technical quality of a software-prototype developed for the systematization of the nursing care. A version of this specific computational environment has been developed to be used in hand-mobile devices with integrated wireless network interface allowing the nurses to access and document data related to vital signals, hydroelectrolytic balance, evolution and nursing prescription at the point-of-care with transmission of data in real time. This study is based on Evaluation Process Model, according to ISO/IEC 9126, Part 1: Model of Quality which is versed in external and internal software quality and specifies it in six characteristics denominated: functionality, reliability, usability, efficiency, maintainability, and portability, which are subdivided in sub-characteristics. Subsidy of NBR ISO/IEC 14598 has been used, which presents a general overview of the software evaluation process, its orientations and requirements. This descriptive/exploratory study has been accomplished in a Nursing College and in two school hospital institutions in the interior of the state of Sao Paulo. It has been totaled 27 appraisers, and constituted by eight specialists on computer science; eight faculty members nurses; and 11 registered nurses - seven from Hospital A, and four from Hospital B. Considering the characteristic of modularity, and adopting the reference proposed by Pressman (2006), two stages of evaluation have been accomplished: modular unity test, and validation. Initially, the verification focused on each one of the 12 modular unities, and then they have been evaluated integrally in order to proceed the validation test. Each one of the specialists participated in the development of these two stages, which occurred in the presence of the researcher. An instrument of evaluation has been elaborated (Appendix I) in order to document the data collected in the modular unity test. Based on the characteristics and sub-characteristics of quality, specific instruments for application of the validation test have been developed along with the computer science specialists (Appendix II a), and the faculty members nurses and registered nurses (Appendix II b). The results demonstrated that the incorporation of the mobile computer technology originated from wireless network to the nursing care activities provided an environment with mobility for actions and became communication and documentation of the assistance easier. The evaluation of the quality attributes of the software-prototype was measured by the computer science specialists, faculty members nurses and registered nurses, highlighting two characteristics: usability and efficiency. The usability was evaluated, resulting $100 \%$ of positive approval among faculty members nurses, and $80.4 \%$ among computer science specialists, demonstrating that the software-prototype for the systematization of nursing care makes the action of inserting and obtaining information easy, and it is presented as a dynamic system to document the provided care. The efficiency was approved with $92.3 \%$ and $87.5 \%$ of positive answers by the faculty members nurses and computer science specialists, respectively, demonstrating that one of the advantages of this tool is to store, process, and make available information about the nursing process, more efficiently than the one made manually.

Key-words: nursing; point-of-care systems; evaluation; nursing informatics; software. 


\section{RESUMEN}

SPERANDIO, D. J. La tecnología computacional móvil en la sistematización de la atención de enfermería: evaluación de un software-prototipo. Tesis (Doctorado), 2008. 141p. Escuela de Enfermería de Ribeirão Preto, Universidad de São Paulo.

El propósito de esta investigación ha sido evaluar el desempeño funcional y la calidad técnica de un software-prototipo desarrollado para la sistematización de la atención de enfermería. Se ha elaborado una versión de este ambiente computacional específica para aplicación en dispositivo de mano móvil con interface de red sin hilo integrada posibilitando a los enfermeros acceder y documentar datos sobre señales vitales, balance hidroeletrolítrico, evolución y prescripción de enfermería al borde del lecho con transmisión de datos en tiempo real. Este estudio está fundamentado en el Modelo del Proceso de Evaluación según la ISO/IEC 9126, Parte 1: Modelo de calidad, que trata sobre calidad externa e interna de software y la específica en seis características denominadas: funcionalidad, confiabilidad, usabilidad, eficiencia, manutenibilidad y portabilidad, las cuales son subdivididas en subcaracterísticas. Se ha utilizado subsidio de la NBR ISO/IEC 14598 que presenta una visión general del proceso de evaluación de software, sus orientaciones y requisitos. Este estudio descriptivo/exploratorio se ha realizado en una institución de enseñanza superior de enfermería y dos instituciones hospitalarias de enseñanza ubicadas en el interior del estado de São Paulo. Los evaluadores han totalizado un número de veintisiete y se han constituido por ocho especialistas en informática; ocho enfermeros docentes y 11 enfermeros, siendo siete del Hospital A y cuatro del Hospital B. Considerándose la característica de modularidad y adoptando la referencia propuesta por Pressman (2006), se han realizado dos etapas de evaluación: test de unidad modular y de validación. Inicialmente, la verificación se ha concentrado en cada una de las doce unidades modulares, enseguida se han evaluado en la forma integrada para procederse al test de validación. El desarrollo de estas dos etapas ha contado con la participación individual de cada uno de los especialistas y ha ocurrido en la presencia de la investigadora. Se ha elaborado un instrumento de evaluación (Anexo I) a fin de documentar los datos recogidos en el test de unidad modular y con base en las características y subcaracterísticas de calidad se han desarrollado instrumentos específicos para aplicación del test de validación junto a los especialistas en informática (Anexo II a) y enfermeros docentes y enfermeros (Anexo II b). Los resultados han demostrado que la incorporación de la tecnología de la computación móvil proveniente de red sin hilo a las actividades asistenciales de enfermería ha proporcionado un ambiente con mobilidad para las acciones y ha facilitado la comunicación y la documentación de la atención prestada. La evaluación de los atributos de calidad del software-prototipo en cuestión se ha medido por los especialistas en informática, enfermeros docentes y enfermeros destacándose dos características: usabilidad y eficiencia. La usabilidad se ha evaluado con un $100 \%$ de respuestas positivas por los docentes y enfermeros y con un $80,4 \%$ de aprobación por los especialistas en informática evidenciando que el software-prototipo para la sistematización de la atención de enfermería (SAE) presenta facilidad para insertar y obtener informaciones y se presenta como un sistema dinámico para documentar la atención prestada. La eficiencia se ha aprobado con un $92,3 \%$ y un $87,5 \%$ de respuestas positivas por los enfermeros docentes y especialistas en informática, respectivamente, demostrando que una de 
las ventajas de esta herramienta es almacenar, procesar y disponibilizar informaciones sobre SAE de forma más eficiente que la realizada manualmente.

Palabras claves: enfermería; sistemas de atención de punto; evaluación; enfermería informática; programas informáticos. 


\section{LISTA DE FIGURAS}

Figura 1- Esquema dos objetos de qualidade de software e suas características. (Fonte: Associação Brasileira de Normas Técnica, NBR 13596, 1996)......

Figura 2- Divisão das métricas em categorias. (Fonte: Pressman, 2006. Engenharia de Software).

Figura 3- Fatores de qualidade de software de McCall. (Fonte: Pressman, 2006. Engenharia de Software).

Figura 4- Estrutura da ISO 9126 (Fonte: Associação Brasileira de Normas Técnica, NBR ISO/IEC 9126-1,2003).

Figura 5- Modelo de Qualidade para qualidade externa e interna (Fonte:Associação Brasileira de Normas Técnica, NBR ISO/IEC 91261,2003). 52

Figura 6- Relacionamento entre as normas do processo de avaliação e as de suporte para avaliação ((Fonte:Associação Brasileira de Normas Técnica, ABNT NBR ISO/IEC 14598-1,2001). 55

Figura 7- Processo de avaliação (Fonte: Associação Brasileira de Normas Técnica, ABNT NBR ISO/IEC 14598-1, 2001)..................................56

Figura 8- Tela de seleção do paciente para cadastramento de dados ..................62

Figura 9- Tela de cadastramento dos Sinais Vitais do paciente. ..........................63

Figura 10- Tela de cadastramento do Balanço Hidroeletrolítrico do paciente.........63

Figura 11- Tela para recuperação e complementação de informação sobre a Evolução de enfermagem................................................................

Figura 12- Tela para leitura e checagem da Prescrição de Enfermagem................65

Figura 13- Microcomputador móvel apoiado em suporte para transporte utilizado para a coleta de dados a beira do leito..............................................78

Figura 14- Tela de Informações Adicionais do Software-protótipo para a SAE

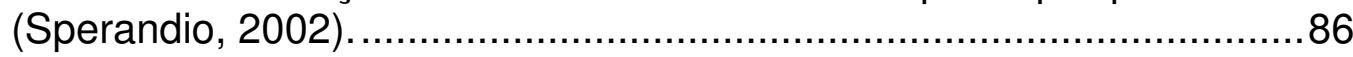

Figura 15- Tela da Entrevista do Software-protótipo para a SAE (Sperandio, 2002).87

Figura 16- Tela de Coleta de Dados do Software-protótipo para a SAE (Sperandio, 2002).

Figura 17- Tela da Lista de Problemas do Software-protótipo para a SAE (Sperandio, 2002). 
Figura 18- Tela da Prescrição de Enfermagem do Software-protótipo para a SAE (Sperandio, 2002).

Figura 19- Tela da Evolução de Enfermagem do Software-protótipo para a SAE (Sperandio, 2002). .96

Figura 20- Tela de Sinais Vitais do Software-protótipo para a SAE (Sperandio, 2002). .98

Figura 21- Tela de Balanço Hidroeletrolítrico do Software-protótipo para a SAE (Sperandio, 2002). .98

Figura 22- Tela de apresentação do Balanço Hidroeletrolítrico do Softwareprotótipo para a SAE (Sperandio, 2002). .99

Figura 23- Microcomputador móvel, dispositivos Pocket PC e Access Point usados especificamente no teste de validação. 102

Figura 24- Valores esperados para Subcaracterísticas e Características adaptados da ABNT NBR ISO/IEC 14598-6-Anexo C (Informativo). Exemplo de um módulo de avaliação - Funcionalidade 116

Figura 25- Validação da Característica Funcionalidade do Software-protótipo para Sistematização da Assistência de Enfermagem pelos Especialistas em Informática / Docentes / Enfermeiros. Catanduva, SP, 2007. 117

Figura 26- Validação da Característica Confiabilidade do Software-protótipo para Sistematização da Assistência de Enfermagem pelos Especialistas em Informática / Docentes / Enfermeiros. Catanduva, SP, 2007.

Figura 27- Validação da Característica Usabilidade do Software-protótipo para Sistematização da Assistência de Enfermagem pelos Especialistas em Informática / Docentes / Enfermeiros. Catanduva, SP, 2007. 121

Figura 28- Validação da Característica Eficiência do Software-protótipo para Sistematização da Assistência de Enfermagem pelos Especialistas em Informática / Docentes / Enfermeiros. Catanduva, SP, 2007. 123

Figura 29- Validação da Característica Manutenibilidade do Software-protótipo para Sistematização da Assistência de Enfermagem pelos Especialistas em Informática. Catanduva, SP, 2007. 125

Figura 30- Validação da Característica Portabilidade do Software-protótipo para Sistematização da Assistência de Enfermagem pelos Especialistas em Informática. Catanduva, SP, 2007. 


\section{LISTA DE TABELAS}

Tabela 1- Avaliação dos módulos do Software-protótipo para SAE pelos Especialistas em Informática. Catanduva, SP, 2007...........................80

Tabela 2- Modificações sugeridas na avaliação dos módulos do Software-protótipo para SAE pelos Especialistas em Informática. Catanduva, SP, 2007. ..80

Tabela 3- Avaliação dos Módulos do Software-protótipo para SAE pelos Docentes e Enfermeiros dos Hospitais A e B. Catanduva, SP, 2007. 82

Tabela 4- Avaliação do módulo Ficha de Identificação do Software-protótipo para SAE pelos Docentes e Enfermeiros dos Hospitais A e B. Catanduva, SP, 2007 84

Tabela 5- Avaliação dos módulos Dados Clínicos, Internações e Informações Adicionais do Software-protótipo para SAE pelos Docentes e Enfermeiros dos Hospitais A e B. Catanduva, SP, 2007. .85

Tabela 6- Avaliação do módulo Entrevista do Software-protótipo para SAE pelos Docentes e Enfermeiros dos Hospitais A e B. Catanduva, SP, 2007 ....88

Tabela 7- Avaliação do módulo Coleta de Dados do Software-protótipo para SAE pelos Docentes e Enfermeiros dos Hospitais A e B. Catanduva, SP, 2007. 90

Tabela 8- Avaliação dos módulos Lista de Problemas e Prescrição de Enfermagem do Software-protótipo para SAE pelos Docentes e Enfermeiros dos Hospitais A e B. Catanduva, SP, 2007. 94

Tabela 9- Avaliação do módulo Evolução de Enfermagem do Software-protótipo para SAE pelos Docentes e Enfermeiros dos Hospitais A e B. Catanduva, SP, 2007.

Tabela 10- Avaliação dos módulos Sinais Vitais, Balanço Hidroeletrolítrico e Telas para Cadastramento do Software-protótipo para SAE pelos Docentes e Enfermeiros dos Hospitais A e B. Catanduva, SP, 2007. 100

Tabela 11- Validação da Característica Funcionalidade do Software-protótipo para SAE pelos Especialistas em Informática. Catanduva, SP, 2007. ......105

Tabela 12- Validação da Característica Confiabilidade do Software-protótipo para SAE pelos Especialistas em Informática. Catanduva, SP, 2007. ......106

Tabela 13- Validação da Característica Usabilidade do Software-protótipo para SAE pelos Especialistas em Informática. Catanduva, SP, 2007. 108

Tabela 14- Validação da Característica Eficiência do Software-protótipo para SAE pelos Especialistas em Informática. Catanduva, SP, 2007. 108 
Tabela 15- Validação da Característica Manutenibilidade do Software-protótipo para SAE pelos Especialistas em Informática. Catanduva, SP, 2007. 109

Tabela 16- Validação da Característica Portabilidade do Software-protótipo para SAE pelos Especialistas em Informática. Catanduva, SP, 2007.

Tabela 17- Validação da Característica Funcionalidade do Software-protótipo para SAE pelos Docentes e Enfermeiros dos Hospitais A e B. Catanduva, SP, 2007. 112

Tabela 18- Validação da Característica Confiabilidade do Software-protótipo para SAE pelos Docentes e Enfermeiros dos Hospitais A e B. Catanduva, SP, 2007. 113

Tabela 19- Validação da Característica Usabilidade do Software-protótipo para SAE pelos Docentes e Enfermeiros dos Hospitais A e B. Catanduva, SP, 2007

Tabela 20- Validação da Característica Eficiência do Software-protótipo para SAE pelos Docentes e Enfermeiros dos Hospitais A e B. Catanduva, SP, 2007 


\section{LISTA DE QUADROS}

Quadro 1- Definição de subcaracterísticas e suas respectivas questões chaves para a utilização no instrumento de avaliação específico aos especialistas em informática. (Fonte: Associação Brasileira de Normas Técnica, NBR 13596, 1996).

Quadro 2- Definição de subcaracterísticas e suas respectivas questões chaves para a utilização no questionário específico enfermeiros docentes e enfermeiros. (Fonte: Associação Brasileira de Normas Técnica, NBR 13596). 74

Quadro 3- Níveis de pontuação 76 


\section{LISTA DE SIGLAS}

ABNT Associação Brasileira de Normas Técnicas

AlH Autorização de Internação Hospitalar

AM Amplitude Modulation

AMN Associação Mercosul de Normalização

ANS American National Standard

$\mathrm{CB} \quad$ Comitês Brasileiros

$\mathrm{CClH}$ Comissão de Controle de Infecção Hospitalar

CE Comissões de Estudo

CNS Conselho Nacional de Saúde

COFEn Conselho Federal de Enfermagem

CONMETRO Conselho Nacional de Metrologia, Normalização e Qualidade Industrial

COPANT Comissão Panamericana de Normas

COREn Conselho Regional de Enfermagem

DIN Deutches Institut fur Normung

DOS Disk Operating System

FAPESP Fundação de Amparo à Pesquisa do Estado de São Paulo

FCC Federal Communications Commission

FM Frequency Modulation

GPS Sistema de Posicionamento Global

IEC International Electrotechinical Commission

ISM Industrial, Scientific and Medical radio bands

ISO International Organization for Standardization

MSS Mobility Support Station

NBR Norma Brasileira

NEPIEn Núcleo de Estudo e Pesquisa em Informática e Enfermagem

NOS Organismos de Normalização Setorial

PDA Assistente Pessoal Digital

SAE Sistematização da Assistência de Enfermagem

SUS Sistema Único de Saúde

USP Universidade de São Paulo 


\section{ÍNDICE}

\section{SUMÁRIO}

APRESENTAÇÃO

1. INTRODUÇÃO

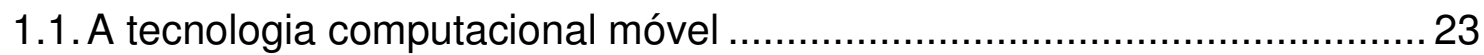

1.2. A tecnologia computacional móvel a beira do leito ..................................27

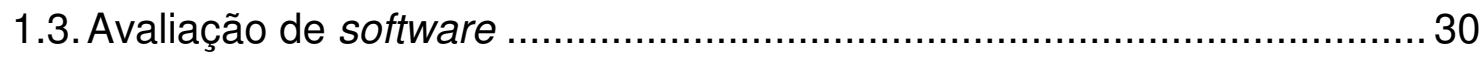

2. OBJETIVOS

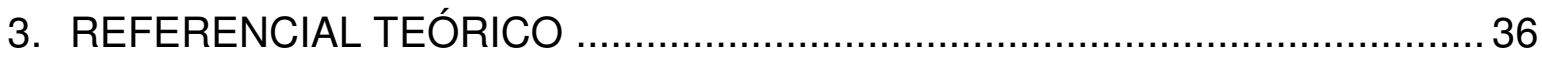

3.1. Qualidade de software e modelos de qualidade......................................36

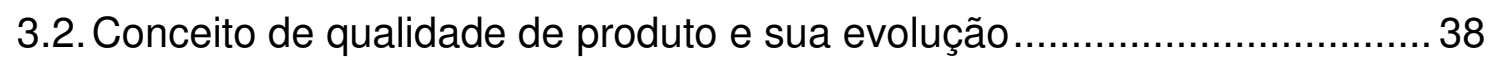

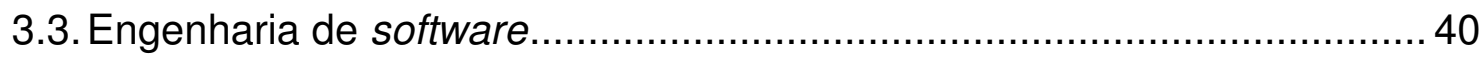

3.4. Modelos de qualidade de software ....................................................... 42

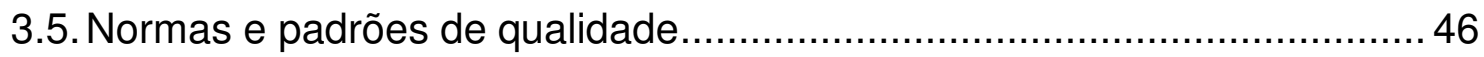

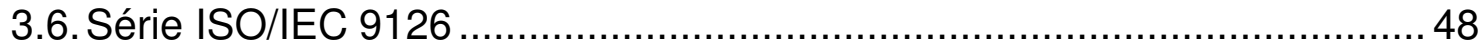

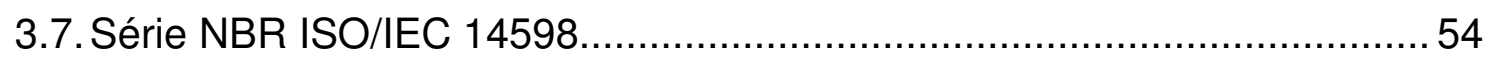

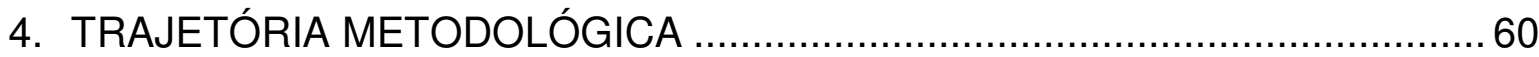

4.1. Apresentação do Software-protótipo para a Sistematização da Assistência de Enfermagem desenvolvido para uso em tecnologia da computação

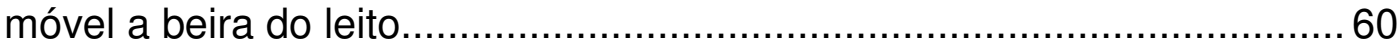

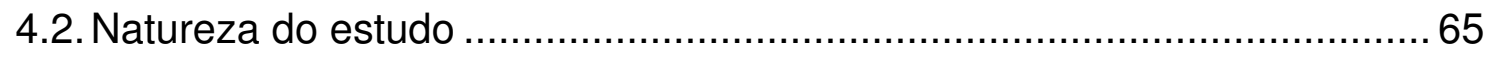

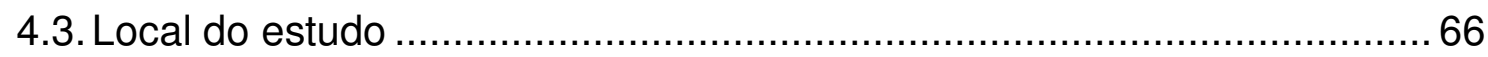

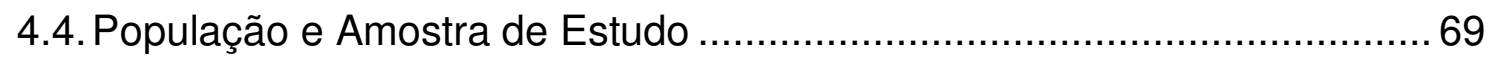

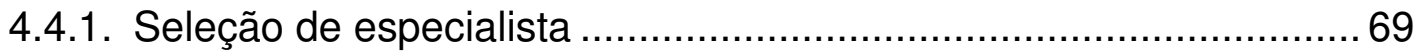

4.4.2. Seleção de enfermeiros docentes................................................ 70

4.4.3. Seleção de enfermeiros de assistência hospitalar ........................... 70

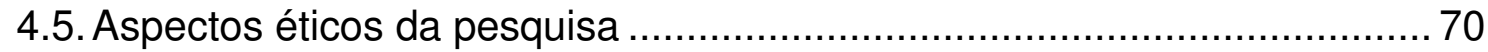

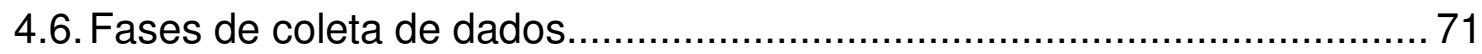

4.6.1. A fase de definição de requisitos de qualidade ............................ 72

4.6.2. A fase de preparação da avaliação............................................. 75

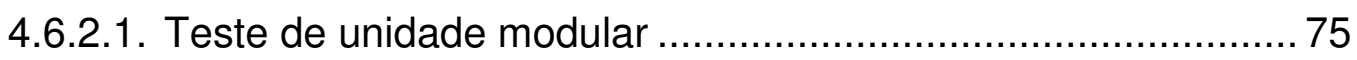

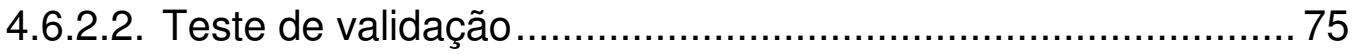

4.6.2.3. Definição dos níveis de pontuação ........................................ 76

4.6.3. A fase de procedimento de avaliação .......................................... 76

4.6.3.1. Validação dos instrumentos ............................................... 77

4.6.3.2. Organização dos dados para análise.................................... 77 
5. APRESENTAÇÃO E DISCUSSÃO DOS RESULTADOS DA AVALIAÇÃO DO SOFTWARE-PROTÓTIPO PARA SISTEMATIZAÇÃO DA ASSISTÊNCIA DE ENFERMAGEM

5.1. Teste de Unidade Modular ................................................................ 79

5.1.1. Teste de Unidade Modular pelos Especialistas em Informática....... 79

5.1.2. Teste de Unidade Modular pelos Docentes e Enfermeiros dos

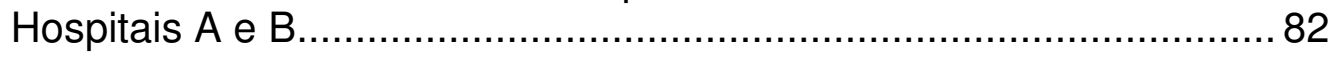

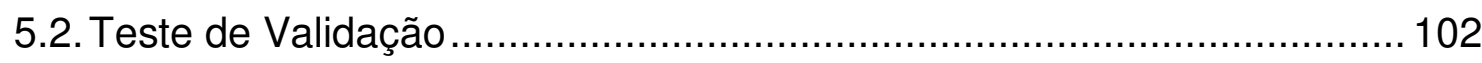

5.2.1. Validação dos Especialistas em Informática................................ 102

5.2.2. Validação dos Docentes e Enfermeiros Hospitais A e B................111

5.2.3. Resultados da Validação dos Especialistas em Informática, Docentes e Enfermeiros dos Hospitais A e B 115

5.2.3.1. Validação da Funcionalidade do Software-protótipo para Sistematização da Assistência de Enfermagem pelos Especialistas em Informática, Docentes e Enfermeiros dos Hospitais A e B. Catanduva, 2007 ..................................... 116

5.2.3.2. Validação da Confiabilidade do Software-protótipo para Sistematização da Assistência de Enfermagem pelos Especialistas em Informática, Docentes e Enfermeiros dos Hospitais A e B. Catanduva, 2007 ....................................... 119

5.2.3.3. Validação da Usabilidade do Software-protótipo para Sistematização da Assistência de Enfermagem pelos Especialistas em Informática, Docentes e Enfermeiros dos Hospitais A e B. Catanduva, 2007 ...................................... 121

5.2.3.4. Validação da Eficiência do Software-protótipo para Sistematização da Assistência de Enfermagem pelos Especialistas em Informática, Docentes e Enfermeiros dos Hospitais A e B. Catanduva, 2007 ..................................... 122

5.2.3.5. Validação da Manutenibilidade do Software-protótipo para Sistematização da Assistência de Enfermagem pelos Especialistas em Informática. Catanduva, 2007 .................... 124

5.2.3.6. Validação da Portabilidade do Software-protótipo para Sistematização da Assistência de Enfermagem pelos Especialistas em Informática. Catanduva, 2007 .................... 127

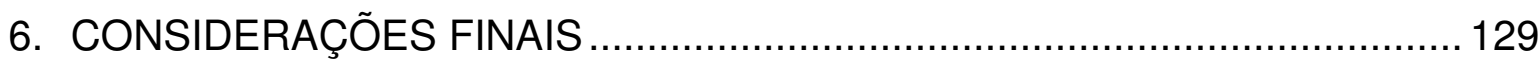

7. REFERÊNCIAS BIBLIOGRÁFICAS...................................................... 133

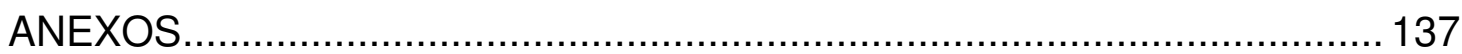




\section{APRESENTAÇÃO}

Este estudo trata da continuidade da dissertação de mestrado concluída em 2002, junto ao Programa de Pós-Graduação em Enfermagem Fundamental da Escola de Enfermagem de Ribeirão Preto, intitulada "Sistematização da Assistência de Enfermagem: Proposta de um Software - Protótipo", que apresentou como proposta central o desenvolvimento de um software para coleta de dados, prescrição de intervenções de enfermagem e sua documentação de forma individualizada e informatizada.

Após a obtenção do grau de bacharel em Enfermagem, cursei Ciência da Computação buscando assim, contribuir para a incorporação da tecnologia computacional na Enfermagem e trazer a reflexão sobre o papel do enfermeiro na era da informação, dispondo de uma ferramenta computacional que assegurasse uma assistência de enfermagem planejada, mais qualificada e adequada, estimulando a reaproximação do enfermeiro ao cuidado.

O avanço científico-tecnológico verificado nos últimos anos, em que o processo de informatização dos serviços de saúde passou a ser prioritário, levou-me a perceber que havia caminhado na direção correta, que minhas inquietações eram pertinentes e que deveria dar continuidade a este estudo. A tendência delineada nestas décadas indica o progresso acelerado da informatização, bem como a facilidade e rapidez de acesso às informações, substituindo tecnologias e procedimentos até então considerados suficientes.

Visando proceder a avaliação do Software-protótipo para a Sistematização da Assistência de Enfermagem (SAE) realizou-se um estudo preliminar em um hospital escola no interior do estado de São Paulo, na unidade de terapia semi-intensiva, 
motivados pela existência de um computador fixo com configuração adequada para o funcionamento do sistema.

Cabe ressaltar que os resultados experimentais obtidos com a utilização deste sistema, embora em escala reduzida, demonstraram que o hardware é uma ferramenta imprescindível para o sucesso na aplicação de software.

Observei que a dificuldade dos enfermeiros no emprego desta ferramenta computacional, consistia no transporte das informações coletadas à beira do leito para o microcomputador. Devido à distância de localização entre o hardware e o leito do paciente, o enfermeiro registrava em papel a coleta de dados acerca de um paciente e, posteriormente, procedia a transcrição para o Software-protótipo para SAE. Considerei ser este um dos principais problemas em utilizar computadores fixos para o registro da prática de enfermagem, uma vez que a atividade assistencial envolve mobilidade dos profissionais para o atendimento de diversos pacientes internados em unidade hospitalar.

Diante deste cenário, a computação móvel emerge como uma tecnologia inovadora para a assistência de enfermagem, por meio de sua aplicação via dispositivo móvel a outros computadores através da interface de rede sem fio integrada e planejada.

Com o apoio da Fundação de Amparo à Pesquisa do Estado de São Paulo (FAPESP), foi possível adquirir equipamentos e adequar o sistema favorecendo a avaliação do desempenho funcional e qualidade técnica do Software-protótipo para a Sistematização da Assistência de Enfermagem a beira do leito. 


\section{INTRODUÇÃO}

Na década de 70, Horta e colaboradores, preconizavam que a comunicação, entre outras habilidades, seria um dos instrumentos básicos da enfermagem, conceituando-os como conhecimentos e habilidades sem as quais o enfermeiro não poderia produzir um trabalho eficiente e se desenvolver profissionalmente, a fim de contribuir para uma enfermagem científica.

Após 30 anos, essa temática ainda constitui um enfoque atual e central na enfermagem. Mendes et al. (2002) asseguram que a comunicação tem importância no processo de enfermagem, no seu produto, tornando-se um componente fundamental na assistência.

O processo de comunicação em saúde, não deve ser visto apenas como uma forma de transmissão e entendimento de informações, mas, também, como uma maneira de possibilitar uma nova postura assistencial, incorporando a informação como condição indispensável ao planejamento da prática de enfermagem adequado às reais necessidades do paciente.

O enfermeiro somente socializa as informações e conhecimentos quando executa a documentação escrita. Para Lopes (1995), enquanto essencialmente orais, as transmissões das atividades de enfermagem desaparecem nos efeitos. Para a autora, a escrita se consolida pouco a pouco e se introduz como complementar à oralidade do cuidado.

Marin (1995) também considera, que a ação de enfermagem não documentada de forma correta e científica contribui para que a profissão permaneça invisível.

Quando o enfermeiro elabora a Sistematização da Assistência de Enfermagem (SAE) adota-se uma metodologia estruturada para o gerenciamento 
dos dados, das informações e do conhecimento, e assim são oportunizados subsídios para o planejamento, coordenação e avaliação das suas ações priorizando o atendimento ao paciente.

Em uma instituição de saúde, as informações são armazenadas e recuperadas no momento de sua utilização, demonstrando a necessidade de ser coletada de forma sistematizada e então organizada, favorecendo sua busca e acesso, e principalmente, o compartilhamento destas informações pela equipe multiprofissional, enfatizando a necessidade da tecnologia computacional ser utilizada como recurso facilitador da comunicação existente.

Nesta perspectiva, Évora e Dalri (2002) expressam que a tecnologia computacional facilita a organização e administração de informações, uma vez que favorece sua disponibilização em tempo real para o gerenciamento e assistência de enfermagem.

Évora (1995) considera que o computador a beira do leito propicia o desenvolvimento do processo de trabalho da enfermagem, uma vez que contribui para o acesso imediato ao prontuário, não ocorrendo à interrupção da assistência de enfermagem para localizar informações do paciente. A referida autora ressalta ainda outros benefícios, como a padronização da informação, a produção de uma documentação melhorada para propósitos legais e de pesquisa, além de uma redução significativa no tempo despendido pelos enfermeiros em atividades relacionadas à escrituração.

É necessário vislumbrar uma nova lógica no cuidar em saúde, que possibilite uma visão integral da assistência com a articulação e integração das informações produzidas pelos profissionais da saúde de forma, que a comunicação estabelecida entre os membros da instituição aperfeiçoe o processo de cuidar. 
Considera-se necessário, portanto, a construção de sistemas informatizados como forma de buscar soluções para aperfeiçoar a administração da informação, e apoiar o desenvolvimento do processo de trabalho na enfermagem e assim, obter resultados adequados para a performance do atendimento centrado no paciente.

À luz deste contexto, justifica-se avaliar o Software-protótipo para a Sistematização da Assistência Enfermagem, objetivando instrumentalizar a comunicação e promover mudanças nas relações multiprofissionais e intra-equipe de enfermagem.

\subsection{A tecnologia computacional móvel}

A história dos sistemas computacionais é marcada por transições de tecnologia sempre acompanhadas por novos paradigmas de interação, como se pode constatar no despertar da computação móvel.

Segundo Mateus e Loureiro (2004), a trajetória de evolução da computação móvel iniciou-se com Hans Christian Oersted em 1820, quando descobriu experimentalmente que a corrente elétrica produz um campo magnético. As equações sobre campos eletromagnéticos elaborados por James Clarck Maxwell e a detecção por Heinrich Rudolph Hertz das ondas eletromagnéticas previstas por Maxwell formaram a base para a criação do primeiro sistema de comunicação baseado na comunicação sem fio, o telégrafo, por Guglielmo Marconi em 1896, que permitia a transferência de palavras faladas à longa distância pelo código Morse.

O telefone, inventado por Alexander Graham Bell evoluiu rapidamente e tornou-se uma tecnologia complementar ao telégrafo durante anos. 
Em 1901 foi enviado um sinal que atravessou o Oceano Atlântico. Sua invenção permitiu que o transmissor enviasse caracteres alfanuméricos codificados em um sinal analógico.

Durante a Primeira Guerra Mundial, a ocorrência de interceptações de informações, gerou o desenvolvimento de novas formas de transmissões. Durante a Segunda Guerra Mundial, a pesquisa e o uso da comunicação via rádio expandiram amplamente e as informações foram transmitidas de forma segura via onda de rádio.

Nos anos 60, a AT\&T Bell Labs inicia os testes para as técnicas de comunicação celular e surgiram os primeiros aparelhos portáteis e também entrou em funcionamento uma rede wireless, desenvolvida por Normam Abramson da Universidade do Hawaii, que utilizava o primeiro algoritmo que permitia a comunicação entre estações utilizando um canal único.

No entanto, o uso comercial das redes sem fio deu-se apenas em meados da década de 80, quando a Federal Communications Commission (FCC), instituição reguladora das telecomunicações nos EUA, autorizou o uso de três faixas de radiofreqüência para finalidades industriais, científicas e médicas (industrial, scientific and medical - ISM). Estas não tinham a necessidade de concessão e assim, as redes sem fio se tornaram objeto de estudo mais profundo por parte de organismos internacionais.

O primeiro sistema de comunicação móvel foi um sistema de rádio utilizado pela polícia de Detroit em 1928 que introduziu um sistema de acionamento de carros baseado em radiodifusão unidirecional na faixa de $2 \mathrm{MHz}$.

A modulação em freqüência FM (Frequency Modulation) surgiu como uma alternativa para a modulação em amplitude AM (Amplitude Modulation) reduzindo os 
problemas na transmissão e melhorando o desempenho com relação à perda de sinal.

$\mathrm{Na}$ década de 90, ocorreu a introdução da tecnologia celular e o grande crescimento desta área, bem como das redes locais sem fio e serviços via satélites permitindo que informações e recursos possam ser utilizados de forma mais acessível.

Weiser (1991) introduziu o conceito da computação umbíqua, ao vislumbrar que o paradigma teclado-mouse-display seria substituído pela proliferação de dispositivos computacionais de variados tamanhos e propósitos.

A computação umbíqua é definida como a integração da tecnologia ao ambiente que cerca o usuário, sem modificar o seu comportamento natural ou deslocá-lo para um ambiente próprio de tecnologia para se beneficiar com seu uso. $\mathrm{Na}$ atualidade, essa disseminação é verificada por meio de dispositivos como computadores pessoais portáteis e assistentes pessoais digitais - PDAs que estão disponíveis no mercado e possuem a capacidade de se comunicar com outros computadores móveis e em rede, sem a necessidade de ter uma posição fixa na rede.

Este ambiente computacional é denominado de computação móvel e representa um novo paradigma que permite aos usuários acesso a serviços, independentes de onde estão localizados, e o mais importante, de mudanças de localização, ou seja, mobilidade.

Dessa forma, a comunicação sem fio eliminou a necessidade do usuário manter-se conectado a uma infra-estrutura fixa, e em geral, estática.

Mateus e Loureiro (2004) consideram que este fato corroborou para a ampliação dos sistemas de computação distribuídos. Um sistema distribuído com 
computadores móveis consiste de duas partes: uma tradicional estrutura de comunicação fixa com computadores estáticos que está interligada a uma parte móvel, representada por uma área geográfica ou célula onde existe a comunicação sem fio dos elementos computacionais móveis. Cada célula é atendida por transmissores de radiofreqüência, ou seja, estações base de apoio (Mobility Support Station-Mss).

Para estes autores, o meio de transmissão utilizado pelas redes sem fio é o não-delimitado, no caso a atmosfera, no qual as ondas eletromagnéticas provenientes do transmissor se propagam livremente no meio e se difundem através dele. Uma grande característica dos meios não delimitados é que o sinal se difunde igualmente em todas as direções, a menos que seja restringido, e continua a se propagar indefinidamente. À medida que a distância da origem aumenta, a energia se difunde por uma área maior, tornando o sinal cada vez mais fraco. No caminho do sinal eletromagnético ao longo do meio, alguns distúrbios naturais podem interferir no sinal.

Esta pesquisa utilizou para a transmissão de rede sem fios, um dispositivo transceptor, denominado Access point, que fornece a comunicação com a rede convencional e faz a intermediação do tráfego com os pontos de acesso vizinhos.

Para Mateus e Loureiro (2004), a computação móvel introduziu alguns problemas inexistentes nos sistemas de computação distribuídos tradicionais, relacionados com a transmissão sem fio, mobilidade e portabilidade.

A instabilidade da transmissão sem fio ocasionada pela interferência de sinais acarreta maior taxa de erros nesta forma de comunicação em relação à conexão com fio. As desconexões involuntárias também são mais freqüentes e existe maior 
risco à segurança das informações devido à facilidade da interceptação das mensagens e no rastreamento dos computadores móveis.

A mobilidade é a capacidade de um computador móvel mudar de localização enquanto está se comunicando com a rede. Certos dados da configuração estática na computação tradicional assumem uma natureza dinâmica na computação móvel. Como exemplo, é citado que um computador com endereço fixo pode ser configurado estaticamente para acessar o servidor mais próximo ou adequado, enquanto o móvel necessita de um mecanismo para selecionar dinamicamente o servidor a ser usado.

Os computadores móveis possuem um tamanho pequeno e são leves a fim de facilitar a portabilidade. Portanto, recursos como energia, capacidade de processamento, memória principal, existência de memória secundária e interface com o usuário apresentam restrições e precisam ser considerados nas aplicações e protocolos da computação móvel.

\subsection{A tecnologia computacional móvel a beira do leito}

Para Laudon e Laudon (2004), um sistema de comunicações envia e recebe informações de um local para outro, através de hardware e software compatíveis e de um canal de comunicação como forma de transmissão de dados em uma rede. Diferentes meios de transmissão podem ser utilizados pelos canais de comunicação como cabos co-axiais, fibras ópticas, satélites e transmissões sem fio, cada um apresentando vantagens e limitações.

A transmissão sem fio envia sinais pelo ar ou pelo espaço sem nenhuma base física. Indubitavelmente, essa característica tem se tornado uma alternativa para os 
canais de comunicação, quando necessário acesso remoto a sistemas corporativos e capacidade de computação móvel.

A tecnologia sem fio proporciona aplicações em diversos segmentos, entre eles, os sistemas de saúde. Laudon e Laudon (2004) descrevem como a transmissão sem fio confere mobilidade ao socorro médico em um serviço de saúde na Suécia.

Utilizando-se de rede wireless e um sistema de posicionamento global (GPS), o sistema denominado IS Swede acessa os bancos de dados dos hospitais. Quando uma ambulância chega à cena do acidente, o paramédico pode acessar os registros do prontuário do paciente armazenado por meio do IS Swede, usando um equipamento de mão. É possível a transmissão de dados referentes aos sinais vitais e de qualquer medicamento ministrado, que conjuntamente com os históricos do acidentado, são enviados via rede sem fio a um médico, que faz a leitura das informações e transmite rapidamente ao paramédico as orientações para o tratamento.

Desta forma, o socorro é prestado de acordo com o tipo de ferimento, com conhecimento de possíveis alergias e acesso ao histórico do paciente. O sistema ainda dispõe da possibilidade de incorporar as informações sobre o socorro prestado no prontuário, atualizando-o.

O Brasil também está despertando para os benefícios da computação móvel, e alguns hospitais de grande porte já incorporaram esta tecnologia às suas realidades. A utilização paralela da computação móvel e o acesso à rede sem fio, poderão, sem dúvida, auxiliar em muito no dia a dia dos profissionais de saúde. 
A tecnologia criou sistemas de informação que estão a serviço de nossa criatividade e, indiscutivelmente, estes serão sistemas efetivos no momento em que, cada um de nós puder integrar-se a eles com competência e responsabilidade.

Cabe ao enfermeiro buscar, inovar e implementar meios que permitam elevar a aquisição de conhecimento sobre esta nova tecnologia, e instrumentalizar-se para gerar visibilidade de suas ações.

A finalidade do computador móvel com rede wireless consiste na viabilização do registro da coleta de dados, e da assistência prestada ao paciente a beira do leito e a possibilidade de transmissão dos dados e informações em tempo real para o prontuário eletrônico do paciente.

São vários os fatores favoráveis e os benefícios da utilização da tecnologia da computação móvel a beira do leito na assistência de enfermagem. Com o dispositivo móvel à mão é possível acessar, coletar e documentar informações sobre o paciente em seu próprio leito, realizar etapas do Processo de Enfermagem, acompanhar a necessidade de mobilidade dos profissionais da enfermagem nas ações de assistência ao paciente, reduzir o tempo despendido na documentação das atividades prestadas ao paciente, diminuir a probabilidade de perda das informações, que passam a ser armazenada no próprio dispositivo e não em papéis, demonstrando como as características de flexibilidade e dinamismo convergem entre si contribuindo para a produtividade da assistência de enfermagem.

Entretanto, esses equipamentos, quando comparados com os computadores convencionais, apresentam algumas limitações como capacidade de memória, poder de processamento, tamanho da tela e bateria. Neste contexto, alguns conteúdos que exigem maior processamento de memória, necessitam ser utilizados em um modelo computacional com capacidade técnica mais avançada. 
A garantia da qualidade de um software constitui um dos importantes desafios e metas daqueles que têm a responsabilidade ética e moral com os usuários/pacientes. Para assegurar que o processo de avaliação melhore a qualidade do objeto que está sendo avaliado, torna-se imprescindível que se estabeleça normas ou padrões, uma vez que os resultados desse processo poderão expressar se esta tecnologia computacional será efetiva na operacionalização e documentação da assistência de enfermagem.

\subsection{Avaliação de software}

A avaliação é uma atividade fundamental para qualquer empreendimento gerador de produtos que serão usados por terceiros. Segundo Pressman (2006), antes do século XX, a avaliação era uma responsabilidade exclusiva do artesão que desenvolvia o produto. A primeira função normal de controle e avaliação foi introduzida nos Laboratórios Bell em 1916, e sua difusão ocorreu mundialmente na indústria de manufatura.

A história da avaliação no contexto do desenvolvimento de software é paralela à avaliação da manufatura do hardware. Durante as décadas de 1950 e 1960, que representaram os primórdios da computação, a avaliação era uma responsabilidade exclusiva do programador. Os padrões de avaliação para a garantia de qualidade do software, foram introduzidos no desenvolvimento de software sob contrato militar durante a década de 1970; a partir de então, estendeu-se para o mundo comercial.

Pressman (2006) enfatiza que a avaliação de software representa um elemento crítico de garantia de qualidade. Considera que o desenvolvimento de sistemas de software, envolve uma série de atividades de produção, em que é oportunizada a projeção de falhas humanas. Ainda cita a crescente utilização do 
software como elemento do sistema, e as implicações associadas aos seus erros como fatores que constituem mecanismos propulsores para a existência de métodos de avaliação. Esse autor define avaliação de software, como o processo de executar um programa com o objetivo de projetar testes, que descubram sistematicamente diferentes tipos de erros em um período de tempo e esforço mínimos.

De acordo com Oliveira (1996), avaliar é o processo técnico de medir a qualidade, com o propósito de determinar sua aceitação ou liberação para uso (NBR 13596).

Por sua vez, qualidade de software é definida por Barreto (1997) como estar de acordo com os requisitos dos usuários, ou, saber o que o usuário deseja e assim satisfazer suas necessidades, ou ainda, escrever tudo o que se deseja fazer, e fazer tudo o que foi escrito.

Para Rocha (1992), qualidade de software é o grau para que este processe uma combinação desejada de atributos. Na concepção de Pressman (2006), qualidade de software é a conformidade a requisitos funcionais e de desempenho explicitamente declarados, a padrões de desenvolvimento claramente documentados, e a características implícitas que são esperadas de todo software profissionalmente desenvolvido.

Polloni (2000) considera que para se obter qualidade de software, deve ser usado os conceitos de engenharia de software, destacando-se as métricas de qualidade diretas e indiretas. A qualidade é importante em todos os processos de engenharia de software, e para isso utiliza a combinação de fatores complexos, que variam de acordo com diferentes aplicações.

A qualidade de um software pode ser entendida como um grupo de características, que devem ser apresentadas para que o mesmo atenda às 
necessidades do usuário. É por meio dessas características que o produto é analisado e avaliado, sendo determinada sua qualidade.

Cada característica pode ser detalhada em vários níveis de subcaracterísticas, de onde se obtém um grande número de parâmetros para a descrição da qualidade de um produto de software. Para a aplicação desses parâmetros na análise de um produto é necessária uma sistematização na sua utilização. Assim sendo há vários modelos que propõem formas de se avaliar a qualidade de um software com a finalidade de dividir as características em subcaracterísticas, para que se torne mais fácil a métrica dos aspectos de qualidade.

Um fato importante mencionado por Pressman (2006) é que, os desenvolvedores de software encontram dificuldade para prever como o usuário realmente usará o produto. Muitas funções de uso podem ser interpretadas de forma errônea, ou aspectos que pareciam claros se tornem ininteligíveis ao consumidor em seu ambiente de uso. É importante, que usuários e desenvolvedores atuem estreitamente unidos ao longo desta fase, sendo que, o usuário avalia o domínio das informações, o desempenho, a implementação do programa, enquanto o desenvolvedor está disponível para atender as alterações necessárias garantindo que as exigências do usuário sejam satisfeitas.

Valendo-se das afirmações de Rocha (1992), Polloni (2000) e Pressman (2006), especificar normas, técnicas e padrões possivelmente acarretarão aos produtos e serviços maior aceitação e, por conseguinte, maior qualidade, sendo que esta deve ser uma atividade permanente dos desenvolvedores de software.

A avaliação de um software é fundamental para assegurar sua qualidade, e para identificar as razões técnicas de deficiências e limitações do produto, assim como observar o desempenho do usuário, e verificar as partes do sistema que 
precisam ser modificadas, a fim de que sejam feitas melhorias antes de ser disponibilizados em sua forma final.

O processo de avaliação do Software-protótipo, objeto desse estudo, é essencial para demonstrar que sua utilização seja adequada aos objetivos de sua concepção. Segundo Évora (1995), o uso da informatização é um recurso adicional para que o enfermeiro possa dinamizar o planejamento das suas ações, disponibilizando meios para aplicar seu conhecimento técnico-científico na assistência de enfermagem, em detrimento de atividades administrativas ou burocráticas, atingindo assim, o principal propósito desta profissão.

A avaliação de um software é fundamental para assegurar sua qualidade e para identificar as razões técnicas de deficiências e limitações do produto, assim como observar o desempenho do usuário e verificar as partes do sistema que precisam ser modificadas, a fim de que sejam feitas melhorias antes de ser disponibilizados em sua forma final.

Dentro dessa perspectiva, este estudo visa avaliar o Software-protótipo para a Sistematização da Assistência de Enfermagem, utilizando-se do Modelo do Processo de Avaliação segundo a norma ISO/IEC 9126-1, publicada em 1991 e revisada e disponibilizada em julho de 2003. Esta norma versa sobre qualidade de produtos de software, definindo seis características que descrevem, com um mínimo de sobreposição, a questão de qualidade do produto de software. Em caráter informativo, divide as características de qualidade de software em subcaracterísticas (Associação Brasileira de Normas Técnicas, ISO/IEC 9126-1, 2003).

A norma ISO/IEC 9126-1 é aplicada a qualquer tipo de software, porém, o protótipo para a SAE constitui um produto em domínio de aplicação específica para 
enfermagem, e poderá ser melhor avaliado segundo as particularidades que sua especificidade implica.

Este processo de avaliação expressará a visão real dos resultados desta nova tecnologia, desvendando se sua aplicação redundará na melhoria da racionalidade organizacional, dinamizando o planejamento das ações do enfermeiro, e disponibilizando meios para aplicar seu conhecimento técnico-científico na forma de assistir ao paciente.

Diante do exposto, e considerando ser necessário e fundamental o desenvolvimento da etapa de avaliação do Software-protótipo para a Sistematização da Assistência de Enfermagem, surgiram alguns questionamentos. Como está a qualidade técnica deste Software-protótipo? Será que o desempenho funcional atende às necessidades dos enfermeiros?

Para responder a estas indagações, desenvolveu-se nesta investigação um estudo para a avaliação desta ferramenta computacional, como parte importante para o aperfeiçoamento desta tecnologia, e sua posterior implementação em unidade de internação hospitalar. 


\section{OBJETIVOS}

\section{Objetivo geral}

- Avaliar o desempenho funcional e a qualidade técnica de um Softwareprotótipo, desenvolvido para a Sistematização da Assistência de Enfermagem, utilizando-se do Modelo do Processo de Avaliação segundo a norma ISO/IEC 9126-1.

\section{Objetivos Específicos:}

- Avaliar junto a especialistas em Informática a qualidade técnica do software em questão.

- Avaliar junto a enfermeiros docentes e enfermeiros o desempenho funcional deste software à beira do leito. 


\section{REFERENCIAL TEÓRICO}

\section{QUALIDADE DE SOFTWARE}

\subsection{Qualidade de software e modelos de qualidade}

A qualidade de software é definida por Pressman (2006) como "a conformidade, a requisitos funcionais e de desempenho explicitamente declarados, a padrões de desenvolvimento claramente documentados, e a características implícitas que são esperadas de todo software profissionalmente desenvolvido". Assim, entende-se que qualidade de software, é determinada pela qualidade dos processos utilizados para o seu desenvolvimento. Portanto, se houver melhoria na qualidade dos processos, haverá melhoria na qualidade de produto de software.

Tais assertivas permitem afirmar que a qualidade de software compreende três objetos: qualidade de projeto, qualidade de produto e qualidade de processo.

A qualidade de projeto é resultante do estabelecimento de um processo de projeto. Para sua eficácia, é pertinente, identificar e definir indicadores para sua execução, analisar o cumprimento das metas, cronogramas e custos previamente estabelecidos, e realizar intervenções necessárias.

A qualidade do processo é determinada pelo grau de flexibilidade para incorporar características implícitas de qualidade de produto e novos métodos, técnicas e ferramentas ao processo. O processo de software é a seqüência de passos para construção de um produto de software, inicia-se com a coleta de requisitos do usuário e finaliza com a entrega do produto final, passando por um ciclo de vida que oferece uma análise crítica dos documentos de requisitos e estende-se à instalação e manutenção do mesmo. Abrangem as relações com o fornecedor, usuário, gerenciamento e a engenharia de produto. 
Da mesma forma, a qualidade de um produto de software é resultante das atividades realizadas no processo de seu desenvolvimento. Avaliar a qualidade de um produto de software é verificar, através de técnicas e atividades operacionais, o quanto os requisitos são atendidos. Tais requisitos, de uma maneira geral, são a expressão das necessidades, explicitados em termos quantitativos ou qualitativos, e têm por objetivo definir as características de um software, a fim de permitir o seu atendimento, ou seja, o produto deve apresentar conformidade aos seus requisitos.

Modernamente, a qualidade de um produto de software é conseguida de forma consistente, em longo prazo, a partir da qualidade de projeto.

Desta maneira, o Esquema dos Objetos da Qualidade de Software e suas Características (Figura 1), expressam a qualidade de processo incorporando a qualidade de produto e a qualidade de projeto.

\section{Objetos de Qualidade de Software}

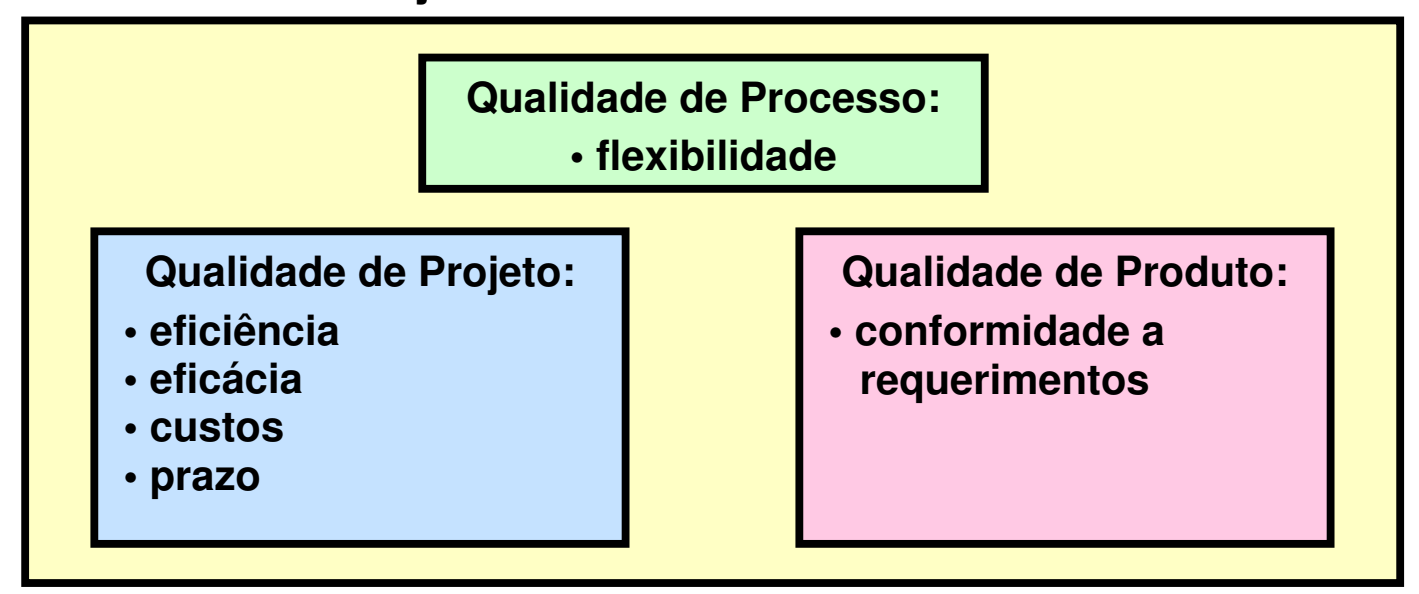

Figura 1 - Esquema dos objetos de qualidade de software e suas características. (Fonte: Associação Brasileira de Normas Técnica, NBR 13596, 1996).

Esta investigação concentrou-se na avaliação de um Software-protótipo para a Sistematização da Assistência de Enfermagem, ou seja, na qualidade de produto de software, e tem por propósito verificar como as características de qualidade de 
produto estão incorporadas nesta ferramenta computacional. Desta forma, a qualidade de produto será tratada neste estudo.

\subsection{Conceito de qualidade de produto e sua evolução}

A Norma ISO 8402 (ISO 8402) define qualidade como "a totalidade de características de uma entidade, que lhe confere a capacidade de satisfazer às necessidades explícitas e implícitas". As necessidades explícitas são aquelas expressas na definição de requisitos propostos pelo usuário. Esses requisitos definem as condições em que o produto deve ser utilizado, seus objetivos, funções e o desempenho esperado.

As necessidades implícitas são aquelas que, embora não expressas claramente pelo usuário, são necessárias. Constituem necessidades reais que muitas vezes não foram documentadas.

Gerlack (2001), afirma que embora o conceito de qualidade seja hoje um dos mais difundidos, tanto na sociedade como no ambiente empresarial, existe ainda pouco entendimento sobre o que é qualidade, certa ambigüidade e até diferentes interpretações no uso desta palavra.

Para esta autora, a qualidade não é algo identificável e observável diretamente. O que é identificável e observável são as características. Ou seja, a qualidade é vista por meio de características. No entanto, essa interpretação introduz uma dimensão subjetiva, ficando a definição, a forma de mensuração, a interpretação, a intensidade da associação das características e a própria característica propensas a análises pessoais.

Gerlack (2001) ainda explica que sempre existiram duas dimensões associadas à definição de qualidade: dimensão objetiva e dimensão subjetiva. 
A dimensão objetiva, também conhecida como qualidade primária, refere-se à qualidade intrínseca do produto, ou seja, aos aspectos relacionados à suas propriedades físicas, sendo impossível de ser separada do mesmo e dessa forma, independentemente do ponto de vista do ser humano.

A dimensão subjetiva, ou qualidade secundária, refere-se à percepção que as pessoas têm das características do produto, ou seja, está representada pela percepção humana na diferenciação da qualidade de produto referente às características visuais e sensoriais do mesmo.

A evolução do conceito de qualidade de produto relaciona-se com a maior aproximação a uma ou outra dimensão associada à qualidade. Até as décadas de 30 e 40 do século passado, o conceito de qualidade de produto se aproximava da idéia de perfeição técnica, associada muito mais a uma visão objetiva da qualidade. As décadas de 50 e 60 foram marcadas pelas obras de importantes autores da qualidade como Deming, Juran, Feigenbaum e Ishikawa. Deming (1990) definia qualidade de produto como a máxima utilidade para o consumidor, Feigenbaum (1994) como o perfeito contentamento do usuário, e Juran (1990) como satisfação das necessidades do usuário. Para Ishikawa apud Toledo (1997), a qualidade efetiva é a que realmente traz a satisfação.

Essas publicações representaram um marco na evolução do conceito de qualidade, uma vez que mudam o ponto de vista do objetivo para o subjetivo. $\mathrm{O}$ conceito de qualidade afasta-se da idéia de perfeição técnica e aproxima-se da satisfação do consumidor

A partir da década de 70 observam-se três vertentes de definição de qualidade de produto. A primeira vertente tem como principal expoente a definição de qualidade de Juram (1990) como adequação ao uso. Essa definição associa 
qualidade com o grau em que o produto atende o seu usuário de forma satisfatória durante o uso.

A segunda, de dimensão objetiva, utiliza a definição de Crosby (1988), para a qual a qualidade de produto precisa atender a um conjunto de especificações de projeto, estabelecendo um grau de conformidade com os requisitos do usuário.

A terceira vertente enfoca o lado não-qualidade, e é representada pela definição de Taguchi apud Toledo (1997), que conceitua qualidade como a perda, mensurável e imensurável, que um produto impõe à sociedade após seu embarque (após deixar a empresa), com exceção das perdas causadas por sua função intrínseca. Essa definição enfoca a falta de qualidade, seja por sua variabilidade das funções intrínsecas ou pelos efeitos colaterais do produto. Quanto maior a perda associada ao produto, menor a sua qualidade.

As vertentes descritas refletem a visão das dimensões objetiva e subjetiva, sob as quais se definiu qualidade.

\subsection{Engenharia de software}

A medição é uma atividade comum nas disciplinas de engenharia. Há medidas para peso, dimensões físicas, temperatura e outros. A engenharia de software não é exceção. Seu objetivo consiste na melhoria da qualidade do seu produto, entretanto, existem dificuldades em um denominador comum sobre o que medir e na avaliação das medidas obtidas.

Para Pressman (2006), a necessidade de medir o software é justificada por fatores como a indicação da qualidade do produto, avaliação da produtividade do pessoal envolvido no desenvolvimento, avaliação dos benefícios derivados de novos 
métodos e ferramentas, e na justificativa para a solicitação de novas ferramentas de desenvolvimento e necessidade de treinamentos adicionais.

De acordo com este autor, a ampla variedade de medidas de software recebe a denominação de métricas. Primeiramente, as métricas de software podem ser categorizadas em dois amplos grupos: medidas diretas que incluem como exemplo velocidade de execução e tamanho de memória, e medidas indiretas que tentam mensurar fatores como funcionalidade e qualidade.

Nada obstante ter-se definido as métricas em diretas e indiretas, podemos ampliar esta categoria, conforme definido na Divisão das métricas em categorias (Figura 2):

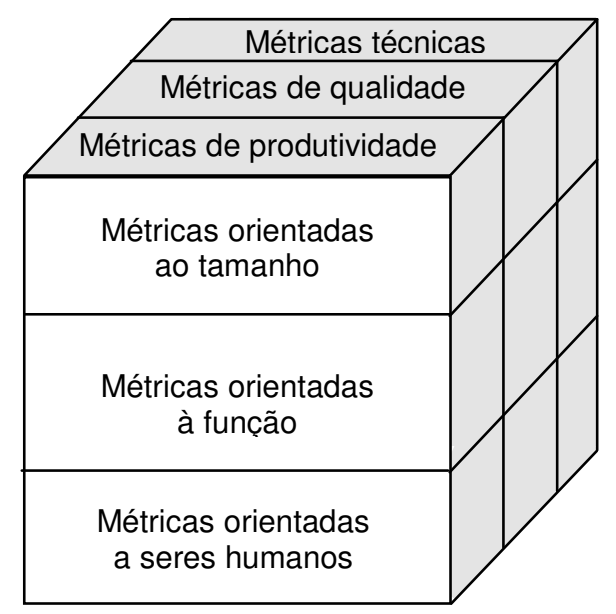

Figura 2 - Divisão das métricas em categorias. (Fonte: Pressman, 2006. Engenharia de Software).

Observa-se na Figura 2 uma categoria formada por métricas orientadas ao tamanho, à função e a seres humanos. As métricas orientadas ao tamanho são usadas para compilar as medições diretas da saída e da qualidade da engenharia de software. Oferecendo medições indiretas, temos as métricas orientadas à função, e finalmente, orientada às pessoas as métricas que compilam informações sobre como 
é o desenvolvimento de software por pessoas, e suas percepções sobre a efetividade das ferramentas e métodos utilizados na sua elaboração.

Uma segunda categoria, também é demonstrada na Figura 2 como métricas de técnicas, produtividade e qualidade. As métricas técnicas explicitam características do software e não do seu processo de desenvolvimento. Concentrando-se na saída do processo de engenharia de software temos as métricas de produtividade. As métricas de qualidade são as que oferecem uma indicação da conformidade do software às exigências implícitas e explicitas.

A definição de métricas de qualidade se justapõe aos objetivos deste estudo, motivando uma discussão detalhada sobre o tema.

\subsection{Modelos de qualidade de software}

Segundo Pressman (2006), foi definido por McCall e seus colaboradores, um conjunto de fatores de qualidade, que era uma primeira iniciativa na direção do desenvolvimento de métricas para a qualidade de software.

Estes fatores, ilustrados em Fatores de qualidade de software de McCall (Figura 3), traduziam a avaliação sob três aspectos: suas características operacionais, ou seja, operação do produto (usando-o), sua manutenibilidade de mudanças, traduzida pela revisão do produto (mudando-o), e sua adaptabilidade a novos ambientes, operando como a transição do produto (modificando-o para funcionar em um ambiente diferente). 


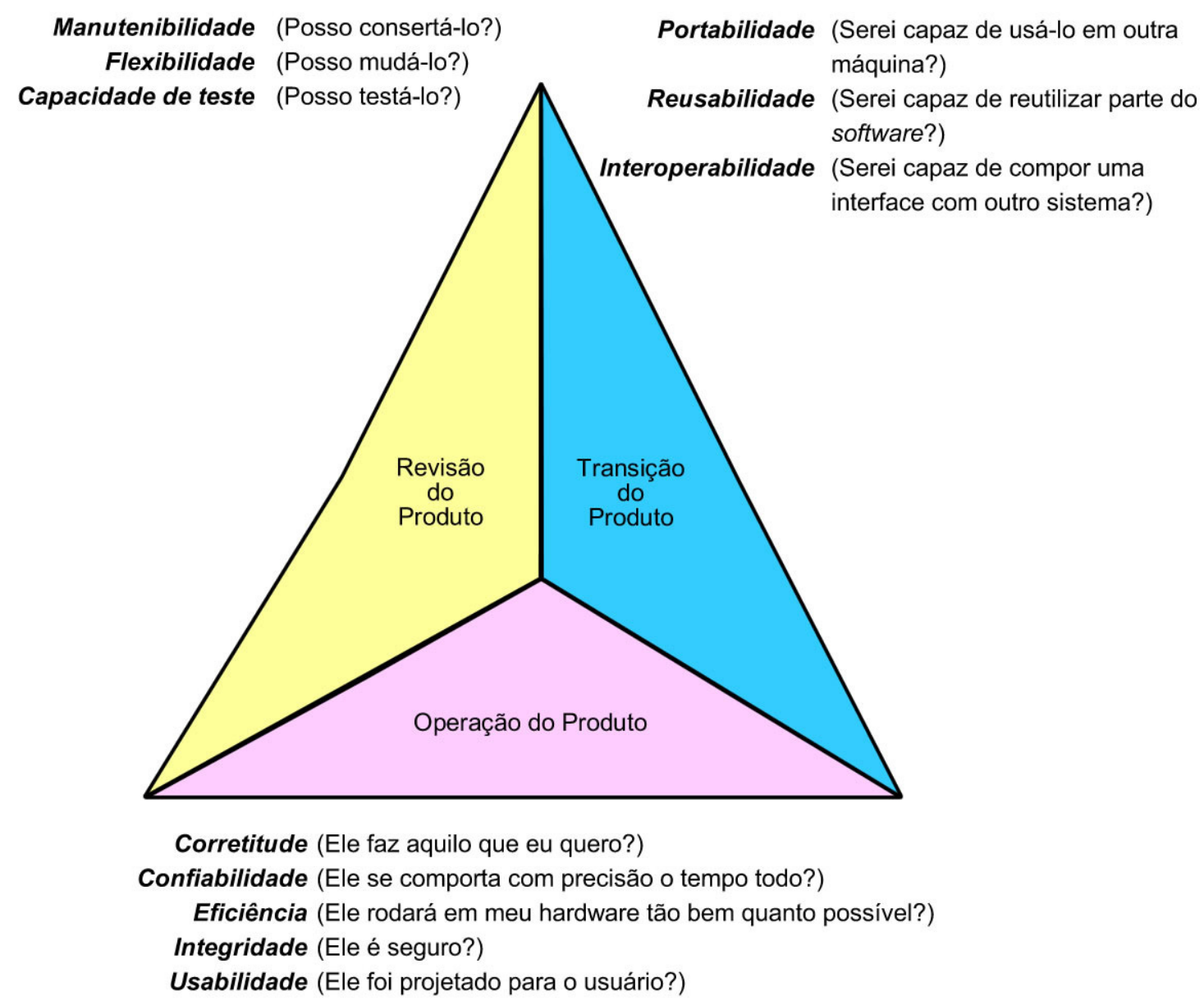

Figura 3- Fatores de qualidade de software de McCall. (Fonte: Pressman, 2006. Engenharia de Software).

Em conformidade com a Figura 3, são apresentadas as seguintes descrições:

Com relação ao uso do produto (características operacionais):

- correção: o quanto um programa satisfaz a sua especificação e cumpre os objetivos visados pelo usuário;

- confiabilidade: o quanto um programa executa a função pretendida com a precisão exigida;

- eficiência: a quantidade de recursos computacionais e de código exigida para que um programa execute sua função;

- integridade: o quanto o acesso ao software ou aos dados ou pessoas não autorizadas pode ser controlado; 
- usabilidade: o quanto de esforço é necessário para aprender, preparar a entrada e interpretar a saída de um programa.

Com relação às alterações do produto (habilidade para ser alterado):

- manutenibilidade: o quanto de esforço é necessário para localizar e eliminar erros em um programa;

- flexibilidade: o quanto de esforço é necessário para modificar um programa;

- testabilidade: o quanto de esforço é necessário para testar um programa a fim de garantir que ele execute a função pretendida.

Com relação a transição do produto (habilidade para ser modificado):

- portabilidade: o quanto de esforço é necessário para transferir um programa de uma plataforma de hardware e/ou software para outra;

- reusabilidade: o quanto um programa (ou partes dele) pode ser reutilizado em outros programas;

- interoperabilidade: o quanto de esforço é necessário para se acoplar um programa a um outro.

Conforme observamos, muitas das métricas definidas no modelo de McCall só podem ser medidas indiretamente, de forma subjetiva. Estas métricas podem ser organizadas na forma de um checklist, que será usado para estimar os atributos específicos do software. Um esquema proposto por este autor consiste em uma escala de 0 (baixo) a 10 (elevado), utilizando as métricas:

- auditabilidade: A facilidade com que se pode checar a conformidade aos padrões; 
- acurácia: a precisão das computações e do controle;

- comunidade de comunicação (Communication Commonality): o grau em que interfaces padrões, protocolos e larguras de banda (bandwidths) são usados;

- inteireza: o quanto a implementação total da função requerida foi conseguida;

- concisão: a compactação do programa em termos de linhas de código;

- consistência: o uso de técnicas de projeto e documentação uniformes ao longo do projeto de desenvolvimento de software;

- comunidade de dados (Data Commonality): o uso de estruturas e tipos de dados padrões ao longo do programa;

- tolerância a erros: o dano que ocorre quando o programa encontra um erro;

- eficiência de execução: o desempenho de run-time de um programa;

- expansibilidade: o quanto o projeto de arquitetura procedimental e de dados podem ser ampliados;

- generalidade: a amplitude de aplicação em potencial de componentes do programa;

- independência de hardware: o quanto o software é desvinculado do hardware em que opera;

- instrumentação: o quanto o programa monitora sua própria operação e identifica erros que venham a ocorrer;

- modularidade: a independência funcional dos componentes do programa;

- operabilidade: a facilidade de operação de um programa; 
- segurança: a disponibilidade de mecanismos que controlem ou protejam programas e dados;

- autodocumentação: o quanto o código-fonte apresenta documentação significativa;

- simplicidade: o quanto um programa pode ser entendido sem dificuldade;

- independência do software básico: o quanto um programa é independente de particularidades não-padronizadas de linguagem de programação nonstandard, das características de sistemas operacionais e de outras sujeições ambientais;

- rastreabilidade: a capacidade de rastrear uma representação de projeto ou componente de programa até os requisitos;

- treinamento: o quanto o software auxilia no sentido de ajudar novos usuários a aplicarem o sistema.

A relação entre os fatores de qualidade de software e as métricas acima descritas é mostrada na Figura 3. Segundo Pressman (2006), o peso dado a cada métrica depende dos produtos e preocupações de cada aplicação.

\subsection{Normas e padrões de qualidade}

As normas foram desenvolvidas objetivando um padrão único mundial a fim de que as empresas possam garantir a qualidade de seu trabalho. São consideradas internacionais, regionais, nacionais e organizacionais em função de sua área de aplicação. Diversas são as instituições de normalização em todo mundo.

Entre as que possuem prospecção internacional podem ser citadas como exemplo as normas Deutches Institut fur Normung - DIN (Instituto Alemão para a 
Normalização) e American National Standard - ANS (Padrões Nacionais Estadunidenses).

Além dos padrões internos de cada país, existem movimentos pela universalização em nível mundial.

Para esse fim foi criada em 1947, a International Organization for Standardization- ISO, uma federação não-governamental sediada em Genebra, cuja missão é promover o desenvolvimento de padrões e atividades relacionadas, de âmbito mundial visando facilitar a troca internacional de bens e serviços, e desenvolver cooperação em atividade intelectual, científica, tecnológica e econômica (ISO 9126-1, 2003). O trabalho da ISO resulta em acordos internacionais, os quais são publicados como Padrões internacionais.

A International Electrotechinical Commission - IEC, fundada em 1906, é outra organização mundial, que publica normas internacionais relacionadas com eletricidade, eletrônica e áreas relacionadas.

No Brasil, a Associação Brasileira de Normas Técnicas - ABNT, fundada em 1940, é o órgão responsável pela normalização técnica no país, fornecendo a base necessária ao desenvolvimento tecnológico brasileiro. Esta associação é uma entidade privada, sem fins lucrativos, reconhecida como Fórum Nacional de Normalização - ÚNICO - através da Resolução no 07 do CONMETRO - Conselho Nacional de Metrologia, Normalização e Qualidade Industrial - de 24.08.1992.

A ABNT é membro fundador da International Organization for Standardization- ISO, da Comissão Panamericana de Normas - COPANT e da Associação Mercosul de Normalização - AMN. Esta associação é a única e exclusiva representante no Brasil das entidades internacionais ISO e IEC e das entidades de normalização regional COPANT E AMN. 
As Normas Brasileiras, cujo conteúdo é de responsabilidade dos Comitês Brasileiros (ABNT/CB) e dos Organismos de Normalização Setorial (ABNT/NOS), são elaboradas por Comissões de Estudo - CE, formada por representantes dos setores envolvidos, delas fazendo parte: produtores, consumidores e neutros (universidades, laboratórios e outros).

\subsection{Série ISO/IEC 9126}

Muito trabalho foi realizado, desde 1976, por diversas pessoas, para definir uma estrutura de qualidade de software. Modelos de McCall, de Boehm, da Força Aérea dos Estados Unidos e outros foram adotados e ampliados ao longo dos anos. Ao mesmo tempo em que os estudos eram bem sucedidos, causavam confusão devido aos muitos aspectos de qualidade oferecidos. Em conseqüência, surgiu a necessidade de um modelo padronizado.

O comitê técnico da ISO/IEC, a partir de 1978, empreendeu esforços para desenvolver o consenso requerido e encorajar a padronização mundial.

Em 1985 foi iniciado o desenvolvimento da ISO 9126, apresentando como proposta inicial propriedades de software, que dependem de aspectos de aplacação e/ou implementação para descrever sua qualidade.

Esta primeira tentativa de sistematizar essas propriedades falhou por falta de definições. Os termos foram interpretados de formas diferentes por diversos especialistas.

Portanto, estabeleceu-se que a melhor condição para o estabelecimento de uma norma, consistia em estipular um conjunto de seis características: funcionalidade, confiabilidade, usabilidade, eficiência, manutenibilidade e portabilidade, as quais são baseadas na definição de qualidade. 
Os requisitos para a escolha das seis características descritas da ISO/IEC 9126 foram os seguintes: contemplar todos os aspectos de qualidade de software resultantes da definição de qualidade da ISO, descrever a qualidade do produto com um mínimo de sobreposição, manter-se próximo da terminologia estabelecida; formar um conjunto de não mais de seis ou oito características, por questões de clareza e manuseio; identificar áreas de atributos de produtos de software para posterior refinamento.

O comitê técnico emitiu a versão 1991 da ISO/IEC 9126 e em 2003 realizou sua revisão, mantendo as mesmas seis características de qualidade e introduzindo clareza nos relacionamentos com métricas externas e internas, e explicitando a qualidade em uso.

A NBR ISO/IEC 9126, sob o título geral "Engenharia de software - Qualidade do produto", consiste nas seguintes partes:

Parte 1: Modelo de qualidade;

Parte 2: Métricas externas;

Parte 3: Métricas internas;

Parte 4: Métricas de qualidade em uso.

Este estudo está alicerçado teoricamente na NBR ISO/IEC 9126, Parte 1: Modelo de qualidade que descreve um modelo de qualidade do produto de software, composto de duas partes. A primeira versa sobre qualidade externa e interna, enquanto a outra explicita a qualidade em uso. A primeira parte do modelo especifica seis características para qualidade interna e externa, as quais são por sua vez subdivididas em subcaracterísticas. Estas subcaracterísticas são manifestadas externamente, quando o software é utilizado como parte de um sistema computacional, e são resultantes de seus atributos internos (Figura 4). 


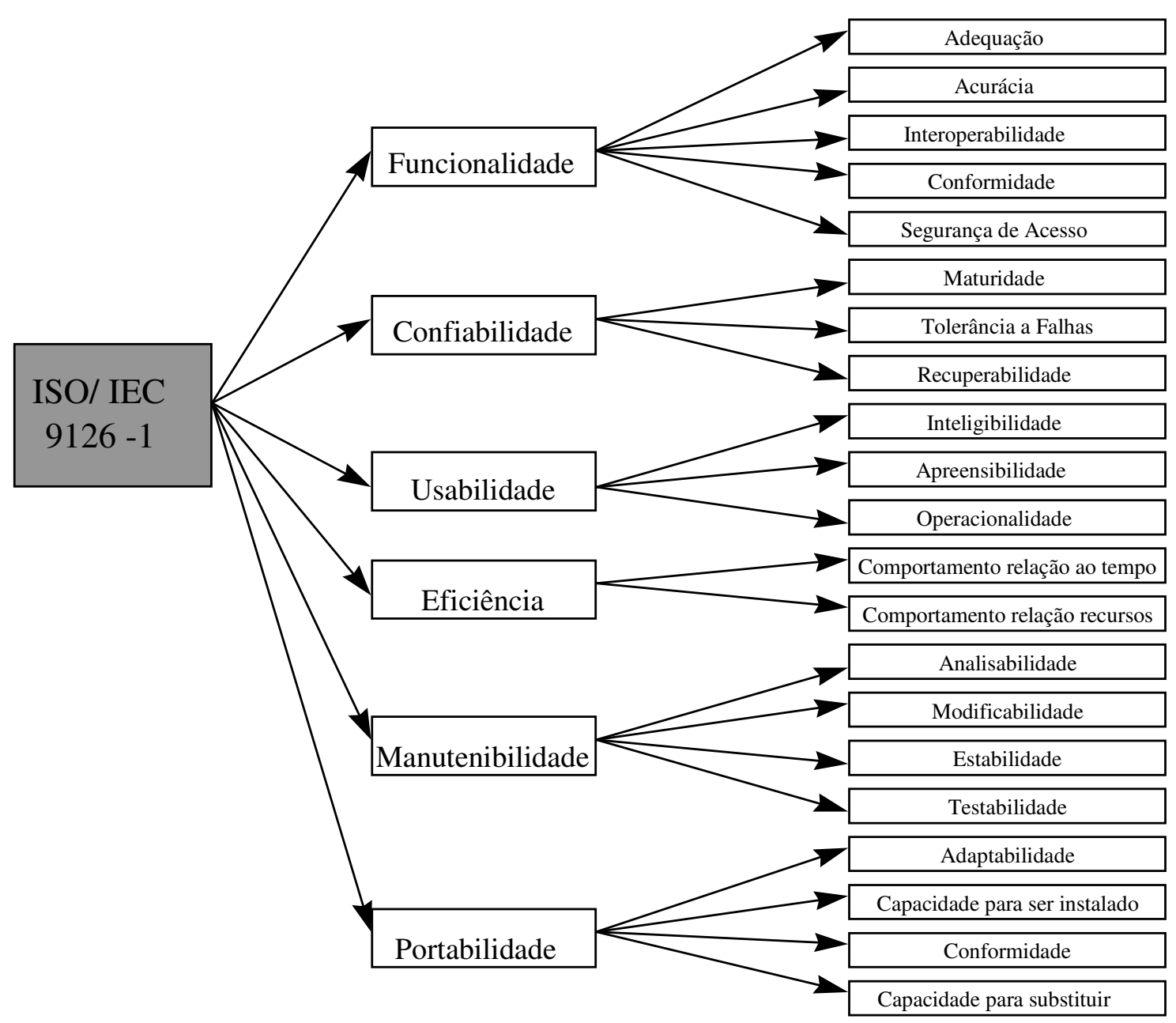

Figura 4- Estrutura da ISO 9126 (Fonte: Associação Brasileira de Normas Técnica, NBR ISO/IEC 9126-1,2003).

Para uma melhor compreensão, os conceitos de qualidade interna e externa e em uso são esclarecidos.

A qualidade interna é entendida como a totalidade das características do produto de software do ponto de vista interno. Detalhes da qualidade do produto podem ser melhorados durante a implementação do código, revisão e teste, mas a natureza fundamental da qualidade do produto de software representada pela qualidade interna mantém-se inalterada, a menos que seja projetada. 
A totalidade das características do produto de software do ponto de vista externo, isto é, a qualidade quando o software é executado, o qual é tipicamente medido e avaliado enquanto está sendo testado em um ambiente simulado e usando métricas externas, é o que conceituamos qualidade externa.

Enquanto que, a visão da qualidade do produto de software do ponto de vista do usuário, quando este produto é usado em um ambiente e um contexto de uso especificado, medindo o quanto usuários podem atingir seus objetivos em um determinado ambiente, e não nas propriedades do software. Assim definimos, qualidade em uso.

A NBR ISO/IEC 9126 - 1 emitida em 2003 constitui-se uma revisão, substituição e cancelamento da NBR 13596 - Tecnologia da Informação (1996).

Sua reformulação mantém as mesmas características de qualidade de software, incluindo modificações como: especificação de um modelo de qualidade, introdução de qualidade em uso, remoção do processo de avaliação (agora especificado na NBR ISO/IEC 14598) e na coordenação de seu conteúdo com a NBR ISO/IEC 14598-1.

A norma NBR ISO/IEC 9126-1 apresenta um Modelo de qualidade para qualidade externa e interna (Figura 5), e categoriza os atributos de qualidade de software em seis características: funcionalidade, confiabilidade, usabilidade, eficiência, manutenibilidade e portabilidade. Por sua vez, cada uma delas é subdividida em subcaracterísticas. 


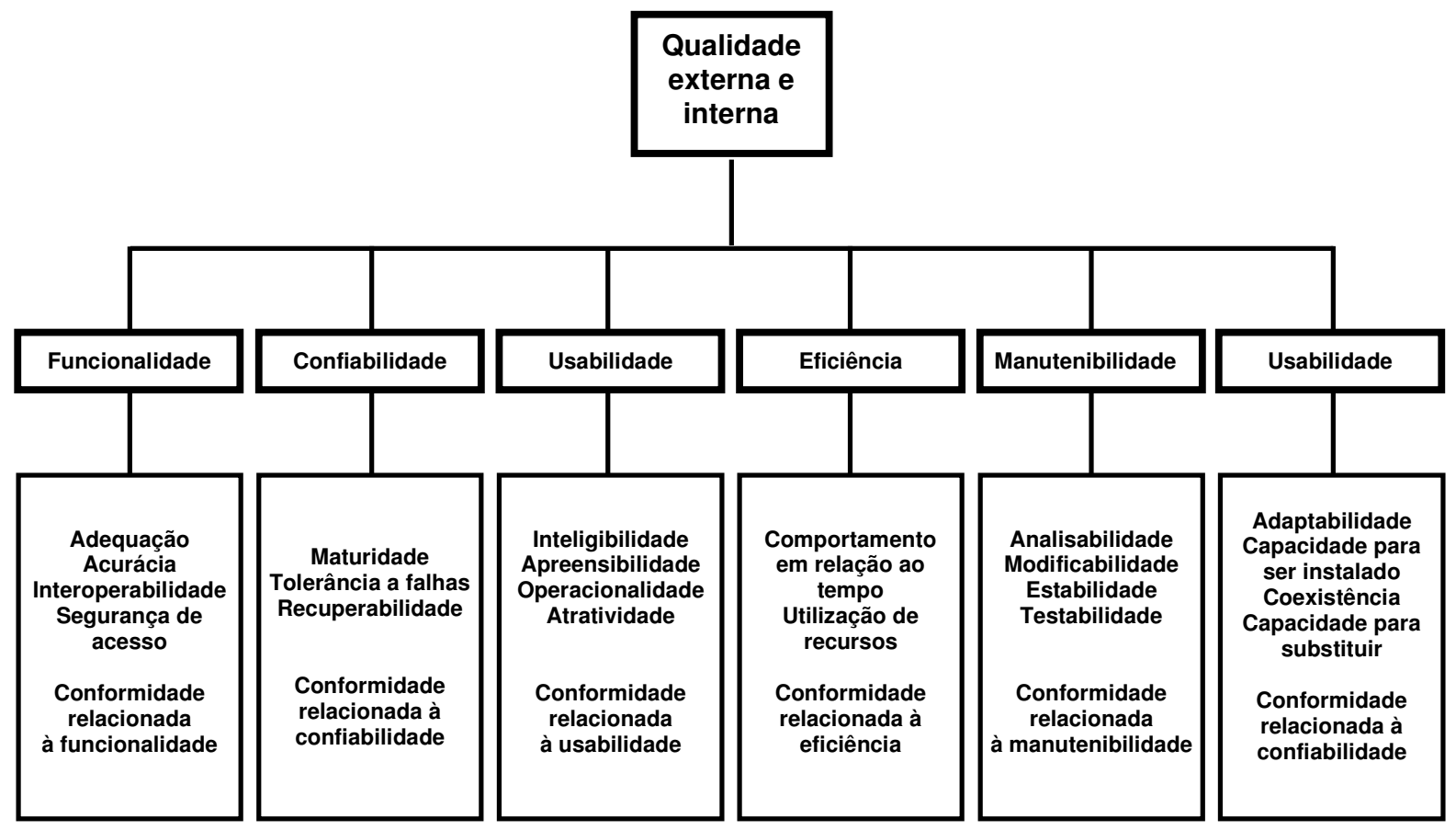

Figura 5 - Modelo de Qualidade para qualidade externa e interna (Fonte:Associação Brasileira de Normas Técnica, NBR ISO/IEC 9126-1,2003).

As características pretendem abranger todos os aspectos de qualidade de software, ou seja, deve ser possível especificar qualquer requisito de qualidade utilizando-se das seis características.

A NBR ISO/IEC 9126-1, sendo um modelo de qualidade, privilegia a visão do usuário, seja este final, pessoal da manutenção ou os operadores de software. Por este motivo, o modelo é representado de forma hierárquica - em níveis. No primeiro nível estão definidas as características de qualidade de produto. Em segundo, são definidas as subcaracterísticas pertinentes a cada característica do nível anterior. O conjunto de características e subcaracterísticas provêm uma terminologia consistente para qualidade de software, e apresenta seis características básicas, através das quais fazem parte várias subcaracterísticas que podem ser verificadas a seguir:

- Funcionalidade: "Conjunto de atributos que evidenciam a existência de um conjunto de funções e suas propriedades específicas". Como 
subcaracterísticas têm-se: adequação, acurácia, interoperabilidade, segurança de acesso e conformidade relacionada à funcionalidade;

- Confiabilidade: "Conjunto de atributos que evidenciam a capacidade do software de manter seu nível de desempenho sob condições estabelecidas durante um período de tempo estabelecido". Como subcaracterísticas apresenta-se: maturidade, tolerância a falhas, recuperabilidade e conformidade relacionada à confiabilidade;

- Usabilidade: "Conjunto de atributos que evidenciam o esforço necessário para se poder utilizar o software, bem como o julgamento individual deste uso, por um conjunto explícito ou implícito de usuários". Para as subcaracterísticas têm-se: Inteligibilidade, apreensibilidade, operacionalidade, atratividade e conformidade relacionada à usabilidade;

- Eficiência: "Conjunto de atributos que evidenciam o relacionamento entre o nível de desempenho do software e a quantidade de recursos usados, sob condições estabelecidas". Como subcaracterísticas têm-se: comportamento em relação ao tempo, utilização de recursos, e conformidade relacionada à eficiência;

- Manutenibilidade: "Conjunto de atributos que evidenciam o esforço necessário para fazer modificações especificadas do software". Têm-se como subcaracterísticas: analisabilidade, modificabilidade, estabilidade, testabilidade e conformidade relacionada à manutenibilidade;

- Portabilidade: "Conjunto de atributos que evidenciam a capacidade do software ser transferido de um ambiente para outro". Como subcaracterísticas têm-se: adaptabilidade, capacidade para ser instalado, 
coexistência, capacidade para substituir e conformidade relacionada à portabilidade.

\subsection{Série NBR ISO/IEC 14598}

A ISO/IEC 9126 define um modelo de qualidade de propósito geral, características de qualidade e fornece exemplos de métrica. A NBR ISO/IEC 14598 apresenta uma visão geral do processo de avaliação de produto de software, e apresenta orientações e requisitos para a avaliação. Sob o título geral "Tecnologia de informação - Avaliação de produto de software", consiste nas seguintes partes:

Parte 1 - Visão geral: apresenta uma introdução e a visão geral às outras partes, e explica o relacionamento entre esta norma técnica e o modelo de qualidade proposta na ISO/IEC 9126. Adicionalmente, também proporciona uma estrutura para avaliar a qualidade de qualquer produto de software, e estabelece os requisitos para métodos de medição e avaliação de produtos de software.

Parte 2 - Planejamento e gestão: define requisitos e orientações relativas às funções de apoio a avaliação de produtos de software relacionado ao planejamento, e gestão de um processo de avaliação de software e atividades associadas, incluindo desenvolvimento, aquisição, normalização, controle, transferência e feedback da experiência de avaliação dentro da organização.

Parte 3 - Processo para desenvolvedores: utilizado por organizações que planejam desenvolver um novo produto ou melhorar um já existente, e pretendam executar esta avaliação utilizando pessoas de seu próprio corpo técnico. O enfoque está no uso de indicadores, que podem prever a qualidade do produto final, através da medição de produtos intermediários desenvolvidos durante o ciclo de vida.

Parte 4 - Processo para adquirentes: sua utilização é efetivada por organizações que planejam adquirir ou reutilizar um produto de software existente, 
ou previamente desenvolvido. Sua aplicação pode abranger o processo decisório quanto a aceitação de produto ou na seleção entre alternativas de produtos.

Parte 5 - Processo para avaliadores: destinada para avaliadores que executam julgamento independente, os quais freqüentemente atuam para empresas de terceira parte.

Parte 6 - Documentação de módulos para avaliação: fornece orientação para módulo de avaliação. Esses módulos contêm a especificação do modelo de qualidade (características, subcaracterísticas, métricas externas e internas correspondentes), as informações e dados relativos à aplicação prevista do modelo, e informações sobre a real aplicação do modelo. Para cada avaliação são selecionados os módulos de avaliação adequados.

O relacionamento entre as normas ISO/IEC 9126 e NBR ISO/IEC 14598, e também a utilização de cada uma das normas do processo de avaliação, em conjunto com a NBR ISO/IEC 14598 partes 2 e 6 podem ser demonstradas através da figura 6:

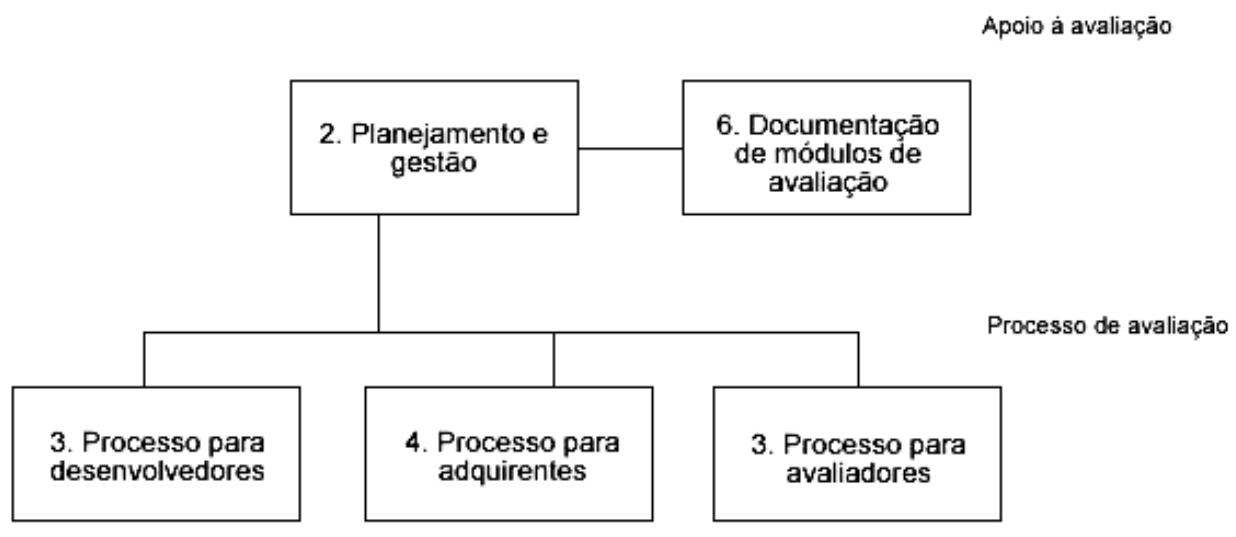

Figura 6- Relacionamento entre as normas do processo de avaliação e as de suporte para avaliação (Fonte:Associação Brasileira de Normas Técnica, ABNT NBR ISO/IEC 14598-1,2001).

O processo de avaliação consiste em um conjunto de atividades conduzidas cooperativamente pelo requisitante e avaliador, cujos dados fornecidos são usados 
como base para as atividades do processo que são projetadas considerando que, os objetivos variam de acordo com a especificação da avaliação; a constituição dos componentes dos produtos de software difere no formato e natureza do seu método de desenvolvimento; a seleção da técnica de avaliação deve considerar os objetivos da avaliação; e a conclusão deve consistir na liberação do relatório e na devolução pelo avaliador do produto avaliado e seus componentes.

Assim, primeiramente, são estabelecidos os requisitos da avaliação e então especificadas, projetadas e executadas a avaliação, como mostra a Figura 7:

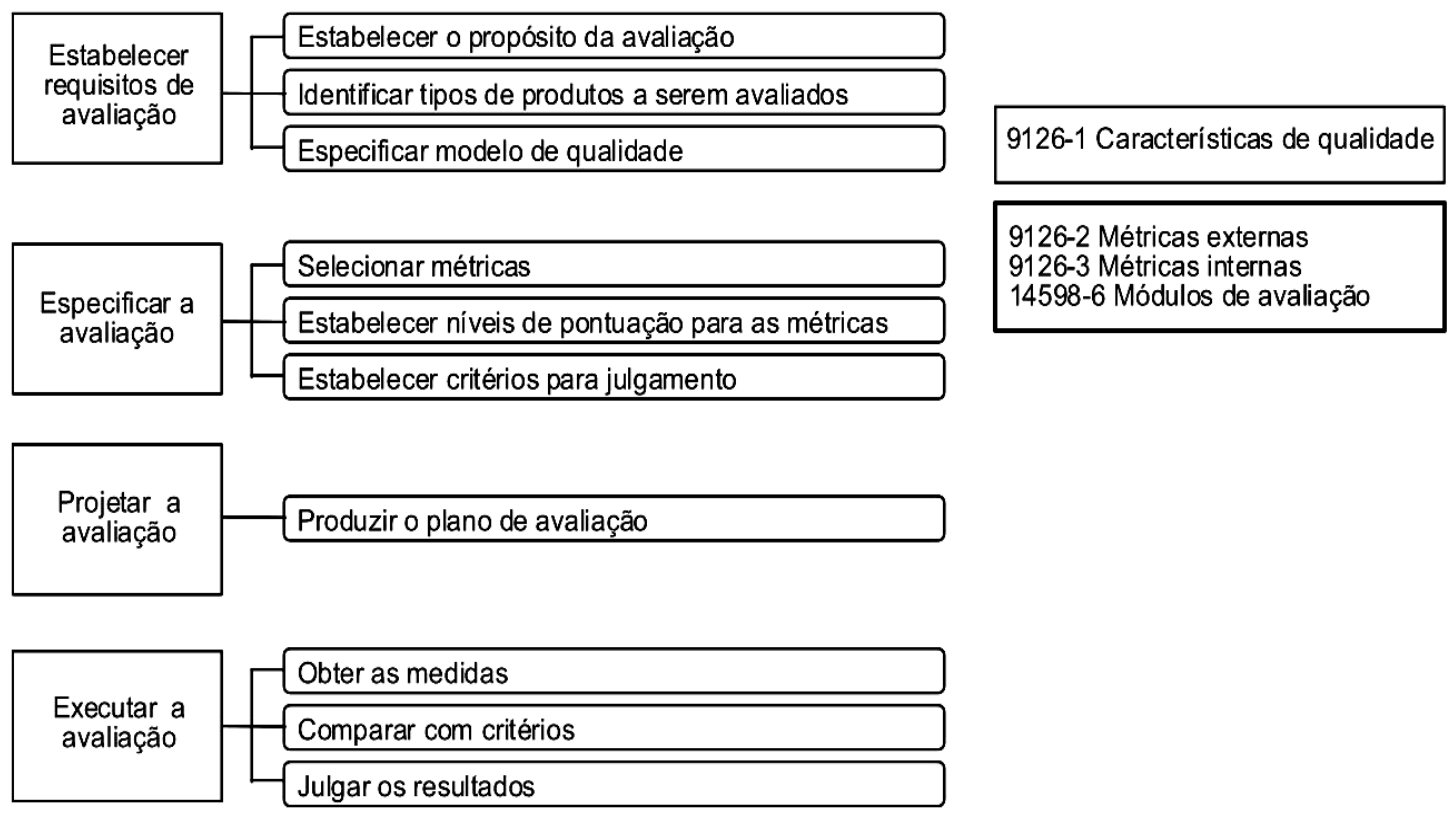

Figura 7 - Processo de avaliação (Fonte: Associação Brasileira de Normas Técnica, ABNT NBR ISO/IEC 14598-1, 2001).

O estabelecimento dos requisitos de avaliação tem o objetivo de obter os requisitos gerais da avaliação, e se divide nas etapas abaixo relacionadas:

- Estabelecer o propósito da avaliação: define quais os objetivos da avaliação, e se estes estão relacionados ao uso pretendido do produto de software e aos riscos associados. Podem ser definidos pontos de vista diferentes de vários 
usuários do produto, tais como: adquirente, fornecedor, desenvolvedor, operador ou mantenedor do produto.

- Identificar os tipos de produtos a serem avaliados: define os produtos em intermediários ou produto final.

- Especificar modelo de qualidade: a primeira etapa na avaliação de software consiste em selecionar as características de qualidade relevantes, utilizando um modelo de qualidade que desdobre sua qualidade em diferentes características.

Já, a especificação da avaliação se faz através do conceito da sua abrangência, e das medições a serem realizadas sobre o produto submetido para avaliação, conforme descrito a seguir:

- Selecionar métricas: estabelece métricas que se correlacionem às características do produto de software.

- Estabelecer níveis de pontuação para as métricas: para cada métrica selecionada devem ser definidos os níveis de pontuação e uma escala para sua apresentação.

- Estabelecer critérios para julgamento: o julgamento da qualidade do produto, e o resultado da avaliação de cada característica precisa ser sintetizado, desta forma, cada característica poderá ser representada em termos de suas subcaracterísticas.

A etapa de projetar a avaliação consiste em documentar os procedimentos a serem utilizados pelo avaliador, para realizar as medições contidas na especificação de avaliação, da seguinte forma: 
- Produzir plano de avaliação: o plano de avaliação deve descrever os recursos necessários para realizar a avaliação especificada, bem como a distribuição destes recursos entre as diversas ações a serem realizadas.

A execução da avaliação ocorre pelos resultados das ações de medição e verificação do produto de software, obtidos de acordo com os requisitos de avaliação, como especificados e planejados no plano de avaliação, através das seguintes ações:

- Obter as medidas: as métricas selecionadas são aplicadas ao produto de software, obtendo como resultado valores nas escalas das métricas.

- Comparar com critérios: o valor medido para cada métrica é comparado com os critérios determinados na especificação da avaliação.

- Julgar os resultados: o julgamento é a etapa final da avaliação, onde um conjunto de níveis pontuados é resumido. O resultado é uma declaração de quanto o produto de software atende aos requisitos de qualidade.

O objetivo principal deste processo de avaliação, descrito na NBR ISO/IEC 14598-1, é promover as seguintes características desejáveis para este processo de avaliação: a repetibilidade (avaliações repetidas do mesmo produto, com a mesma especificação de avaliação, pelo mesmo avaliador, produzam resultados que possam ser aceitos como idênticos); reprodutibilidade (mesmo processo com diferentes avaliadores); imparcialidade e objetividade (resultado da avaliação desprovido de opiniões do avaliador).

Esta avaliação utilizou subsídios da NBR ISO/IEC 14598, das partes 1 até 6 para a elaboração dos procedimentos metodológicos.

Desta forma, foram relacionadas cinco atividades que estabeleceram 0 processo de avaliação. Primeiramente foi estabelecido o requisito da avaliação. Sua 
especificação foi seguida baseada nos requisitos do produto. O próximo passo consistiu na elaboração do plano de avaliação, evoluindo para a execução do plano que foi definido pela inspeção, modelagem e teste do produto. Finalmente, obtevese a conclusão da avaliação. 


\section{TRAJETÓRIA METODOLÓGICA}

\subsection{Apresentação do Software-protótipo para a Sistematização da Assistência de Enfermagem desenvolvido para uso em tecnologia da computação móvel a beira do leito.}

O Software-protótipo para a Sistematização da Assistência de Enfermagem desenvolvido por Sperandio (2002) e objeto desta pesquisa, foi estruturado em 12 módulos, referentes ao processo de enfermagem. Os módulos denominados: Ficha de Identificação, Dados Clínicos, Internações, Informações adicionais e Entrevista armazenam dados relativos às necessidades humanas básicas e abrangem: o índice de massa corpórea, situação clínica, resumo de admissão, internações anteriores e os dados para identificação do paciente. O módulo para Coleta de Dados foi desenhado para cadastrar informações diferenciadas sobre os sinais e sintomas e gerar, automaticamente, o módulo Lista de Problemas. Este viabiliza a elaboração da prescrição de enfermagem específica para cada paciente por meio da utilização de uma base de dados previamente estabelecida pelo sistema.

Visando disponibilizar para a equipe de enfermagem tecnologia de ponta para a documentação do processo de enfermagem, foi desenvolvida uma versão do Software-protótipo para a Sistematização da Assistência de Enfermagem (SAE), para ser utilizado em computador móvel à beira do leito do paciente. Para esse fim foram adquiridos os seguintes equipamentos: um computador portátil, modelo Notebook onde todos os dados e informações coletados para a documentação da assistência de enfermagem foram armazenados e processados; dispositivo móvel, modelo HP iPAQ Pocket PC rx 1950; dispositivo de Wireless, Access Point Corega CG-WLAPGMN 108 M, que possibilitou a conexão em tempo real dos dois 
equipamentos (Pocket PC e Notebook), via ondas eletromagnéticas, sem o uso de fios. Foi possível atingir com essa conexão uma distância de 15 a 40 metros.

O Pocket PC apresentou como vantagem a bateria de íon-lítio removível e recarregável para uso contínuo (110 m Ah), permitindo que os enfermeiros utilizassem o equipamento por mais tempo. A fonte interna garantiu que ao trocar rapidamente as baterias, os dados coletados a beira do leito não se perdessem.

Este modelo de equipamento ofereceu tela colorida e transflectiva de 3,5 polegadas. Esta exibição de imagens maiores e de boa qualidade facilitou a leitura das telas do Software-protótipo para Sistematização da Assistência de Enfermagem.

Devido ao constante progresso da informática, alterou-se o acesso à base de dados oferecido pelo Delphi 5.0 pela arquitetura Firebird, dada a necessidade de armazenamento de dados relativo a Sistematização da Assistência de Enfermagem implementada para cada paciente.

Para a construção das telas específicas e adequação do sistema para acesso no Pocket $P C$, utilizou-se a ferramenta de desenvolvimento denominada Visual Studio. Net 2003 (MICROSOFT CORPORATION,2003).

Concebido para atender às necessidades de desenvolvimento de software, o Visual Studio.NET 2003 é um produto que inclui uma série de funcionalidades, como modeladores que auxiliam na composição visual de aplicações para a instalação nos menores dispositivos tais como o Pocket $P C$, além de outros dispositivos que rodam sob o sistema operacional Microsoft Windows CE. NET.

O Visual Studio. NET permite que as aplicações compartilhem dados por meio da Internet, viabilizando a montagem de aplicações a partir de código novo ou existente, independentemente da plataforma, linguagem de programação ou modelo de objeto. Disponibiliza política de segurança de alto nível de detalhe, baseado em 
papéis e no acesso ao código, provendo de forma segura, o código-fonte, os documentos de design e outras funcionalidades de desenvolvimento, através de recursos de controle de versões.

Esta plataforma reuniu características que atenderam às necessidades móveis do enfermeiro à beira do leito.

A versão do Software-protótipo para a Sistematização da Assistência Enfermagem (SAE) implementada no Pocket $P C$, foi elaborada em cinco módulos denominados: Seleção de Pacientes, Sinais Vitais, Balanço Hidroeletrolítico, Evolução e Prescrição de Enfermagem.

O primeiro módulo (Figura 8) seleciona os pacientes previamente disponibilizados no Software-protótipo, instalado no microcomputador móvel tipo Notebook.

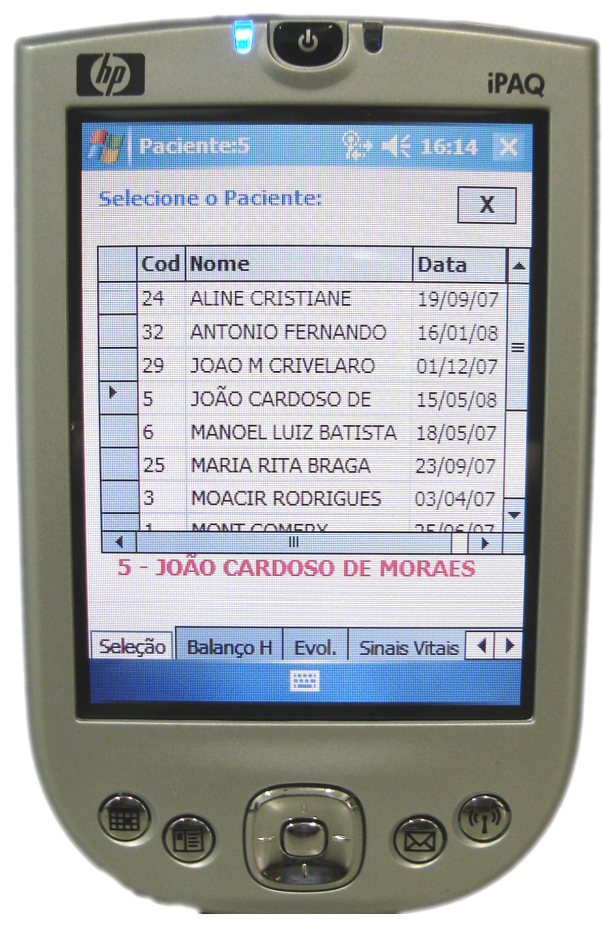

Figura 8 - Tela de seleção do paciente para cadastramento de dados 
O segundo e o terceiro módulos cadastram os dados referentes aos sinais vitais (Figura 9) e balanço hidroeletrolítrico (Figura 10) coletados à beira do leito, e ainda permitem que estes sejam transmitidos em tempo real ao microcomputador portátil através da rede local sem fio.

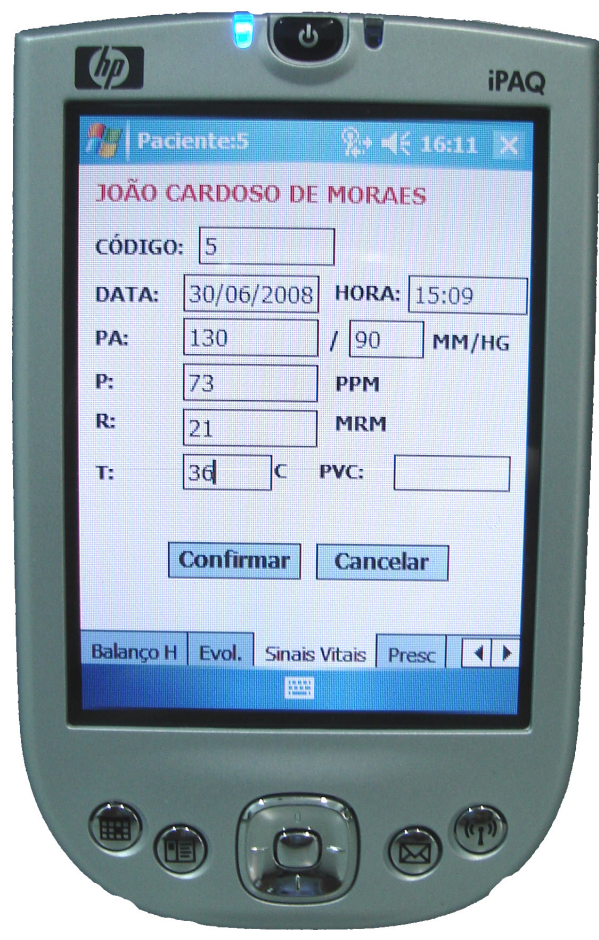

Figura 9- Tela de cadastramento dos Sinais Vitais do paciente.

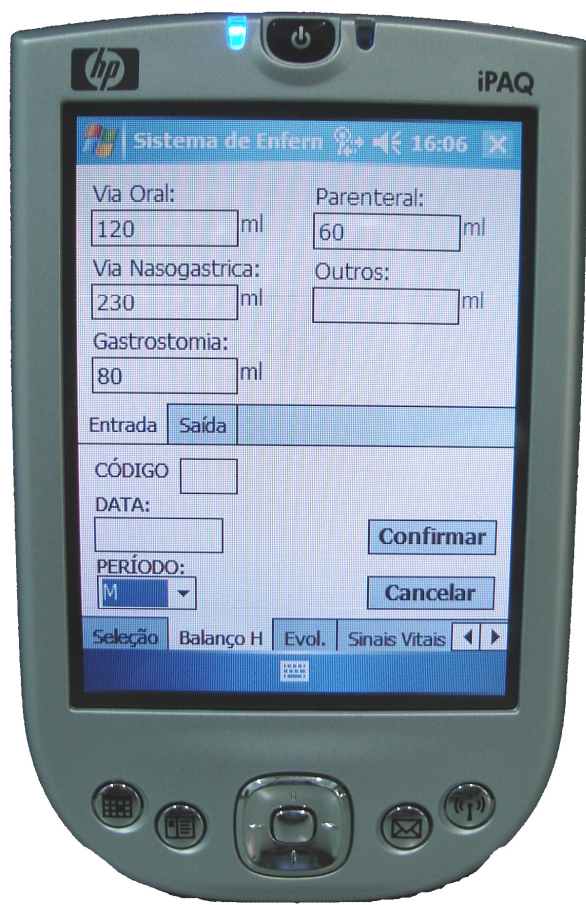

Figura 10- Tela de cadastramento do Balanço Hidroeletrolítrico do paciente. 
No módulo 4, Evolução de Enfermagem, é permitido que informações cadastradas no Software-protótipo instalado no Notebook, sejam acessadas e complementadas pelo enfermeiro que está efetivando a evolução do paciente à beira do leito (Figura 11).

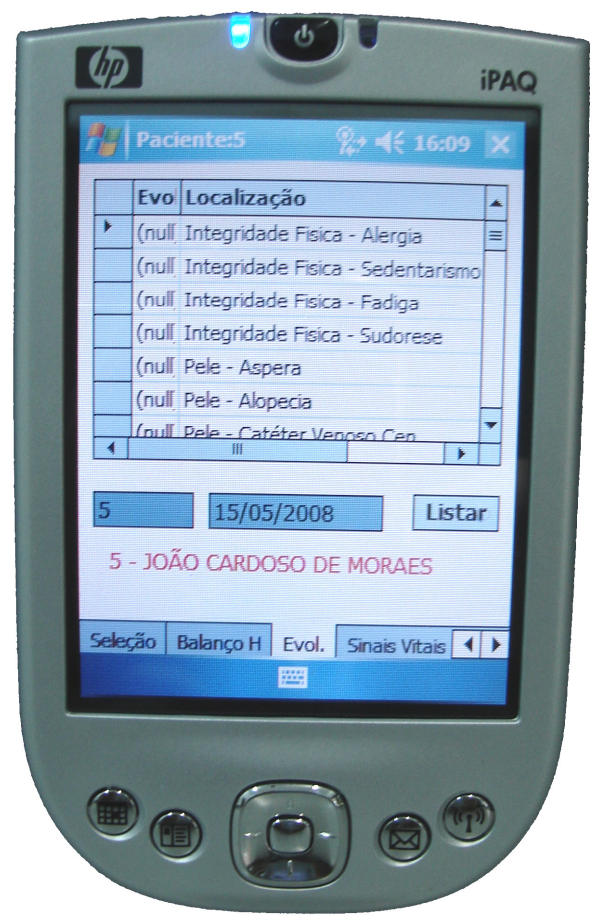

Figura 11 - Tela para recuperação e complementação de informação sobre a Evolução de enfermagem

A Prescrição de Enfermagem (módulo 5) também é acessada neste dispositivo, na forma de leitura, e uma vez executada pode ser checada no Pocket PC (Figura 12), sendo a informação incorporada ao Software-protótipo por meio da rede de sem fio. 


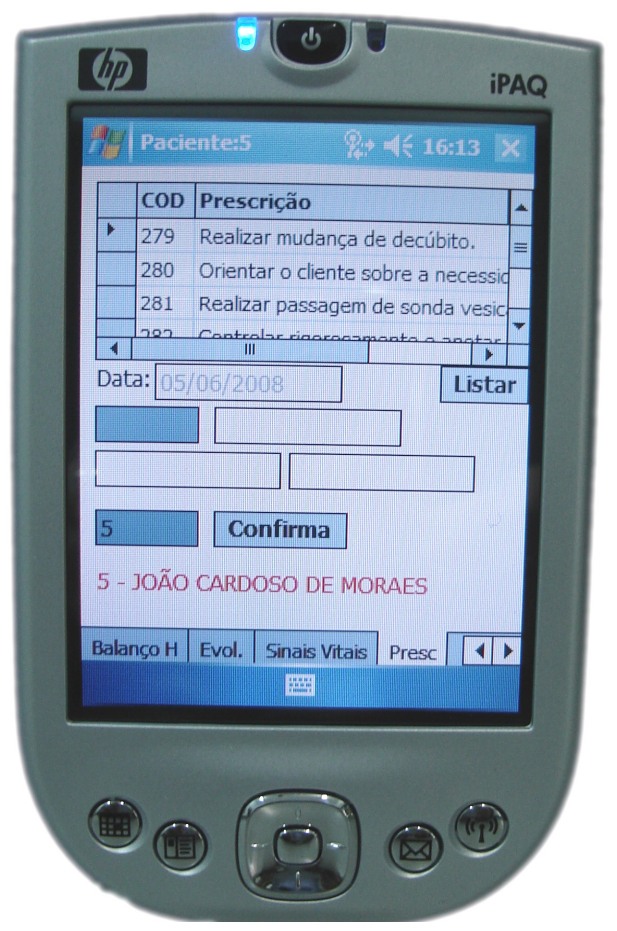

Figura 12- Tela para leitura e checagem da Prescrição de Enfermagem.

O sincronismo entre o Pocket PC e o banco de dados do Software-protótipo para SAE instalado no Notebook, ocorre de forma bidirecional, ou seja, a informação é transmitida pela rede sem fio do dispositivo móvel para o Notebook e vice-versa.

\subsection{Natureza do estudo}

Trata-se de um estudo descritivo/exploratório. Neste tipo de estudo, os fatos são observados, registrados, analisados, classificados e interpretados, sem que o pesquisador interfira neles. Usa-se este desenho para buscar informações precisas sobre a freqüência de ocorrência de um fenômeno, quando se sabe pouco sobre ele (Lobiondo-Wood; Haber, 2001). 


\subsection{Local do estudo}

A pesquisa foi realizada em uma instituição de ensino superior identificada como Faculdades Integradas, e em duas instituições hospitalares, designadas de Hospital A e Hospital B, localizadas na região noroeste do estado de São Paulo.

O curso de Enfermagem oferecido nas Faculdades Integradas é diurno integralizado no regime seriado anual, com duração mínima de 04 anos, oferecendo 60 vagas anuais. $O$ corpo docente é formado por 20 enfermeiros.

Com base nas informações da Ficha de Cadastro de Estabelecimento de Saúde - Ministério da Saúde, os dois hospitais (A e B) incluídos neste estudo, podem ser caracterizados como hospitais gerais e de ensino. O Hospital $\mathrm{A}$ atende demanda espontânea e referenciada, de pacientes exclusivamente do Sistema Único de Saúde - SUS, nas especialidades de clínica médica, cirúrgica e psiquiátrica. O Hospital B tem atendimento ao SUS e outros convênios, nas especialidades de clínica geral, cirúrgica, pediátrica e obstétrica. Ambos com regime ambulatorial e de internação com atividade auxiliar de ensino. Em termos de natureza jurídica, os dois hospitais são filantrópicos, ou seja, privados sem fins lucrativos.

Quanto ao número de leitos, os Hospitais A e B são considerados de médio porte (01 a 150 leitos) com 151 leitos, e de porte especial (acima de 300 leitos) com 722 leitos, respectivamente.

Quanto aos recursos humanos, o Hospital A é composto por 22 enfermeiros, 42 técnicos e 93 auxiliares de enfermagem, e o Hospital B por 182 enfermeiros, 52 técnicos e 1.114 auxiliares de enfermagem.

Os enfermeiros dos Hospitais A e B aplicam o processo de enfermagem alicerçado no modelo proposto por Horta (1979), sendo operacionalizado em cada 
uma das instituições por instrumentos individualizados que contemplam todas as suas fases. O registro da documentação da assistência de enfermagem prestada ao paciente é realizado pelos enfermeiros por meio de anotações manuais, procedendo de forma escrita o plano de cuidados para os pacientes internados.

A instituição de saúde B não oferece serviços informatizados aos profissionais da enfermagem, enquanto o Hospital A utiliza um software específico denominado Sistema Hospitalar. Atualmente esta ferramenta está disponibilizada na plataforma Disk Operating System (DOS) com migração progressiva para Windows, objetivando maior abrangência dos setores informatizados e para assegurar maior consistência nos dados.

O Sistema Hospitalar da instituição de saúde A permite a modulação e criação de protocolos individualizados para cada unidade da instituição. Atualmente os módulos disponíveis e implantados são constituídos por:

- Cadastros: Pacientes, Profissionais da Saúde, Municípios, Enfermarias, Leitos, Especialidades, Procedimentos e Tabelas de apoio (sexo, estado civil, cor, raça).

- Internação: Controle de leitos, Internação por especialidade e disponibilidade de leito vago, Posição do leito/enfermaria, Status do leito (bloqueado, vago, ocupado, acompanhante), Coeficientes e Estatísticas.

- Agendamento e faturamento ambulatorial: Consultas ambulatoriais, Exames, Cirurgia Ambulatorial e Quimioterapia.

- Autorização de Internação Hospitalar - AlH: Procedimentos e serviços efetuados, Controle de laudos de AlH e Faturamento.

- Laboratório de Análises Clínicas: Cadastramento de solicitação de exames, Coleta, Processamento (Hematológicos, Bioquímica, Sorológicos 
Endocrinológicos, Microbiologia, Líquidos, Urinálise e Coprológico), Análise e liberação dos exames, Estatísticas, Consulta dos resultados na rede, Consultas da $\mathrm{CCIH}$ dos resultados positivos da microbiologia, Mapa mensal de custos, Calibração dos equipamentos, Procedimento Operacional Padrão para cada tipo de exame, Gráficos de evolução de exames.

- Centro Cirúrgico: Controle de salas, Programa cirúrgico, Estatística e Gráficos. Controle de Infecção Hospitalar: estatísticas, relatórios e gráficos.

- Almoxarifado: Cadastro, Controle de estoque e Relatórios administrativos.

- Custos: Cadastro dos centros de custos; Relações entre centro de custos e parâmetros de mensuração; Lançamento das fontes de receitas e despesas; Dados de produção; Criação de indicadores; Interface entre sistemas préexistentes para aquisição de informações como, folha de pagamento e consumo de estoque; Módulo de apuração de resultado e Elaboração de relatórios gerenciais.

Observa-se que neste Sistema Hospitalar mencionado, ainda não foi desenvolvido um módulo que ofereça sustentação à assistência de enfermagem específica, e que atenda às necessidades inerentes destes profissionais. Até o momento, em seu cotidiano profissional, os enfermeiros utilizam este software, apenas para digitalizar as prescrições médicas manuscritas através do scanner de mesa, ou para efetuar a digitação diretamente no sistema e assim, enviar as informações de forma eletrônica até o serviço de farmácia, e também para efetuar requisição de materiais e medicamentos.

Este fato somado à vivência da pesquisadora, como enfermeira assistencial junto a esta instituição Hospitalar A nos anos de 1992 a 2001, quando participou ativamente do primeiro processo de elaboração da Sistematização da Assistência de 
Enfermagem, contribuiu sobremaneira para a escolha desta instituição como campo para a realização desta pesquisa, que desponta como um primeiro passo, para a incorporação da tecnologia da informática no processo de trabalho dos enfermeiros desta instituição hospitalar.

\subsection{População e Amostra de Estudo}

Participaram como sujeitos da pesquisa três categorias de avaliadores: especialistas em informática, enfermeiros docentes e enfermeiros atuantes na assistência hospitalar.

De acordo com a NBR ISO/IEC 14598-6, para que a amostra seja representativa em relação ao grupo de usuários pretendido, a avaliação de software deve ser conduzida com um mínimo de oito avaliadores para cada categoria de usuários.

Frente ao exposto, a amostra de estudo foi constituída por vinte e sete participantes, sendo oito especialistas em informática, oito enfermeiros docentes, e onze enfermeiros que atuam em assistência hospitalar, sendo sete pertencentes ao Hospital A e quatro com atividades profissionais no Hospital B.

\subsubsection{Seleção de especialista}

Foram considerados especialistas em Informática os sujeitos que atenderam aos seguintes critérios de inclusão:

- Aceitar voluntariamente a participação no estudo conforme Termo de Consentimento Livre e Esclarecido (Anexo III);

- Apresentar formação em análises de sistemas ou graduação correspondente; 
- Ter experiência em desenvolvimento de software;

- Apresentar, no mínimo, o grau de mestre em Informática.

\subsubsection{Seleção de enfermeiros docentes}

Foram selecionados os sujeitos que atenderam aos seguintes critérios de inclusão:

- Aceitar voluntariamente a participação no estudo conforme Termo de Consentimento Livre e Esclarecido (Anexo III);

- Apresentar conhecimentos básicos de Informática;

- Ser docente da instituição de ensino superior em estudo;

- Ministrar disciplinas que envolvam a Sistematização da Assistência de Enfermagem;

- Apresentar, no mínimo, o grau de mestre em Enfermagem.

\subsubsection{Seleção de enfermeiros de assistência hospitalar}

- Aceitar voluntariamente a participação no estudo conforme Termo de Consentimento Livre e Esclarecido (Anexo III);

- Apresentar conhecimentos básicos de Informática;

- Ser enfermeiro de uma das instituições hospitalares em estudo;

- Ter experiência ou participar de grupos de estudos que envolvem o desenvolvimento da Sistematização da Assistência de Enfermagem.

\subsection{Aspectos éticos da pesquisa}

O projeto foi aprovado pelo Comitê de Ética em Pesquisa da Faculdade de Medicina de Catanduva. Os sujeitos da pesquisa foram contatados e informados, 
individualmente, a respeito dos objetivos e do direito de se recusarem a participar ou de, posteriormente, desistir do estudo se julgar conveniente. Nessa oportunidade, foi esclarecido que a forma de participação seria por meio da avaliação do Softwareprotótipo para Sistematização da Assistência de Enfermagem, e do preenchimento do Instrumento de Coleta de Dados (Anexo I e Anexo Ila ou Anexo Ilb). Os dados foram coletados após a assinatura do Termo de Consentimento Livre e Esclarecido, atendendo às exigências da Resolução 196/96 do Conselho Nacional de Saúde (CNS).

\subsection{Fases de coleta de dados}

O processo de avaliação de qualidade de software, segundo a norma ISO/IEC 9126, foi constituído de três fases: definição de requisitos de qualidade, preparação da avaliação e procedimento de avaliação.

A primeira, segundo Herbert (1995), apresentou a finalidade de especificar requisitos em termos de características de qualidade e suas possíveis subcaracterísticas, com o objetivo de melhor especificar todas as características envolvidas.

A preparação da avaliação envolveu três atividades distintas: a seleção de métricas de qualidade, ou seja, foram estabelecidas métricas correlacionadas às características do produto de software; a definição dos níveis de pontuação, onde as particularidades do software são medidas quantitativamente. O resultado, isto é, o valor medido, foi mapeado em uma escala, a qual foi dividida em faixas correspondentes aos diversos graus de satisfação do usuário; e finalmente a definição dos critérios de julgamento que sintetizou os resultados da avaliação das características. 
A última fase, ou seja, o procedimento de avaliação foi composto de três etapas: medição - as métricas escolhidas foram aplicadas ao produto de software e o resultado foi fornecido em valores nas escalas das métricas; pontuação - o nível de pontuação foi determinado pelo valor medido; julgamento - neste estágio foi realizado uma síntese do conjunto de níveis pontuados. O resultado foi uma declaração da qualidade do produto de software. O resultado final foi a decisão gerencial quanto à aceitação (liberação) ou rejeição (não liberação) do produto de software.

\subsubsection{A fase de definição de requisitos de qualidade}

A primeira ação desenvolvida durante esta fase foi o estabelecimento das características e subcaracterísticas de qualidade, e a definição do que pretendemos avaliar em cada uma destas. Também foram elaboradas as questões chaves para as subcaracterísticas específicas para os especialistas em informática, e também para enfermeiros docentes e enfermeiros que atuam nas instituições definidas para o estudo.

O Quadro 1 apresenta as perguntas chaves para as subcaracterísticas, que foram utilizadas no instrumento de avaliação específico aos especialistas em informática. 


\begin{tabular}{|c|c|c|}
\hline Característica & Subcaracterística & Pergunta chave para a subcaracterística \\
\hline \multirow{12}{*}{ 1. Funcionalidade } & \multirow[b]{2}{*}{ 1.1 Adequação } & 1.1.1 O software propõe-se a fazer o que é apropriado? \\
\hline & & $\begin{array}{l}\text { 1.1.2 O software dispõe de todas as funções necessárias } \\
\text { para sua execução? }\end{array}$ \\
\hline & \multirow{3}{*}{ 1.2Acurácia } & 1.2.1 O software faz o que foi proposto de forma correta? \\
\hline & & 1.2.2 O software é preciso na execução de suas funções? \\
\hline & & 1.2.3 O software é preciso nos resultados? \\
\hline & \multirow{3}{*}{ 1.3Interoperabilidade } & 1.3.1 O software interage com os módulos especificados? \\
\hline & & $\begin{array}{l}\text { 1.3.2 O software tem capacidade para processamento } \\
\text { multiusuário? }\end{array}$ \\
\hline & & $\begin{array}{l}\text { 1.3.3 O software tem capacidade para operação com } \\
\text { redes? }\end{array}$ \\
\hline & 1.4Conformidade & 1.4.1 O software está conciso com as normas, leis, etc.? \\
\hline & \multirow{3}{*}{$\begin{array}{l}\text { 1.5 Segurança de } \\
\text { acesso }\end{array}$} & $\begin{array}{l}\text { 1.5.1 O software dispõe segurança de acesso através de } \\
\text { senhas? }\end{array}$ \\
\hline & & 1.5.2 O software dispõe de rotina interna de backup? \\
\hline & & 1.5.3 O software dispõe de rotina interna de restore? \\
\hline \multirow{4}{*}{ 2. Confiabilidade } & 2.1Maturidade & 2.1.1 O software apresenta falhas com que freqüência? \\
\hline & \multirow[b]{2}{*}{ 2.2Tolerância a falhas } & 2.2.1 Quando ocorrem falhas como o software reage? \\
\hline & & $\begin{array}{l}\text { 2.2.2 O software informa ao usuário a entrada de dados } \\
\text { inválida? }\end{array}$ \\
\hline & 2.3Recuperabilidade & $\begin{array}{l}\text { 2.3.1 O software é capaz de recuperar dados em caso de } \\
\text { falha? }\end{array}$ \\
\hline \multirow{7}{*}{ 3. Usabilidade } & \multirow{2}{*}{ 3.1. Inteligibilidade } & 3.1.1 É fácil entender o conceito e a aplicação? \\
\hline & & 3.1.2 É fácil executar suas funções? \\
\hline & \multirow{3}{*}{ 3.2Apreensibilidade } & 3.2.1 É fácil aprender a usar? \\
\hline & & 3.2.2 O software facilita a entrada de dados pelo usuário? \\
\hline & & 3.2.3 O software facilita a saída de dados para o usuário? \\
\hline & \multirow{2}{*}{ 3.3Operacionalidade } & 3.3.1 É fácil de operar e controlar? \\
\hline & & 3.3.2 O software fornece ajuda de forma clara? \\
\hline \multirow{3}{*}{ 4. Eficiência } & \multirow[b]{2}{*}{ 4.1Tempo } & 4.1.1 O tempo de resposta do software é adequado? \\
\hline & & $\begin{array}{l}\text { 4.1.2 O tempo de execução do software } \\
\text { é adequado? }\end{array}$ \\
\hline & 4.2Recursos & 4.2.1 Os recursos utilizados são adequados? \\
\hline \multirow{4}{*}{ 5. Manutenibilidade } & 5.1Analisabilidade & 5.1.1 É fácil de encontrar uma falha, quando ocorre? \\
\hline & 5.2Modificabilidade & 5.2.1 É fácil modificar e adaptar? \\
\hline & 5.3Estabilidade & 5.3.1 Há grande risco quando se faz alterações? \\
\hline & 5.4Testabilidade & 5.4.1 É fácil testar quando se faz alterações? \\
\hline \multirow{4}{*}{ 6.Portabilidade } & 6.1Adaptabilidade & 6.1.2 É fácil adaptar a outros ambientes? \\
\hline & $\begin{array}{l}\text { 6.2Capacidade para } \\
\text { ser instalado }\end{array}$ & 6.2.1 É fácil instalar em outros ambientes? \\
\hline & 6.3Conformidade & 6.3.1 Está de acordo com padrões de portabilidade? \\
\hline & $\begin{array}{l}\text { 6.4Capac. para } \\
\text { substituir }\end{array}$ & 6.4 \\
\hline
\end{tabular}

Quadro 1- Definição de subcaracterísticas e suas respectivas questões chaves, para a utilização no instrumento de avaliação específico aos especialistas em informática. (Fonte: Associação Brasileira de Normas Técnica, NBR 13596, 1996). 
O Quadro 2 apresenta as perguntas chaves para as subcaracterísticas que foram utilizadas no instrumento de avaliação específico aos enfermeiros docentes e enfermeiros que atuam nas instituições em estudo.

\begin{tabular}{|c|c|c|}
\hline Caraterística & Subcaracterística & Pergunta chave para a subcaracterística \\
\hline \multirow{7}{*}{ 1. Funcionalidade } & \multirow[b]{2}{*}{ 1.1 Adequação } & $\begin{array}{l}\text { 1.1.1 O software atende a aplicação da Sistematização } \\
\text { da Assistência de Enfermagem? }\end{array}$ \\
\hline & & $\begin{array}{l}\text { 1.1.2 O software dispõe de todas as funções necessárias } \\
\text { para a execução da Sistematização da Assistência de } \\
\text { Enfermagem? }\end{array}$ \\
\hline & \multirow{3}{*}{ 1.2Acurácia } & $\begin{array}{l}\text { 1.2.1 O software permite a aplicação da Sistematização } \\
\text { da Assistência de Enfermagem de forma correta? }\end{array}$ \\
\hline & & $\begin{array}{l}\text { 1.2.2 O software é preciso na execução das funções da } \\
\text { Sistematização da Assistência de Enfermagem? }\end{array}$ \\
\hline & & $\begin{array}{l}\text { 1.2.3 O software é preciso nos resultados desejados para } \\
\text { a Sistematização da Assistência de Enfermagem? }\end{array}$ \\
\hline & 1.3Interoperabilidade & $\begin{array}{l}\text { 1.3.1 O software permite ao enfermeiro a adequada } \\
\text { interação dos módulos para a aplicação da } \\
\text { Sistematização da Assistência de Enfermagem? }\end{array}$ \\
\hline & $\begin{array}{l}\text { 1.5Segurança de } \\
\text { acesso }\end{array}$ & $\begin{array}{l}\text { 1.5.1 O software dispõe segurança de acesso através de } \\
\text { senhas? }\end{array}$ \\
\hline \multirow{4}{*}{ 2. Confiabilidade } & 2.1Maturidade & 2.1.1 O software apresenta falhas com que freqüência? \\
\hline & \multirow{2}{*}{$\begin{array}{l}\text { 2.2Tolerância a } \\
\text { falhas }\end{array}$} & 2.2.1 Quando ocorrem falhas como o software reage? \\
\hline & & $\begin{array}{l}\text { 2.2.2 O software informa ao usuário a entrada de dados } \\
\text { inválida? }\end{array}$ \\
\hline & 2.3Recuperabilidade & $\begin{array}{l}\text { 2.3.1 O software é capaz de recuperar dados em caso de } \\
\text { falha? }\end{array}$ \\
\hline \multirow{7}{*}{ 3. Usabilidade } & \multirow{2}{*}{ 3.1. Inteligibilidade } & 3.1.1 É fácil entender o conceito e a aplicação? \\
\hline & & 3.1.2 É fácil executar suas funções? \\
\hline & \multirow{3}{*}{ 3.2Apreensibilidade } & 3.2.1 É fácil aprender a usar? \\
\hline & & $\begin{array}{l}\text { 3.2.2 O software facilita a entrada de dados pelo } \\
\text { usuário? }\end{array}$ \\
\hline & & $\begin{array}{l}\text { 3.2.3 O software facilita a saída de dados para o } \\
\text { usuário? }\end{array}$ \\
\hline & \multirow{2}{*}{ 3.30peracionalidade } & 3.3.1 É fácil de operar e controlar? \\
\hline & & 3.3.2 O software fornece ajuda de forma clara? \\
\hline \multirow{3}{*}{ 4. Eficiência } & \multirow{2}{*}{ 4.1Tempo } & 4.1.1 O tempo de resposta do software é adequado? \\
\hline & & 4.1.2 O tempo de execução do software é adequado? \\
\hline & 4.2Recursos & 4.2.1 Os recursos disponibilizados são adequados? \\
\hline
\end{tabular}

Quadro 2- Definição de subcaracterísticas e suas respectivas questões chaves, para a utilização no questionário específico aos enfermeiros docentes e enfermeiros. (Fonte: Associação Brasileira de Normas Técnica, NBR 13596).

Uma vez definidas as características e subcaracterísticas de qualidade, deuse prosseguimento à fase subseqüente denominada Preparação da avaliação. 


\subsubsection{A fase de preparação da avaliação}

A elaboração desta fase concentrou-se em atividades não apresentadas pela norma ISO/IEC 9126(2003), no entanto julgou-se pertinente esta inclusão, devido à especificidade do domínio de aplicação do Software-protótipo a ser avaliado.

Considerando-se a característica de modularidade e adotando-se o referencial proposto por Pressman (2006), formulou-se uma forma de avaliação que inicialmente concentrou-se em cada unidade dos módulos. Em seguida, estes foram verificados na forma integrados, e finalmente evoluíram para um teste de validação, em que foi verificado se todos os elementos combinaram-se adequadamente, e se o desempenho global do produto foi conseguido. Desta forma, obteve-se a garantia final que o software atendeu ou não, a todas as exigências funcionais, comportamentais e de desempenho.

Estas duas etapas foram denominadas como: teste de unidade modular e teste de validação.

\subsubsection{Teste de unidade modular}

Este teste concentrou-se no esforço de verificação da menor unidade de projeto, o módulo. Seu desenvolvimento contou com a participação individual de cada um dos avaliadores, e ocorreu na presença do desenvolvedor.

Foi utilizado um instrumento de avaliação (Anexo I) a fim de documentar os dados coletados no referido teste.

\subsubsection{Teste de validação}

Ao término da atividade de avaliação da unidade modular, o teste de validação foi realizado pelos especialistas em informática em laboratório de ensino, e 
pelos enfermeiros docentes e enfermeiros assistenciais em um ambiente hospitalar, à beira do leito ou em laboratório de ensino com a participação da pesquisadora.

Os instrumentos elaborados com base nas características e subcaracterísticas de qualidade, definidas na fase de definição de requisitos de qualidade, foram aplicados aos especialistas de Informática (Anexo II a) e aos enfermeiros docentes e enfermeiros assistenciais que atuam nas instituições em estudo (Anexo II b).

\subsubsection{Definição dos níveis de pontuação}

Os valores de pontuação para os instrumentos de avaliação objetivaram definir, de forma precisa, como mensurar cada uma das características determinadas.

Foram estabelecidos os seguintes níveis de pontuação,conforme o Quadro 3:

\begin{tabular}{|l||}
\hline \multicolumn{1}{|c|}{ NIVEIS DE PONTUAÇÃO } \\
\hline A- de acordo \\
\hline D- em desacordo \\
\hline NA- não se aplica \\
\hline Justifique \\
\hline
\end{tabular}

Quadro 3- Níveis de pontuação

\subsubsection{A fase de procedimento de avaliação}

Nesta etapa foram efetuados os testes de unidade modular e validação, com a aplicação dos respectivos instrumentos de avaliação, no período compreendido entre junho a dezembro de 2007.

Em seguida os dados foram organizados conforme o tipo de instrumento aplicado, e construído os quadros que resumiram os pontos de análise dos mesmos.

A partir dos dados coletados procedeu-se ao refinamento do protótipo, visando retornar à fase do projeto rápido, construção e avaliação, até à obtenção de um software de produção. 


\subsubsection{Validação dos instrumentos}

Os instrumentos foram submetidos à validação por integrantes do Núcleo de Estudo e Pesquisa em Informática e Enfermagem - NEPIEn da Escola de Enfermagem de Ribeirão Preto - USP, que não foram sujeitos da pesquisa. A intenção deste procedimento foi o de testar a objetividade, clareza e compreensão das questões. De acordo com Cassiani (1987) a validade aparente ou de face constitui-se numa forma subjetiva de validação, porém mantêm a preocupação dos juízes em avaliar o instrumento quanto à clareza dos itens, facilidade de leitura, compreensão e forma de apresentação.

\subsubsection{Organização dos dados para análise}

Os dados obtidos foram tabulados de acordo com a freqüência, e a análise obedeceu às normas para um estudo descritivo/exploratório, e foram apresentados na forma de tabelas e gráficos. 


\section{APRESENTAÇÃO E DISCUSSÃO DOS RESULTADOS DA AVALIAÇÃO DO SOFTWARE-PROTÓTIPO PARA SISTEMATIZAÇÃO DA ASSISTÊNCIA DE ENFERMAGEM}

O processo de avaliação é considerado fundamental neste estudo que busca subsídios e elementos essenciais para que este protótipo para Sistematização da Assistência de Enfermagem evolua a um modelo de software final.

Sua operacionalização ocorreu em duas etapas denominadas teste de unidade modular e teste de validação e contou com a presença da pesquisadora.

O procedimento de avaliação dos Testes de Unidade Modular e Teste de Validação dos especialistas em informática foi realizado com microcomputador móvel em laboratório de ensino enquanto que para os enfermeiros docentes e enfermeiros, a avaliação ocorreu à beira do leito em ambiente hospitalar ou em laboratório de ensino com a utilização de um microcomputador móvel apoiado em um suporte específico para transporte (Figura 13)

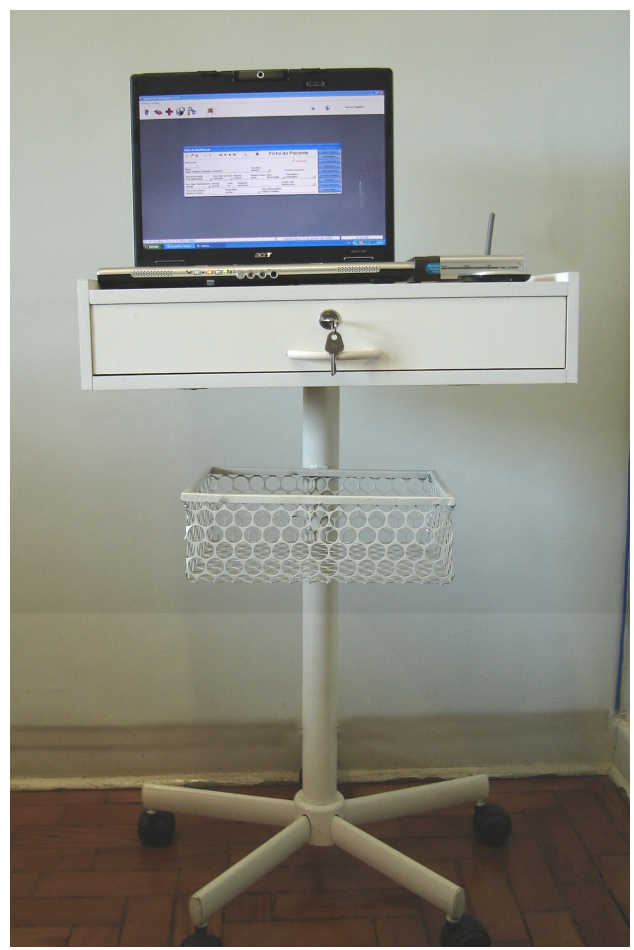

Figura 13 - Microcomputador móvel apoiado em suporte para transporte utilizado para a coleta de dados a beira do leito. 
A apresentação dos resultados segue a seqüência dos testes de unidade modular e validação, verificados pela totalidade de vinte e sete avaliadores.

\subsection{Teste de Unidade Modular}

Este procedimento de avaliação foi desenvolvido com a participação de especialistas em informática, docentes e enfermeiros que procederam individualmente a verificação dos doze módulos integrantes do Software-protótipo para Sistematização da Assistência de Enfermagem instalado em um microcomputador móvel e resultou na aceitação ou não de cada unidade modular e também nas justificativas para as necessidades de alteração, conforme Instrumento de Avaliação (Anexo I).

\subsubsection{Teste de Unidade Modular pelos Especialistas em Informática}

Conforme mostra a Tabela 1, os módulos Evolução, Sinais Vitais e Balanço Hidroeletrolítrico receberam a aceitação da totalidade dos especialistas em informática. Os módulos referentes a: Internações, Entrevista, Lista de Problemas e Prescrição de Enfermagem receberam apenas uma sugestão de modificação. 0 módulo que diz respeito a Coleta de Dados apresentou quatro acordos e quatro sugestões de alterações. 
Tabela 1 - Avaliação dos módulos do Software-protótipo para SAE pelos Especialistas em Informática. Catanduva, SP, 2007.

\begin{tabular}{lcc}
\hline \multicolumn{1}{c}{ Módulo } & Aceito como está & Não aceito \\
\hline Ficha de identificação & 6 & 2 \\
Dados clínicos & 6 & 2 \\
Internações & 7 & 1 \\
Informações adicionais & 5 & 3 \\
Entrevista & 7 & 1 \\
Coleta de dados & 4 & 4 \\
Lista de problemas & 7 & 1 \\
Prescrição de Enfermagem & 7 & 1 \\
Evolução de enfermagem & 8 & 0 \\
Sinais vitais & 8 & 0 \\
Balanço hidroeletrolítico & 8 & 0 \\
Telas para cadastramento & 6 & 2 \\
\hline
\end{tabular}

A Tabela 2 apresenta vinte e uma sugestões de modificações no Softwareprotótipo para a Sistematização da Assistência de Enfermagem, apontadas pelos especialistas em informática.

Tabela 2 - Modificações sugeridas na avaliação dos módulos do Software-protótipo para SAE pelos Especialistas em Informática. Catanduva, SP, 2007.

\begin{tabular}{|c|c|c|}
\hline Módulo & & Modificações Sugeridas \\
\hline Ficha de identificação & $\begin{array}{l}\text { Esp. Inf. 5, } \\
\text { Esp. Inf. 7: }\end{array}$ & $\begin{array}{l}\text {-Inserir data e admissão no setor e o sistema não } \\
\text { deverá aceitar o mesmo horário para admissão na } \\
\text { unidade de terapia semi-intensiva. }\end{array}$ \\
\hline Dados clínicos & $\begin{array}{l}\text { Esp. Inf. 1, } \\
\text { Esp. Inf. 6: }\end{array}$ & $\begin{array}{l}\text { - Acrescentar registro de data para os dados } \\
\text { antropométricos. }\end{array}$ \\
\hline Internações & Esp. Inf. 1: & $\begin{array}{l}\text {-Escrever o título "Internações Anteriores" no } \\
\text { singular, pois o sistema possibilita armazenar } \\
\text { apenas } 01 \text { local para a internação anterior. }\end{array}$ \\
\hline Informações adicionais & $\begin{array}{l}\text { Esp. Inf. 1: } \\
\text { Esp. Inf. 5, } \\
\text { Esp. Inf. 7: }\end{array}$ & $\begin{array}{l}\text { - Registrar no forma decimal os valores referentes } \\
\text { a moeda. } \\
\text {-Verificar a programação da "Lista de Objetos } \\
\text { Pessoais, Alergias e Medicamentos" para não } \\
\text { aparecer o número da lista quando clicar sobre } \\
\text { estes itens. }\end{array}$ \\
\hline
\end{tabular}

Entrevista

Esp. Inf. 2: -Aumentar o tamanho da fonte. 
Conclusão

Módulo

Coleta de dados

Lista de problemas

Prescrição de Enfermagem

Evolução de enfermagem

Sinais vitais

Balanço hidroeletrolítico

Telas para cadastramento

\section{Modificações Sugeridas}

Esp. Inf. 3, "Acrescentar os campos "Voltar" e "Sair" em todas Esp. Inf. 4 as telas deste módulo.

Esp. Inf. 7:

Esp. Inf. 5,

Esp. Inf. 7:

Esp. Inf. 3: -Possibilitar a inclusão de novas situações.

Esp. Inf. 5: -Acrescentar mensagem explicativa sobre a necessidade de clicar 2 vezes sobre o item para possibilitar prescrição;

- Relacionar o nome do enfermeiro e seu número de inscrição no COREn com o módulo "Coleta de Dados".

Esp. Inf. 5: -Definir chave primária nos campos de consulta para possibilitar a verificação que o item já existe, e portanto, não é necessário cadastrar novamente; - Ordenar alfabeticamente os itens cadastrados.

Esp. Inf. 2 -Modificar os ícones de representação das Esp. Inf. 5: funções de cadastro, é necessário a inserção de ícones adequados ao significado das funções.

Observa-se que destas alterações propostas, seis foram coincidentes com dois ou até três especialistas em informática e sete foram proposições individuais.

As modificações sugeridas foram minuciosamente estudadas pela equipe de desenvolvimento do Software-protótipo para a Sistematização da Assistência de Enfermagem, constituída pela pesquisadora, graduada em enfermagem e análises de sistemas, por um analista de sistemas e um programador. Estes estabeleceram os critérios para as atividades de manutenção a curto e médio prazo para a implementação das propostas sugeridas.

A aplicação das atividades de manutenção em curto prazo atenderá as solicitações de revisão de texto, os pontos de acréscimo: campos "Voltar" e "Sair" e mensagens explicativas, e a ordenação alfabética dos itens cadastrados, bem como a elaboração da senha de acesso individualizada e as rotinas de backup.

As tarefas de manutenção que terão impacto de forma significativa na modificação do código-fonte serão contempladas em longo prazo e irão abranger as 
seguintes modificações referenciadas na avaliação dos especialistas em informática: acréscimo de data e horário para admissão e dados antropométricos, relação do nome do enfermeiro e sua inscrição no COREn, modificação dos ícones de representação e o cadastro de internações com seu respectivo histórico completo.

A modificação referente à inclusão de novas situações na Lista de Problemas deverá ser contemplada apenas quando o Software-protótipo for implementado em ambiente hospitalar, uma vez que deve estar em concordância com as características específicas da unidade de internação que utilizará a tecnologia computacional em questão.

\subsubsection{Teste de Unidade Modular pelos Docentes e Enfermeiros dos Hospitais A e B}

A Tabela 3 apresenta os números de modificações sugeridas na avaliação dos módulos do Software-protótipo para a Sistematização da Assistência de Enfermagem, bem como os dados pertinentes a aceitação de cada unidade modular.

Tabela 3 - Avaliação dos Módulos do Software-protótipo para SAE pelos Docentes e Enfermeiros dos Hospitais A e B. Catanduva, SP, 2007.

\begin{tabular}{lccccccccc}
\hline \multicolumn{1}{c}{ Módulo } & \multicolumn{4}{c}{ Aceito como está } & \multicolumn{5}{c}{ Não aceito } \\
& Do & Enf. & Enf. & T & Do & Enf.A & Enf.B & T \\
\hline Ficha de identificação & 5 & 6 & 2 & 13 & 3 & 1 & 2 & 6 \\
Dados clínicos & 6 & 6 & 2 & 14 & 2 & 1 & 2 & 5 \\
Internações & 5 & 4 & 3 & 12 & 3 & 3 & 1 & 7 \\
Informações adicionais & 6 & 6 & 4 & 16 & 2 & 1 & 0 & 3 \\
Entrevista & 3 & 7 & 2 & 12 & 5 & 0 & 2 & 7 \\
Coleta de dados & 4 & 6 & 1 & 11 & 4 & 1 & 3 & 8 \\
& & & & & & & & Continua
\end{tabular}




\begin{tabular}{|c|c|c|c|c|c|c|c|c|}
\hline \multirow[b]{2}{*}{ Módulo } & \multicolumn{4}{|c|}{ Aceito como está } & \multicolumn{4}{|c|}{ Não aceito } \\
\hline & Do & $\begin{array}{c}\text { Enf. } \\
\text { A }\end{array}$ & $\begin{array}{c}\text { Enf. } \\
\text { B }\end{array}$ & $\mathrm{T}$ & Do & Enf.A & Enf.B & $\mathrm{T}$ \\
\hline Lista de problemas & 4 & 7 & 3 & 14 & 4 & 0 & 1 & 5 \\
\hline Prescrição de Enfermagem & 7 & 1 & 1 & 9 & 1 & 6 & 3 & 10 \\
\hline Evolução de enfermagem & 6 & 0 & 3 & 9 & 2 & 7 & 1 & 10 \\
\hline Sinais vitais & 5 & 6 & 4 & 15 & 3 & 1 & 0 & 4 \\
\hline Balanço hidroeletrolítico & 7 & 4 & 4 & 15 & 1 & 3 & 0 & 4 \\
\hline Telas para cadastramento & 5 & 6 & 4 & 15 & 3 & 1 & 0 & 4 \\
\hline
\end{tabular}

Do - Docentes; Enf. A - Enfermeiros HA; Enf. B - Enfermeiros HB; T - Total.

Verificou-se que os módulos: Informações Adicionais, Sinais Vitais, Balanço Hidroeletrolítrico e Telas para Cadastramento foram os que receberam maior número de aceitação pelos enfermeiros e docentes em contraposição com os Módulos - Prescrição de Enfermagem e Evolução de Enfermagem, que obtiveram maior número de indicações para modificações.

Uma avaliação detalhada de cada módulo que integra o Software-protótipo desenvolvido por Sperandio (2002) e objeto deste estudo, pode ser observado a seguir.

O módulo Ficha de Identificação foi elaborado para cadastrar os dados de identificação do paciente, minimizando as atividades de digitação, para tanto, os campos: data, grau de instrução, sexo, procedência, estado civil e respondido (pelo próprio paciente ou não) podem ser cadastrados com um toque no dispositivo de entrada (mouse). Este módulo recebeu treze aceitações e seis sugestões para alterações (Tabela 4). 
Tabela 4 - Avaliação do módulo Ficha de Identificação do Software-protótipo para SAE pelos Docentes e Enfermeiros dos Hospitais A e B. Catanduva, SP, 2007.

\begin{tabular}{|c|c|c|c|}
\hline Módulo & Avaliador & & Modificações Sugeridas \\
\hline \multirow{4}{*}{ Ficha de identificação } & Docentes & $\begin{array}{l}\text { Docente 3: } \\
\text { Docente 4: }\end{array}$ & $\begin{array}{l}\text {-Acrescentar no campo "Data de } \\
\text { Nascimento": anos anteriores a 1990. } \\
\text {-Interligar o software protótipo SAE ao } \\
\text { sistema hospitalar, importando os } \\
\text { dados de outras telas. } \\
\text {-Acrescentar o campo } \\
\text { "Naturalidade"; } \\
\text {-Acrescentar nos campos: } \\
\text {-"Grau de Instrução": não relatado; } \\
\text {-"Estado Civil": não consta; } \\
\text {-"Sexo": outras classificações (além } \\
\text { de feminino e masculino). }\end{array}$ \\
\hline & $\begin{array}{l}\text { Enfermeiros } \\
\text { Hospital A }\end{array}$ & Enf. A 4: & $\begin{array}{l}\text {-Acrescentar no campo "Procedência" o o } \\
\text { cadastramento de cidades não } \\
\text { necessitando retornar ao Menu Inicial e } \\
\text { abrir a tela de Cadastramento; }\end{array}$ \\
\hline & & & $\begin{array}{l}\text { - Cadastrar cidades na classificação } \\
\text { alfabética. }\end{array}$ \\
\hline & $\begin{array}{l}\text { Enfermeiros } \\
\text { Hospital B }\end{array}$ & $\begin{array}{l}\text { Enf. B 1: } \\
\text { Enf. B 3: }\end{array}$ & $\begin{array}{l}\text {-Não ser obrigatório preencher todos os } \\
\text { campos deste módulo. } \\
\text {-Preencher este módulo na Recepção } \\
\text { Hospitalar. }\end{array}$ \\
\hline
\end{tabular}

As atividades de manutenção em curto prazo contemplaram o acréscimo sugerido para os campos "Naturalidade", "Grau de Instrução" e "Estado Civil".

Para o campo "Data de Nascimento" julgou-se mais adequado os enfermeiros digitarem 0 ano a procurar em uma janela contendo o número de anos compreendido entre 1910 a 2008, como exemplo.

A sugestão feita por uma enfermeira docente que o referido Softwareprotótipo tenha interface com o sistema hospitalar visando o preenchimento da ficha de identificação na Recepção do hospital, constará de uma manutenção em longo prazo.

Com respeito ao Módulo Dados Clínicos, este permite cadastrar: unidade de internação, resumo de admissão, peso e altura com geração automática do índice de 
massa corpórea. A avaliação deste módulo resultou em um número de aceitação igual a catorze e cinco sugestões para modificações (Tabela 5).

Tabela 5 - Avaliação dos módulos Dados Clínicos, Internações e Informações Adicionais do Software-protótipo para SAE pelos Docentes e Enfermeiros dos Hospitais A e B. Catanduva, SP, 2007.

\begin{tabular}{|c|c|c|c|}
\hline Módulos & Avaliador & & Modificações Sugeridas \\
\hline \multirow{3}{*}{ Dados clínicos } & Docentes & $\begin{array}{l}\text { Docente 3: } \\
\text { Docente 5: }\end{array}$ & $\begin{array}{l}\text {-Cadastrar "Clínicas" na classificação } \\
\text { alfabética. } \\
\text {-Acrescentar no campo: } \\
\text {-"Índice de Massa Corpórea - IMC": } \\
\text { não consta. }\end{array}$ \\
\hline & $\begin{array}{c}\text { Enfermeiros } \\
\text { Hospital A }\end{array}$ & Enf. A 4: & $\begin{array}{l}\text {-Acrescentar no campo "Clínica" o } \\
\text { cadastramento neste módulo, não } \\
\text { necessitando retornar ao Menu Inicial e } \\
\text { abrir a tela de cadastramento; } \\
\text {-Cadastrar "Clínicas" na classificação } \\
\text { alfabética; } \\
\text {-Acrescentar os campos: diagnóstico } \\
\text { médico, cirurgias anteriores, tratamento } \\
\text { de saúde específico, antecedentes } \\
\text { pessoais e familiares. }\end{array}$ \\
\hline & $\begin{array}{c}\text { Enfermeiros } \\
\text { Hospital B }\end{array}$ & $\begin{array}{l}\text { Enf. B 1: } \\
\text { Enf. B 2: }\end{array}$ & $\begin{array}{l}\text {-Acrescentar algumas informações } \\
\text { mais específicas. } \\
\text {-Especificar melhor o conteúdo. }\end{array}$ \\
\hline \multirow{3}{*}{ Internações } & Docentes & $\begin{array}{l}\text { Docente 1: } \\
\text { Docente 4: } \\
\text { Docente 5: }\end{array}$ & $\begin{array}{l}\text {-Acrescentar o campo: } \\
\text { procedência do paciente. } \\
\text {-Acrescentar o campo: cirurgias } \\
\text { anteriores. } \\
\text {-Acrescentar no campo: } \\
\text {-"Destino": transferência para setor e } \\
\text { óbito. }\end{array}$ \\
\hline & $\begin{array}{c}\text { Enfermeiros } \\
\text { Hospital A }\end{array}$ & $\begin{array}{l}\text { Enf. A 2: } \\
\text { Enf. A 3: } \\
\text { Enf. A 7: }\end{array}$ & $\begin{array}{l}\text {-Não há necessidade das informações } \\
\text { contidas neste módulo do Software- } \\
\text { protótipo para SAE. }\end{array}$ \\
\hline & $\begin{array}{c}\text { Enfermeiros } \\
\text { Hospital B }\end{array}$ & Enf. B 4: & $\begin{array}{l}\text {-Acrescentar janelas para as } \\
\text { transferências do paciente durante a } \\
\text { internação. }\end{array}$ \\
\hline \multirow{3}{*}{ Informações adicionais } & Docentes & $\begin{array}{l}\text { Docente 1: } \\
\text { Docente 3: }\end{array}$ & $\begin{array}{l}\text {-Acrescentar o campo: outras } \\
\text { patologias presentes. } \\
\text {-Cadastrar os objetos pessoais, } \\
\text { medicamentos e alergias ordenados } \\
\text { alfabeticamente. }\end{array}$ \\
\hline & $\begin{array}{c}\text { Enfermeiros } \\
\text { Hospital A }\end{array}$ & Enf A 4: & $\begin{array}{l}\text {-Acrescentar no campo "Objetos } \\
\text { Pessoais": } \\
\text {-Campo para registrar os nomes das } \\
\text { pessoas que receberam e/ou } \\
\text { entregaram os objetos pessoais do } \\
\text { paciente, a data e o horário. }\end{array}$ \\
\hline & $\begin{array}{c}\text { Enfermeiros } \\
\text { Hospital B }\end{array}$ & & \\
\hline
\end{tabular}


As alterações sugeridas para acréscimo de diagnóstico médico, cirurgias anteriores, antecedentes pessoais e familiares serão efetivadas em médio prazo. Planeja-se elaborar um campo para entrada de texto livre para o preenchimento de informações adicionais, caso o usuário julgue necessário.

O Módulo Internações foi desenhado para cadastrar o destino do paciente e internações anteriores. Este foi avaliado como "Aceito" por cinco docentes e sete enfermeiros, enquanto três docente e quatro enfermeiros sugeriram alterações.

Dentre as sugestões, o acréscimo das opções óbitos e transferências serão contemplados na atividade de manutenção em curto prazo. Com respeito a informação sobre a procedência do paciente e as cirurgias anteriores, estas poderão ser registradas no campo Antecedentes Pessoais e Familiar que será desenvolvido para o módulo Dados Clínicos.

O Módulo Informações Adicionais permite cadastrar os objetos pessoais, medicações de uso diário e alergia, como mostra a figura 14.

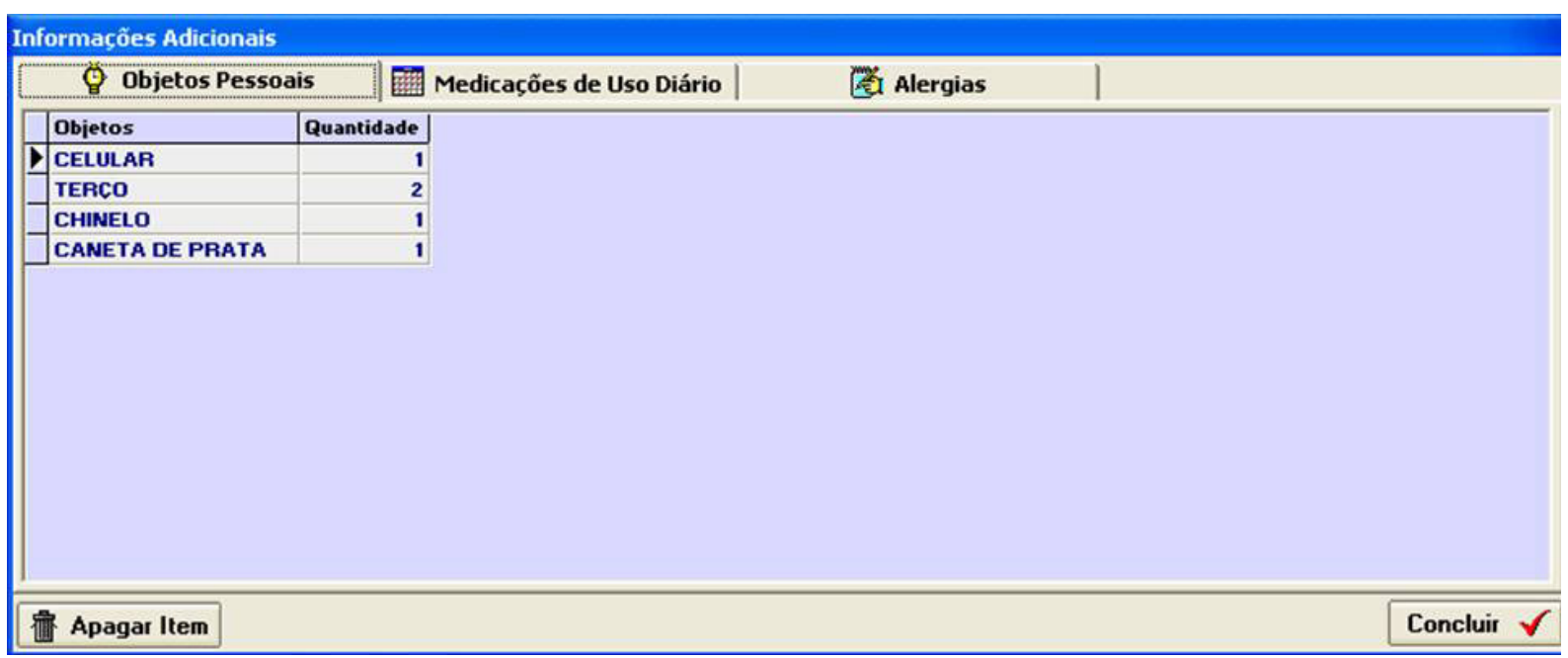

Figura 14 - Tela de Informações Adicionais do Software-protótipo para a SAE (Sperandio, 2002).

Este módulo recebeu apenas três sugestões para modificações. Optou-se por não acrescentar o campo "Outras patologias presentes", conforme sugerido, pois 
esta informação poderá ser contemplada no campo Antecedentes Pessoais e Familiares. Decidiu-se também não registrar nome/data/horário das pessoas que receberam ou entregaram os objetos pessoais, pois essas informações devem ser registradas na Tela de Cadastramento.

O módulo Entrevista (Figura 15) engloba informações sobre as necessidades nutricionais/metabólicas, eliminações, atividades/exercícios, sono/repouso, valores/crença e recreação/lazer organizadas na forma de questionário estruturado (check list). Os dados são inseridos com um toque no dispositivo de entrada (mouse) e disponibilizados campos com entrada de texto livre.

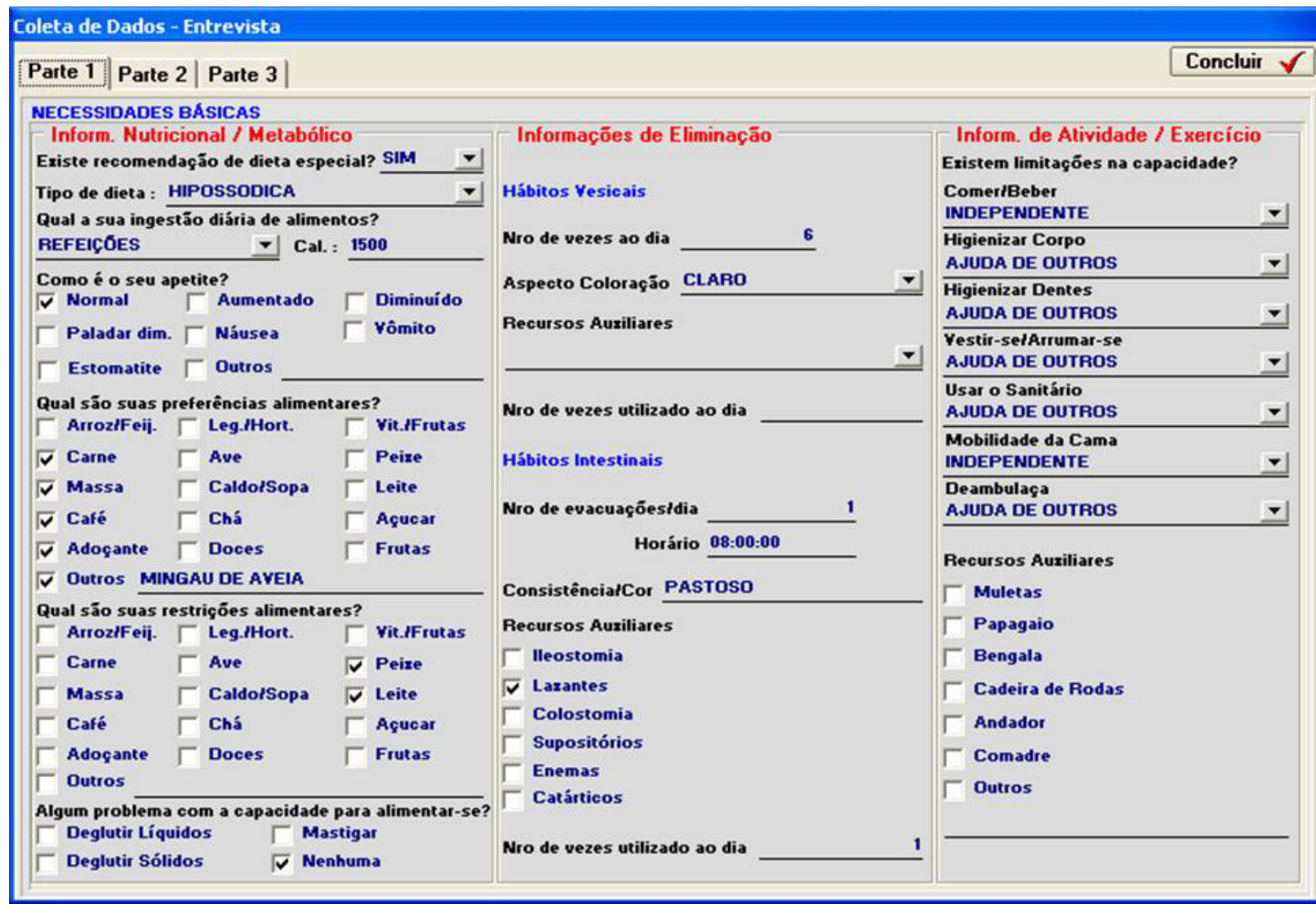

Figura 15 - Tela de Entrevista do Software-protótipo para a SAE (Sperandio, 2002).

Como mostra a Tabela 6, cinco docentes e um enfermeiro apresentaram sugestões para melhoria deste módulo. 
Tabela 6 - Avaliação do módulo Entrevista do Software-protótipo para SAE pelos Docentes, Enfermeiros dos Hospitais A e B. Catanduva, SP, 2007.

\begin{tabular}{|c|c|c|c|}
\hline Módulo & Avaliador & & Modificações Sugeridas \\
\hline \multirow[t]{3}{*}{ Entrevista } & \multirow[t]{2}{*}{ Docentes } & $\begin{array}{l}\text { Docente 1: } \\
\text { Docente 3: }\end{array}$ & $\begin{array}{l}\text {-Acrescentar no campo: } \\
\text { "Religião": diversidade de religiões. } \\
\text {-Acrescentar no campo: } \\
\text {-"Dieta": todos os tipos de dieta } \\
\text {-"Evacuação": quantidade e } \\
\text { Características; } \\
\text {-"Hábitos Vesicais": quantidade e } \\
\text { características; } \\
\text {-Verificar a possibilidade de digitação } \\
\text { de letras nos campos; "Evacuação" e } \\
\text { "Hábitos Vesicais":-Acrescentar no } \\
\text { campo: } \\
\text {-“Urina": cor amarelo-claro. }\end{array}$ \\
\hline & & $\begin{array}{l}\text { Docente 4: } \\
\text { Docente 5: } \\
\text { Docente 8: }\end{array}$ & $\begin{array}{l}\text {-Retirar o título "Necessidades } \\
\text { Humanas" ou acrescentar as demais } \\
\text { propostas da Teoria de Wanda Horta. } \\
\text {-Acrescentar em todos os campos o } \\
\text { item "Não Consta". } \\
\text {-Associar os módulos Entrevista e } \\
\text { coleta de Dados em único módulo. } \\
\text {-Melhorar o conteúdo das informações. }\end{array}$ \\
\hline & $\begin{array}{c}\text { Enfermeiros } \\
\text { Hospital A }\end{array}$ & & \\
\hline Entrevista & $\begin{array}{c}\text { Enfermeiros } \\
\text { Hospital B }\end{array}$ & Enf. B 3: & $\begin{array}{l}\text {-Elaborar este módulo de acordo com a } \\
\text { teoria de Wanda Horta ou outra teoria } \\
\text { de enfermagem. } \\
\text {-Acrescentar no campo "Evacuação": } \\
\text { quantidade, características e } \\
\text { possibilidade de digitação de letras. }\end{array}$ \\
\hline
\end{tabular}

Duas sugestões sobre a organização do questionário estruturado embasado em uma teoria de enfermagem registram a importância de se refletir e estudar este aspecto para a reestruturação deste módulo que será efetuada em médio prazo.

A associação dos módulos Entrevista e Coleta de Dados, em único módulo sugerida por enfermeiro não será adotada, pois acredita-se que esta forma de organização acarretaria dificuldade na recuperação e consulta das informações armazenadas. 
Serão adotados como medidas de adequações em curto prazo, os acréscimos solicitados nos campos: "Evacuação", "Hábitos Vesicais", "Dieta" e "Religião".

O módulo Coleta de Dados (Figura 16) viabiliza que as informações sobre os sinais e sintomas dos sistemas do corpo humano selecionadas pelo usuário sejam automaticamente apresentadas no módulo Lista de Problemas e também configura interface com o módulo Evolução de Enfermagem.

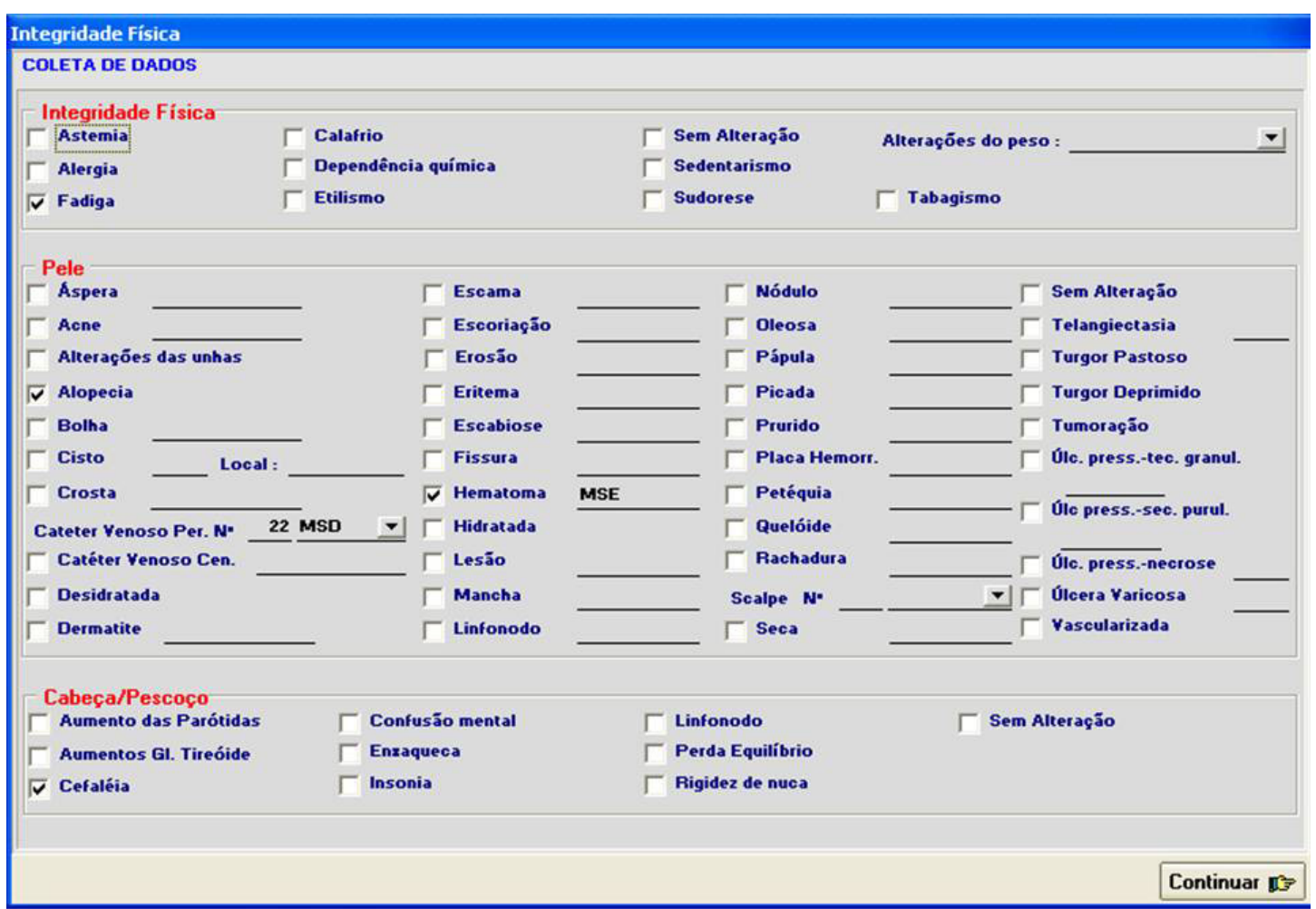

Figura 16 - Tela de Coleta de Dados do Software-protótipo para a SAE (Sperandio, 2002).

Este módulo apresentou a aceitação por quatro docentes e sete enfermeiros e recebeu sugestões para alterações de três docentes e quatro enfermeiros, conforme apresentado na Tabela 7. 
Tabela 7- Avaliação do módulo Coleta de Dados do Software-protótipo para SAE pelos Docentes e Enfermeiros dos Hospitais A e B. Catanduva, SP, 2007.

\begin{tabular}{|c|c|c|c|}
\hline Módulo & Avaliador & & Modificações Sugeridas \\
\hline Coleta de dados & Docentes & $\begin{array}{l}\text { Docente 1: } \\
\text { Docente 3: } \\
\text { Docente 5: }\end{array}$ & $\begin{array}{l}\text {-Acrescentar o campo "Voltar" em todas } \\
\text { as telas deste módulo } \\
\text {-Acrescentar no campo: } \\
\text {-"Olhos": não enxerga de longe e não } \\
\text { enxerga de perto; } \\
\text {-Acrescentar no campo: } \\
\text {-"Ouvido": acuidade auditiva. } \\
\text {-Acrescentar o campo "Voltar" em todas } \\
\text { as telas deste módulo; } \\
\text {-A primeira tela deste módulo deve iniciar } \\
\text { pelo campo: "Sistema Nervoso Central" - } \\
\text { SNC, seguidos de "Cabeça/Pescoço" e } \\
\text { "Escala de Glasgow"; } \\
\text {-Acrescentar no campo: "Sistema } \\
\text { Nervoso Central": inconsciente, } \\
\text { consciente, sedação, nome da droga; } \\
\text {-Retirar o termo confusão mental do } \\
\text { campo "Cabeça" e inserir no campo } \\
\text { "Sistema Nervoso Central"; } \\
\text {-Avaliar se os termos cefaléia, insônia e } \\
\text { enxaqueca são mais adequados para o } \\
\text { campo "Cabeça/Pescoço" ou no campo } \\
\text { "Sistema Nervoso Central"; } \\
\text {-Avaliar se os termos astenia, fadiga e } \\
\text { dependência química são adequados } \\
\text { para permanecerem no campo } \\
\text { "Integridade Física"; } \\
\text {-Avaliar se o termo cateter venoso deve } \\
\text { permanecer no campo "Pele" ou ser } \\
\text { transportado para o campo "Integridade } \\
\text { Física"; } \\
\text {-Acrescentar no campo "Faringe/Boca": } \\
\text { nro tubo oro traqueal; } \\
\text {-Acrescentar no campo "Aparelho } \\
\text { Respiratório": ventilação mecânica, } \\
\text { freqüência de O O, saturação de O O. } \\
\text {-Acrescentar no campo "Aparelho } \\
\text { Circulatório": medicações vasoativas; } \\
\text {-Acrescentar no campo "Aparelho Genito } \\
\text { Urinário": colúria, infecção trato Urinário, } \\
\text { agente Etiológico, presença } \\
\text { sedimentos; de } \\
\text {-Acrescentar em todos os Sistemas o } \\
\text { campo: "Não Avaliado" e "Outros" (com } \\
\text { campo aberto para escrever). }\end{array}$ \\
\hline
\end{tabular}


Continuação

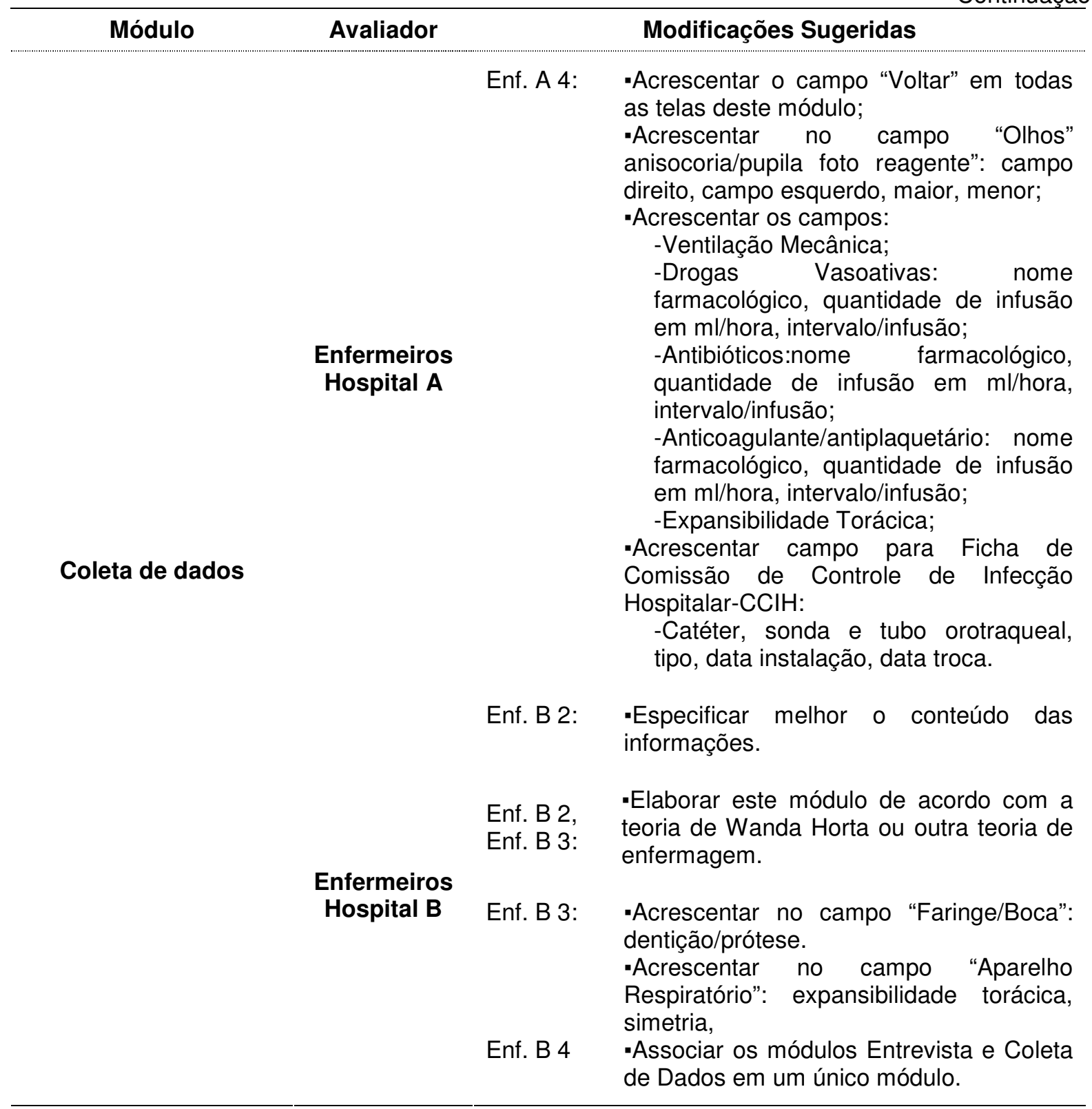

As atividades de manutenção em curto prazo se concentrará na elaboração do campo "Voltar" sugerido por três avaliadores e também no acréscimo das modificações solicitadas nos campos: "Olhos", "Ouvidos", "Faringe/Boca", "Aparelho Respiratório", "Aparelho Genito Urinário" e "Sistema Nervoso Central”. Julga-se pertinente acatar as sugestões para retirar o termo insônia do campo "Cabeça/Pescoço" e adicioná-lo no campo "Sistema Nervoso Central”. 
A avaliação deste módulo evidenciou a necessidade de se elaborar dois campos adicionais: Drogas Infundidas e Ficha de Comissão de Controle de Infecção Hospitalar - CCIH.

O campo Drogas Infundidas deve englobar a assistência de enfermagem com drogas vasoativas, antibiótico, anticoagulantes/antiplaquetário e sedativos e o campo $\mathrm{CCIH}$ deve viabilizar as ações do enfermeiro com a diversidade de cateter, sondas e tubo oro- traqueal.

O módulo Lista de Problemas (Figura 17) configura interface com o módulo Coleta de Dados gerenciando para que os dados da base de sinais e sintomas selecionados pelo usuário seja apresentado e visualizado em um esquema representativo do corpo humano. Este módulo também apresenta interface com o módulo Prescrição de Enfermagem (Figura 18). O usuário seleciona um dado visualizado e com um duplo toque no dispositivo de entrada (mouse) sobre este, o referido módulo será disponibilizado.

No módulo Lista de Problemas é permitido visualizar os sinais e sintomas escolhidos para efetuar a prescrição de enfermagem e também decidir se utilizará a base de prescrições já disponível no banco de dados ou se realizará alterações ou digitará sua própria prescrição. 


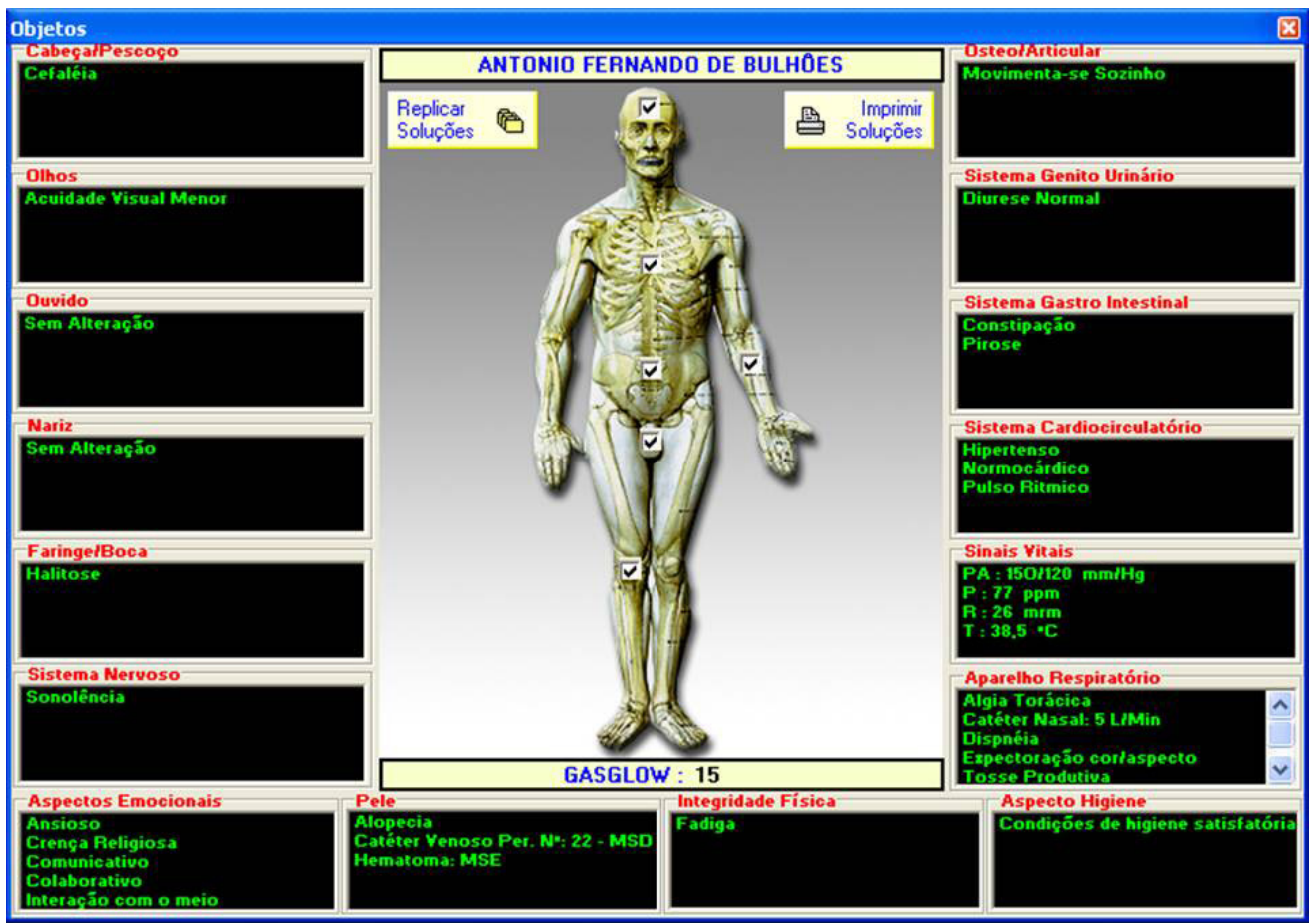

Figura 17 - Tela da Lista de Problemas do Software-protótipo para a SAE (Sperandio, 2002).

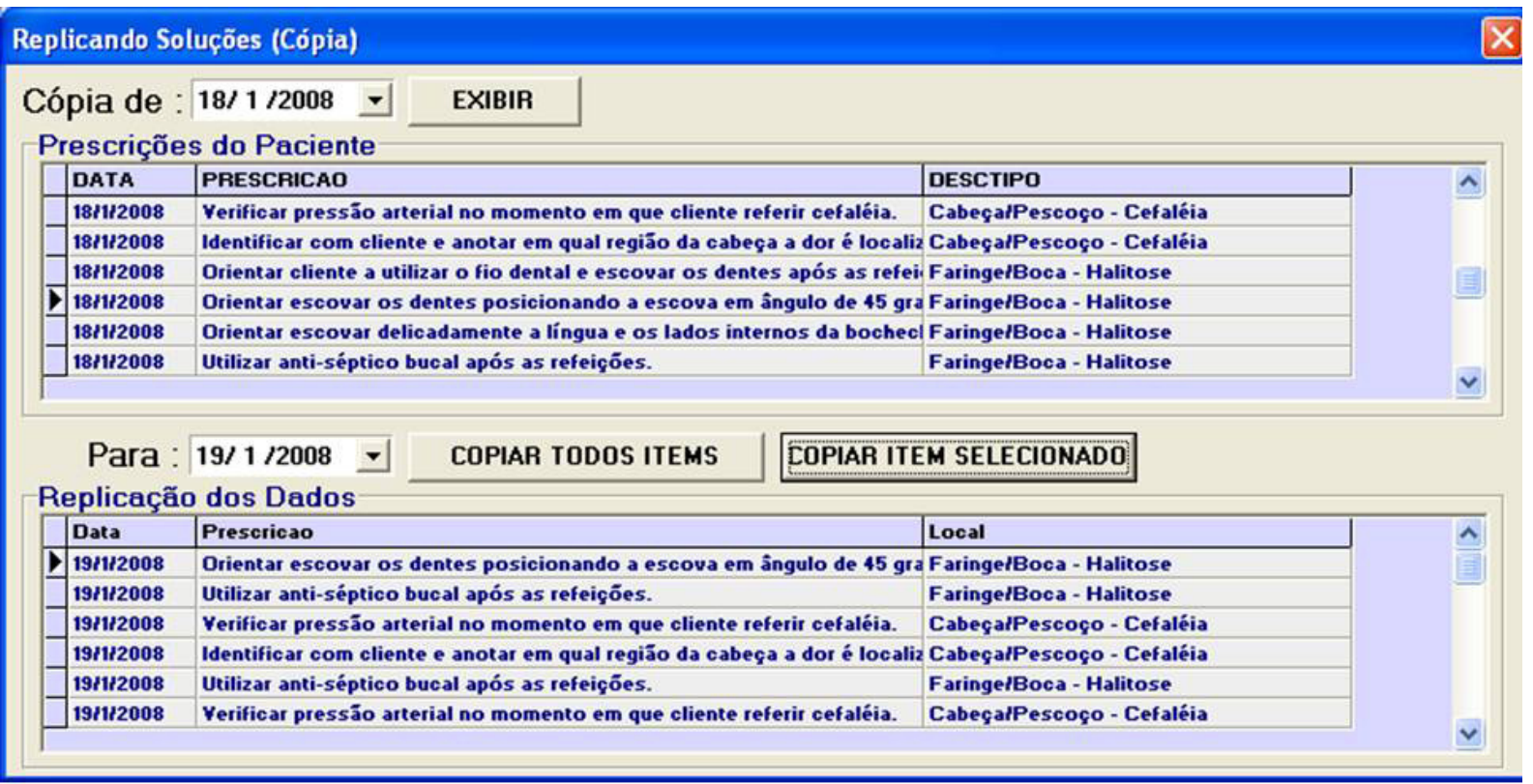

Figura 18 - Tela da Prescrição de Enfermagem do Software-protótipo para a SAE (Sperandio, 2002).

Como mostra a Tabela 8, o módulo de Lista de Problemas apresentou cinco solicitações para manutenção e o módulo Prescrição de Enfermagem concentrou dez sugestões a serem efetuadas, sendo que uma única solicitação de excluir o item copiado da prescrição anterior, coincidiu com seis enfermeiros. Observa-se que a 
avaliação destes dois módulos resultou em quatro sugestões, uma de docente e três de enfermeiros, sobre a necessidade de elaboração da fase do Diagnóstico de Enfermagem para efetuar a Prescrição de Enfermagem neste Software.

Tabela 8 - Avaliação dos módulos Lista de Problemas e Prescrição de Enfermagem do Softwareprotótipo para SAE pelos Docentes e Enfermeiros dos Hospitais A e B. Catanduva, SP, 2007.

\begin{tabular}{|c|c|c|c|}
\hline Módulo & Avaliador & & Modificações Sugeridas \\
\hline \multirow{6}{*}{ Lista de problemas } & \multirow{4}{*}{ Docentes } & Docente 3: & $\begin{array}{l}\text {-Acrescentar no campo "Pele" uma } \\
\text { orientação salientando } \\
\text { obrigatoriedade do preenchimento do } \\
\text { campo em branco ao lado direito dos } \\
\text { sinais/sintomas, para que ocorra o } \\
\text { correto cadastramento deste } \\
\text { sinal/sintoma. }\end{array}$ \\
\hline & & Docente 4: & $\begin{array}{l}\text {-Verificar a possibilidade da } \\
\text { visualização apenas de "Problemas } \\
\text { Reais", pois aparecem situações que } \\
\text { não são problemas. }\end{array}$ \\
\hline & & Docente 5: & $\begin{array}{l}\text {-Visualizar as normalidades e não } \\
\text { apenas os problemas. }\end{array}$ \\
\hline & & Docente 8: & $\begin{array}{l}\text { - Usar a taxonomia da NANDA, por ser } \\
\text { uma tendência atual. }\end{array}$ \\
\hline & $\begin{array}{l}\text { Enfermeiros } \\
\text { Hospital A }\end{array}$ & & \\
\hline & $\begin{array}{l}\text { Enfermeiros } \\
\text { Hospital B }\end{array}$ & Enf. B 4 & $\begin{array}{l}\text { - Usar a taxonomia da NANDA, por ser } \\
\text { uma tendência atual. }\end{array}$ \\
\hline \multirow{4}{*}{$\begin{array}{l}\text { Prescrição de } \\
\text { Enfermagem }\end{array}$} & \multirow[t]{2}{*}{$\begin{array}{l}\text { Enfermeiros } \\
\text { Hospital A }\end{array}$} & $\begin{array}{l}\text { Docente 8: } \\
\text { Enf. A 1, } \\
\text { Enf. A 2, } \\
\text { Enf. A 3, } \\
\text { Enf. A 4, } \\
\text { Enf. A 5, } \\
\text { Enf. A 6: }\end{array}$ & $\begin{array}{l}\text {-Usar NIC como referência. } \\
\text {-Acrescentar em "Replicar Prescrição" a } \\
\text { possibilidade de excluir o item da } \\
\text { prescrição anterior que foi copiado. }\end{array}$ \\
\hline & & Enf. A 4: & $\begin{array}{l}\text {-Corrigir na "Prescrição de } \\
\text { Enfermagem": o segundo horário } \\
\text { exibido deve ser o horário da execução } \\
\text { da Prescrição, não o horário que } \\
\text { ocorreu a prescrição. }\end{array}$ \\
\hline & \multirow{2}{*}{$\begin{array}{l}\text { Enfermeiros } \\
\text { Hospital B }\end{array}$} & $\begin{array}{l}\text { Enf. B 1, } \\
\text { Enf. B 2: }\end{array}$ & $\begin{array}{l}\text {-Ampliar as prescrições de } \\
\text { Enfermagem. }\end{array}$ \\
\hline & & Enf. B 4 & $\begin{array}{l}\text {-Realizar prescrição de enfermagem, } \\
\text { em cima do diagnóstico de enfermagem }\end{array}$ \\
\hline
\end{tabular}

O Software-protótipo para a Sistematização da Assistência de Enfermagem foi desenvolvido para a aplicação do Processo de Enfermagem utilizando o 
levantamento de problemas consistindo na coleta sistemática de dados significativos apoiados na anamnese e exame físico de enfermagem. Levam à identificação dos problemas de saúde constituindo-se assim, uma base de problemas identificados. 0 enfermeiro utiliza a descrição dos dados colhidos, sua percepção, conhecimento clínico associado ao seu conhecimento técnico adquirido e frente a esta lista de problemas faz a análise e a interpretação que determinará quais intervenções necessitam ser priorizadas e realizadas para o atendimento das necessidades dos pacientes.

Conforme discorrido, a avaliação dos módulos Lista de Problemas e Prescrição de Enfermagem favoreceu um questionamento sobre a aplicação de teoria em enfermagem e das etapas do diagnóstico de enfermagem na implementação do Processo de enfermagem.

Conforme proposto por Horta (1979), o Processo de Enfermagem compreende seis etapas sistematizadas, onde a segunda etapa focaliza o Diagnóstico de Enfermagem.

Potter e Perry (1998) discorrem sobre o processo de enfermagem estruturado em cinco etapas denominadas: abordagem, diagnóstico de enfermagem, planejamento, implementação e avaliação.

Para essas autoras, "o diagnóstico de enfermagem é a determinação do problema real ou
potencial do estado de saúde do paciente, para o qual o profissional de
enfermagem é licenciado e tem competência para tratar. O propósito geral
do diagnóstico de enfermagem é interpretar os dados de avaliação e então
identificar os problemas de saúde que envolvem o paciente a família e
outros indivíduos de relevância."( POTTER,PERRY,1998,p;109) Embora seja apontado por alguns avaliadores deste estudo e pela literatura científica que o enfermeiro precisa estabelecer o conhecimento sobre as fases do processo de enfermagem e incorporar os conceitos propostos pelo modelo, a 
elaboração do Módulo Diagnóstico de Enfermagem será contemplada a longo prazo, pois demanda estudo específico para a instrumentalização e posterior desenvolvimento deste módulo.

Com respeito à correção do relatório de impressão sobre o item execução da prescrição, este será atendido em curto prazo.

O módulo Evolução de Enfermagem (Figura 19) apresenta interface com o módulo Coleta de Dados disponibilizando a visualização dos sinais e sintomas selecionados pelo usuário. Oferece também para cada item a escolha de uma dessas opções: melhorado, piorado, resolvido e não alterado. Podem ser acessadas com um toque no dispositivo de entrada (mouse).

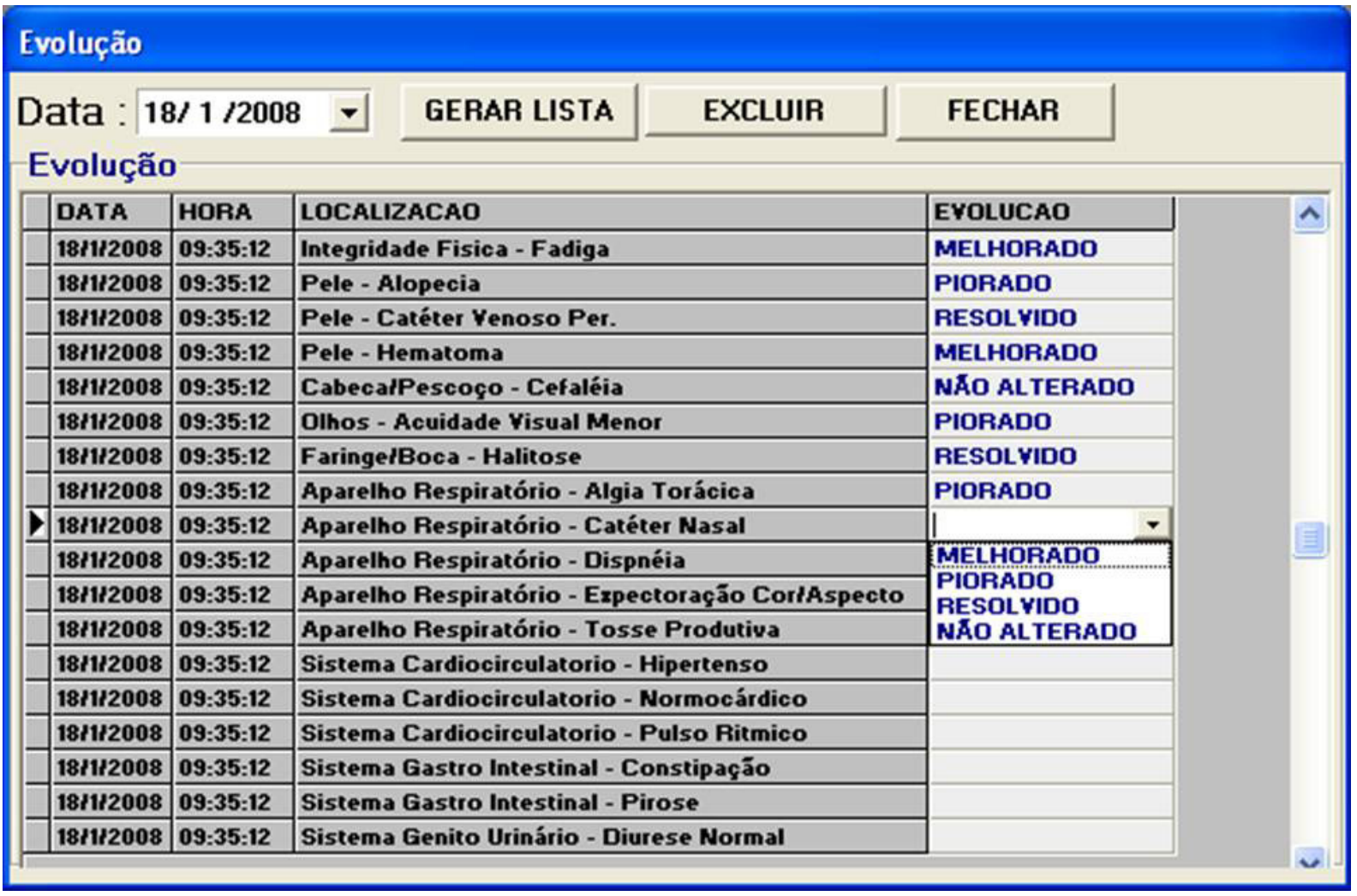

Figura 19 - Tela da Evolução de Enfermagem do Software-protótipo para a SAE (Sperandio, 2002).

A Tabela 9 apresenta a avaliação realizada pelos enfermeiros docentes e enfermeiros. Evidenciam-se dez sugestões para aperfeiçoamento do módulo, sendo 
duas de docentes e oito de enfermeiros, uma solicitação coincidiu para os sete enfermeiros que atuam profissionalmente no Hospital $A$.

Tabela 9 - Avaliação do módulo Evolução de Enfermagem do Software-protótipo para SAE pelos Docentes e Enfermeiros dos Hospitais A e B. Catanduva, SP, 2007.

\begin{tabular}{|c|c|c|c|}
\hline Módulo & Avaliador & & Modificações Sugeridas \\
\hline \multirow{3}{*}{$\begin{array}{l}\text { Evolução de } \\
\text { enfermagem }\end{array}$} & Docentes & $\begin{array}{l}\text { Docente 5: } \\
\text { Docente 8: }\end{array}$ & $\begin{array}{l}\text {-Acrescentar campo para } \\
\text { itens:aumentado, diminuído } \\
\text { mantendo. } \\
\text { Usar NOC }\end{array}$ \\
\hline & $\begin{array}{l}\text { Enfermeiros } \\
\text { Hospital A }\end{array}$ & $\begin{array}{l}\text { Enf. A 1, } \\
\text { Enf. A 2, } \\
\text { Enf. A 3, } \\
\text { Enf. A 4, } \\
\text { Enf. A 5, } \\
\text { Enf. A 6, } \\
\text { Enf. A 7: }\end{array}$ & $\begin{array}{l}\text {-Acrescentar campo para prescrever } \\
\text { nos turnos Matutino, Vespertino e } \\
\text { Noturno. }\end{array}$ \\
\hline & $\begin{array}{l}\text { Enfermeiros } \\
\text { Hospital B }\end{array}$ & Enf. B 4 & $\begin{array}{l}\text {-Evoluir em cima do diagnóstico, se está } \\
\text { melhorado, piorado ou resolvido. }\end{array}$ \\
\hline
\end{tabular}

As sugestões serão atendidas nas atividades de manutenção de médio prazo devido ao impacto que irão gerar no código-fonte do Software-protótipo para a Sistematização da Assistência de Enfermagem.

O módulo Sinais Vitais (Figura 20) armazena os dados sobre pressão arterial, temperatura, respiração, pulso e pressão venosa central e gera automaticamente o Gráfico de Sinais Vitais. O sistema faz a atualização a cada novo valor inserido. 


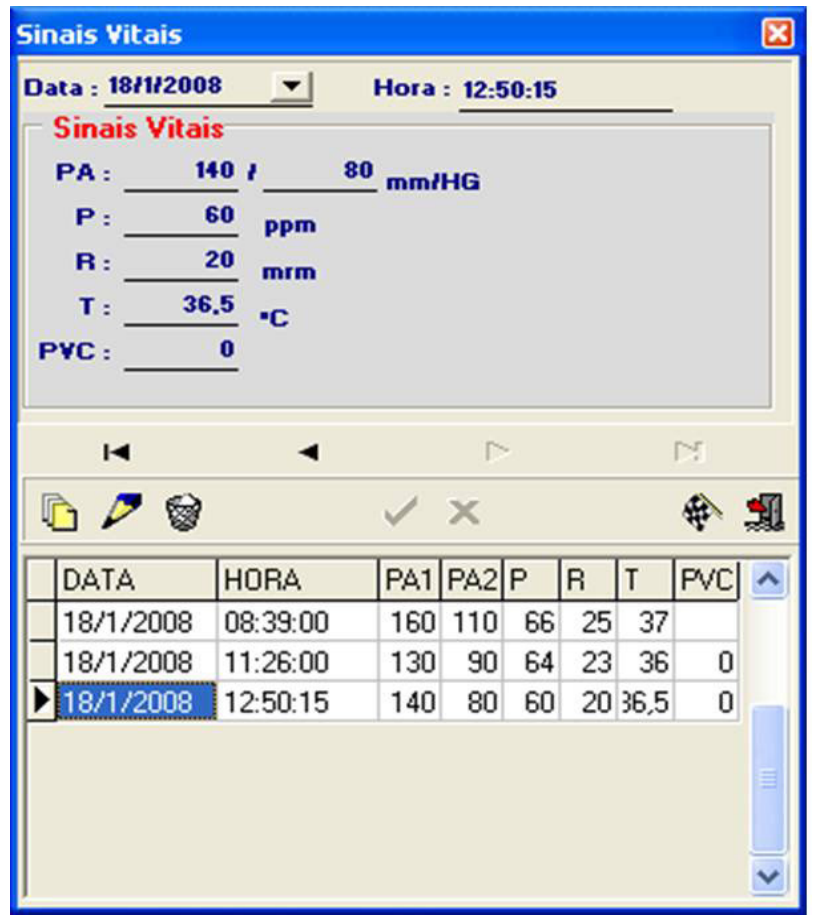

Figura 20 - Tela de Sinais Vitais do Software-protótipo para a SAE (Sperandio, 2002).

\section{O módulo Balanço Hidroeletrolítrico (Figuras 21 e 22) calcula}

\section{eletronicamente os valores do subtotal das 24 horas de Entrada e Saída.}

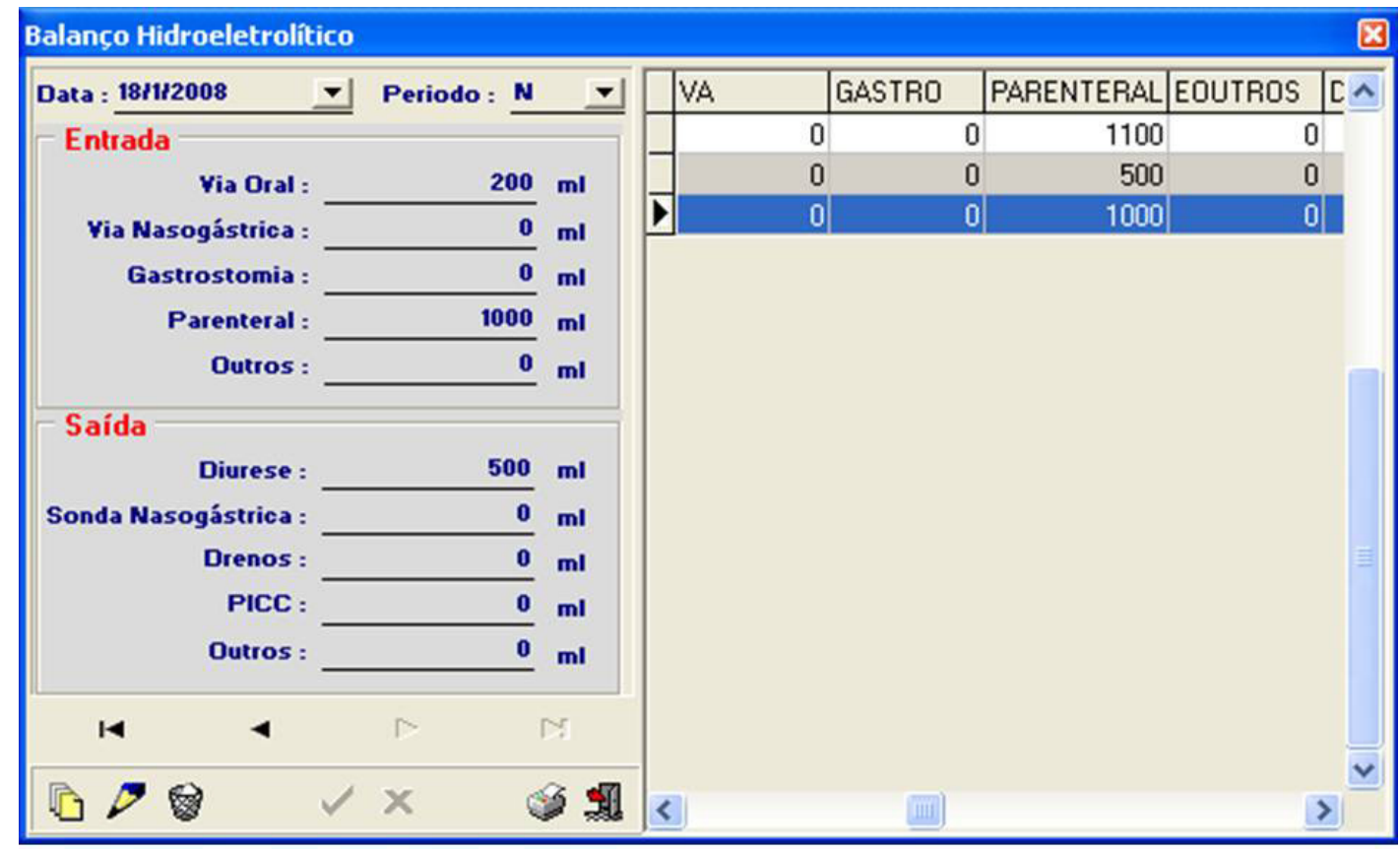

Figura 21 - Tela de Balanço Hidroeletrolítrico do Software-protótipo para a SAE (Sperandio, 2002). 


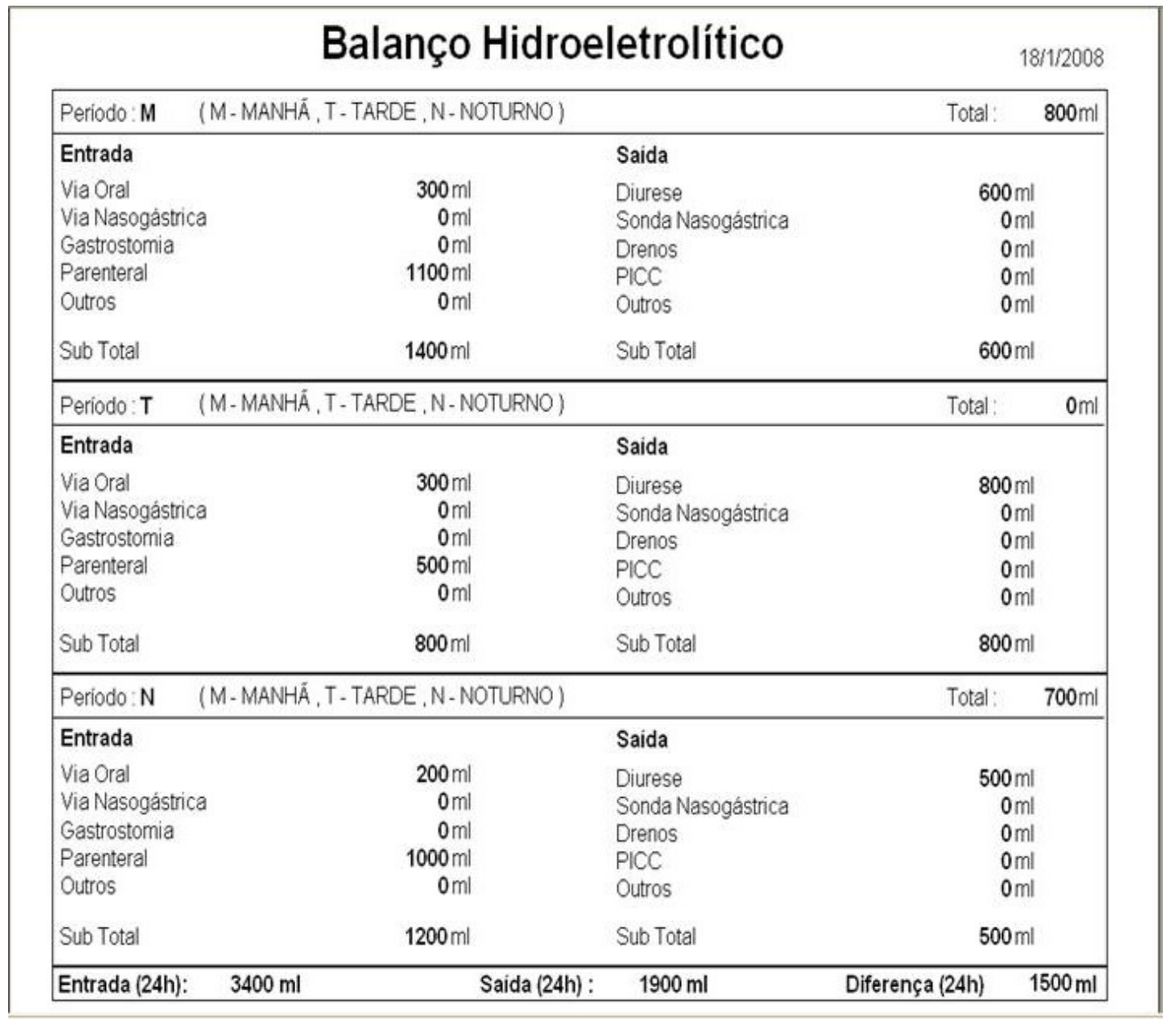

Figura 22 - Tela de apresentação do Balanço Hidroeletrolítrico do Software-protótipo para a SAE (Sperandio, 2002).

O módulo Telas para Cadastramento permite cadastrar previamente de acordo com as necessidades de cada usuário: procedência (Módulo Ficha de Identificação), clínica (Módulo Dados Clínicos), destino (Módulo Internações), objetos pessoais - medicações de uso diário - alergias (Módulo Informações Adicionais).

De acordo com a Tabela 10, o módulo Sinais Vitais foi aceito por cinco docentes e dez enfermeiros, enquanto três docentes e um enfermeiro solicitaram mudanças. Para atendê-las serão desenvolvidos dois novos campos. Um abrangerá a Escala da dor e o outro a documentação proveniente das informações do cateter arterial, Swans Gans e débito cardíaco. 
Tabela 10 - Avaliação dos módulos Sinais Vitais, Balanço Hidroeletrolítrico e Telas para Cadastramento do Software-protótipo para SAE pelos Docentes e Enfermeiros dos Hospitais A e B. Catanduva, SP, 2007.

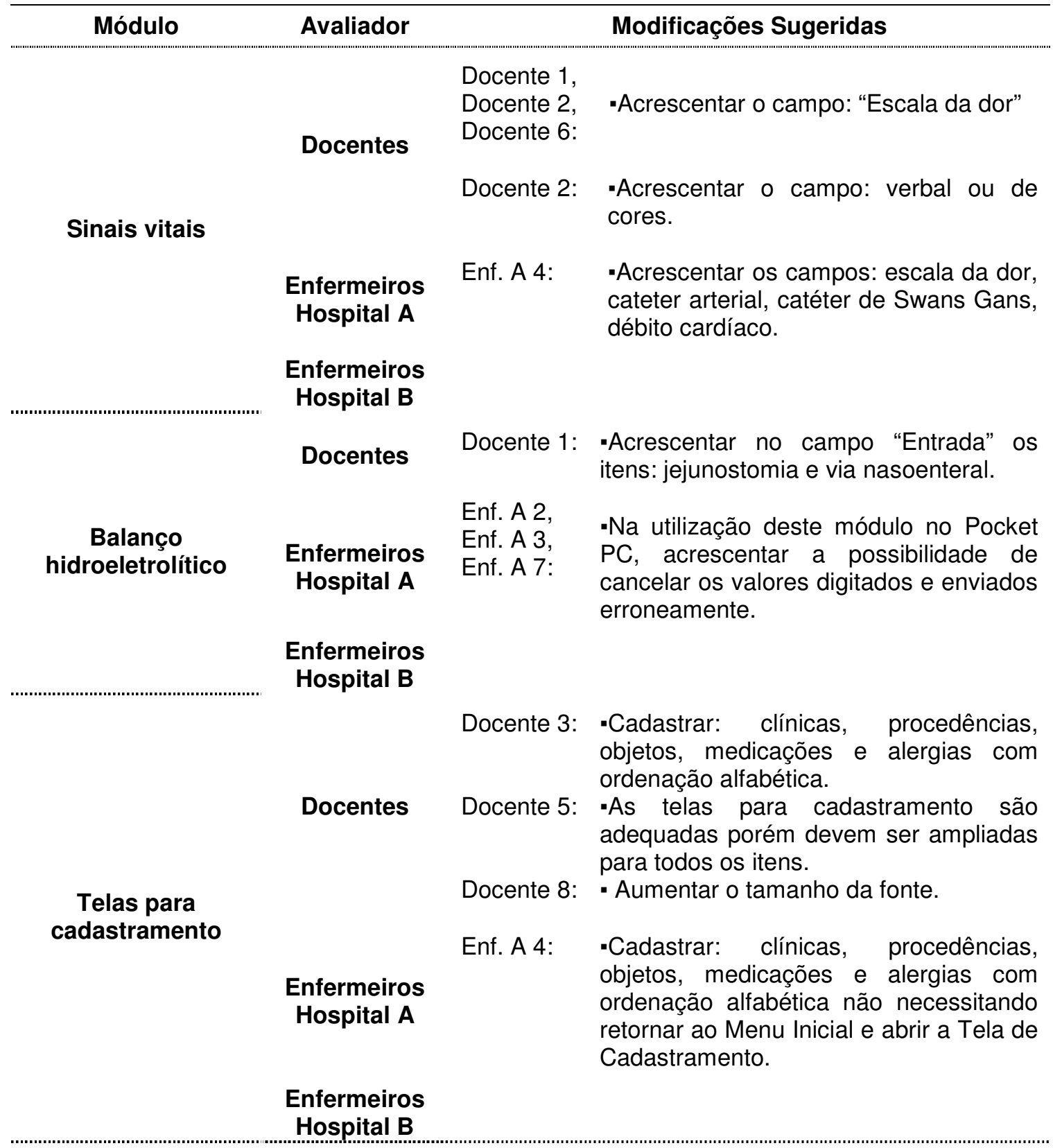

Os docentes e enfermeiros apontaram quatro aspectos para modificações no Módulo Balanço Hidroeletrolítico.

Os pontos de acréscimo propostos serão atendidos em médio prazo, enquanto a solicitação para o cancelamento de valores digitados e enviados erroneamente pelo Pocket $P C$ não será possível ser contemplado, pois o dispositivo 
móvel permite apenas o cadastramento de dados e sua alteração somente é viável no sistema instalado no microcomputador móvel tipo Notebook.

Quanto ao Módulo Cadastramento, observa-se na Tabela 10 que foram feitas duas sugestões, uma por docentes e outra por enfermeiro, para que os dados cadastrados sejam inseridos em ordem alfabética, favorecendo sua busca neste módulo.

Estes avaliadores também sugeriram à possibilidade do cadastramento ser efetuado no módulo em que o campo está inserido, como exemplo, as procedências serem cadastrada no Módulo Ficha de Identificação, local onde o campo procedência está localizado. Na avaliação dos módulos Ficha de Identificação, Dados Clínicos, internações e Informações Adicionais esta sugestão foi apresentada por dois docentes e o cadastro em ordem alfabética foi proposto por dois docentes e por dois enfermeiros.

Observa-se que este módulo foi incompreendido nesta avaliação, uma vez que ele permite que todos os dados sejam cadastrados previamente de acordo com a necessidade dos usuários. Portanto, antecipando a implementação do Softwareprotótipo em uma unidade hospitalar serão cadastrados todos os itens que os usuários julgarem necessários.

Diante do exposto, conclui-se que será preciso disponibilizar esta informação no Manual do Usuário. 


\subsection{Teste de Validação}

O teste para a validação do Software-protótipo através das características:

Funcionalidade, Confiabilidade, Usabilidade, Eficiência, Manutenibilidade e Portabilidade foi desenvolvido com a participação de especialistas de informática, docentes e enfermeiros que avaliaram o Software-protótipo para a Sistematização da Assistência de Enfermagem utilizando os microcomputador móvel e os dispositivos: Pocket PC e Access Point (Figura 23).

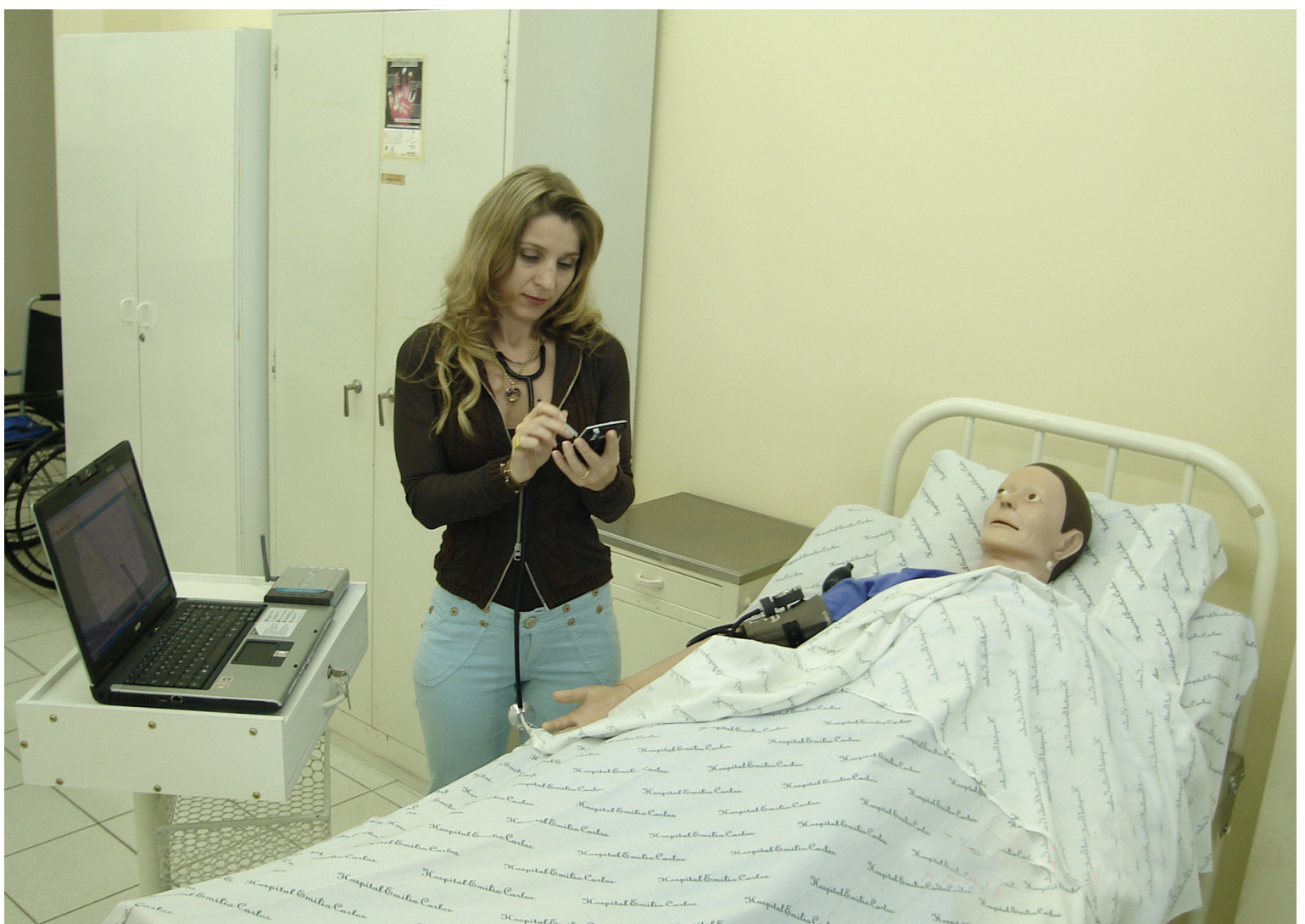

Figura 23 - Microcomputador móvel dispositivos Pocket PC e Access Point usados especificamente no teste de validação

\subsubsection{Validação dos Especialistas em Informática}

Os especialistas em Informática avaliaram a característica Funcionalidade do Software-Protótipo para Sistematização da Assistência de Enfermagem por meio das subcaracterísticas: adequação, acurácia, interoperabilidade, conformidade e segurança de acesso (Tabela 11). 
A subcaracterística adequação evidencia a apropriação do software em executar suas tarefas especificadas sendo considerada de acordo pelos oito especialistas em informática. As funções necessárias para a sua execução receberam o acordo de seis especialistas e dois discordaram, pois estes observaram a falha de comunicação com o banco de dados.

A subcaracterística acurácia relaciona-se ao software realizar o que foi proposto de forma correta e com grau de exatidão na execução de suas funções e nos resultados gerados.

Seis especialistas em informática concordaram com estes aspectos e dois discordaram, uma vez que verificaram a necessidade de revisão no código fonte.

A subcaracterística interoperabilidade trata da interação do software com um ou mais sistemas específicos.

Os dados da Tabela 11 demonstram que todos os avaliadores concordaram que existe a interação entre os doze módulos que estruturam este Softwareprotótipo.

A capacidade para processamento multiusuário foi julgada como de acordo por três avaliadores enquanto dois discordaram em decorrência de falhas na comunicação com banco de dados e três avaliadores concluíram que não foi possível a avaliação.

Cinco avaliadores concordaram com a capacidade do Software-protótipo operar com redes e três justificaram que não foi possível esta avaliação.

A subcaracterística conformidade demonstra a capacidade do produto estar de acordo com normas, convenções ou regulamentações previstas em leis relacionadas à funcionalidade. 
O Software-protótipo em questão atende a Resolução do Conselho Federal de Enfermagem COFEN - 272/2002 que dispõe sobre a Sistematização da Assistência de Enfermagem (SAE) nas Instituições de Saúde Brasileiras. A avaliação desta subcaracterística resultou em cinco respostas de acordo e três especialistas em informática que responderam que não foi possível avaliar.

A subcaracterística segurança de acesso resume a capacidade de proteção de informações e dados, de forma que pessoas ou sistemas não autorizados não possam efetuar leituras ou modificações e não ocorra que o acesso às pessoas ou sistemas autorizados seja negado.

O aplicativo em avaliação disponibiliza senha de acesso de forma a possibilitar permissão ou restrição de uso apenas aos dados necessários. Para enfermeiros é assegurado autorização ampla e total atendendo a Resolução COFEN - 272/2002 que ao enfermeiro incumbe privativamente a implantação, planejamento, organização, execução e avaliação do processo de enfermagem.

Os técnicos e auxiliares de enfermagem utilizam a senha com permissão para leitura em todos os módulos e permissão para a entrada de dados somente nos Módulos Sinais Vitais e Balanço Hidroeletrolítrico.

Na tabela 11 podemos verificar que a avaliação de acesso através de senhas resultou em cinco respostas de acordo, uma em desacordo e duas em que esta questão não foi aplicada.

Durante a avaliação não foi disponibilizado o código-fonte aos especialistas em Informática, portanto, as rotinas internas de backup e restore foram percebidas como inexistentes e resultaram em desacordo por seis avaliadores e dois assinalaram que não foi aplicável. 
Tabela 11 - Validação da Característica Funcionalidade do Software-protótipo para SAE pelos Especialistas em Informática. Catanduva, SP, 2007.

\begin{tabular}{llll}
\hline \multicolumn{1}{c}{ FUNCIONALIDADE } & A & D & NA \\
\hline $\begin{array}{l}\text { 1.1.1 O software propõe-se a fazer o que é apropriado (Adequação) } \\
\text { 1.1.2 O software dispõe de todas as funções necessárias para sua execução }\end{array}$ & 8 & 0 \\
(Adequação) & 6 & 0 \\
1.2.1 O software faz o que foi proposto de forma correta (Acurácia) & 6 & 2 & 0 \\
1.2.2 O software é preciso na execução de suas funções (Acurácia) & 6 & 2 & 0 \\
1.2.3 O software é preciso nos resultados (Acurácia) & 6 & 2 & 0 \\
$\begin{array}{l}\text { 1.3.1 O software interage com os módulos especificados (Interoperabilidade) } \\
\text { 1.3.2 O software tem capacidade para processamento multiusuário }\end{array}$ & 8 & 0 & 0 \\
(Interoperabilidade) & 3 & 2 & 3 \\
1.3.3 O software tem capacidade para operação com redes (Interoperabilidade) & 5 & 0 & 3 \\
$\begin{array}{l}\text { 1.4.1 O software está conciso com as normas, leis, etc. (Conformidade) } \\
\text { 1.5.1 O software dispõe segurança de acesso através de senhas (Tolerância a }\end{array}$ & 5 & 0 & 3 \\
falhas) & 5 & 1 & 2 \\
1.5.2 O software dispõe de rotina interna de backup (Tolerância a falhas) & 0 & 6 & 2 \\
1.5.3 O software dispõe de rotina interna de restore (Tolerância a falhas) & 0 & 6 & 2 \\
\hline
\end{tabular}

A - de Acordo; D - Desacordo; NA - Não se aplica.

A característica Confiabilidade apresenta como subcaracterísticas: maturidade, tolerância a falhas e recuperabilidade (Tabela 12).

A subcaracterística maturidade diz respeito à freqüência que ocorrem falhas, causadas por defeitos no software. Falha, segundo a ISO/IEC 14598-1, é "o término da capacidade de um item de executar funções requeridas ou sua incapacidade de executá-las dentro de limites previamente especificados". Defeito é uma imperfeição contida no produto e que não compromete a qualidade de serviço.

Da Tabela 12 depreende-se que quatro especialistas em informática consideram de acordo com este aspecto, três discordaram em decorrência de falhas ocorridas durante a avaliação do Software-protótipo para Sistematização da Assistência de Enfermagem e um considerou que não foi possível avaliar.

A subcaracterística tolerância a falhas abrange a forma que o Softwareprotótipo para Sistematização da Assistência de Enfermagem protege os dados armazenados na ocorrência de falhas. 
Dois avaliadores concordaram com este item e dois concluíram que não foi possível avaliar. Quatro avaliadores discordaram, pois o sistema operacional parou durante a avaliação e não houve a recuperação dos dados.

A recuperabilidade é a capacidade deste Software-protótipo recuperar os dados em tempo hábil na ocorrência de falha. Quatro especialistas estão em desacordo com esta subcaracterística, três observaram que não foi possível a avaliação da recuperação de dados e um especialista está de acordo.

A informação de dados inválidos pelo usuário foi avaliada como de acordo por três especialista em informática, três discordaram, pois observaram que não foi informada a entrada de "Data" errada ao usuário e dois consideraram que não foi possível avaliar.

Tabela 12 - Validação da Característica Confiabilidade do Software-protótipo para SAE pelos Especialistas em Informática. Catanduva, SP, 2007.

\begin{tabular}{|c|c|c|c|}
\hline CONFIABILIDADE & A & D & NA \\
\hline 2.1.1 O software apresenta falhas com freqüência (Maturidade) & 4 & 3 & 1 \\
\hline 2.2.1 O software reage adequadamente quando ocorre falhas (Tolerância a falhas) & 2 & 4 & 2 \\
\hline 2.2.2 O software informa ao usuário a entrada de dados inválida (Tolerância a falhas) & 3 & 3 & 2 \\
\hline 2.3.1 O software é capaz de recuperar dados em caso de falha (Recuperabilidade) & 1 & 4 & 3 \\
\hline
\end{tabular}

A - de Acordo; D - Desacordo; NA - Não se aplica.

A Usabilidade utiliza-se das subcaracterísticas: inteligibilidade, apreensibilidade e operacionalidade (Tabela 13).

O item inteligibilidade corresponde ao esforço dos usuários do Softwareprotótipo para Sistematização da Assistência de Enfermagem para reconhecer a facilidade no entendimento dos conceitos utilizados e sua aplicação, avaliado como de acordo por sete especialistas em informática e um expressou que não foi possível avaliar. 
A totalidade dos especialistas concordou com a facilidade para executar as funções deste recurso tecnológico.

A facilidade no aprendizado da utilização e na inserção de dados determina a apreensibilidade deste software em avaliação. Sete avaliadores expressaram o acordo com este item e um considerou a necessidade de treinamento para a utilização do sistema.

A entrada de dados recebeu a concordância de seis avaliadores e dois discordaram, acreditando que o excesso de informações dos formulários prejudicam esta função. A saída de dados foi considerada de acordo para sete especialistas e um julgou não ser possível proceder à avaliação.

A facilidade de operar e controlar as operações e o entendimento claro de suas funções, correspondem a subcaracterística operacionalidade.

Os dados da Tabela 13 evidenciaram que a totalidade dos avaliadores concordou sobre a facilidade em operar o Software-protótipo para a Sistematização da Assistência de Enfermagem.

O item clareza das funções foi considerado em desacordo por cinco especialistas e destes, três julgaram pertinente a elaboração da função Help; um justificou não ser possível a avaliação e dois estiveram de acordo.

Embora a característica Usabilidade foi percebida pelos especialistas como fácil de compreender e de utilizar, considera-se ser apropriado elaborar o manual de usuário, assim como adicionar a função Ajuda neste ambiente informatizado para implementação da Sistematização da Assistência de Enfermagem. 
Tabela 13 - Validação da Característica Usabilidade do Software-protótipo para SAE pelos Especialistas em Informática. Catanduva, SP, 2007.

\begin{tabular}{llll}
\hline \multicolumn{1}{c}{ USABILIDADE } & A & D & NA \\
\hline 3.1.1 É fácil entender o conceito e a aplicação (Inteligibilidade) & 7 & 0 & 1 \\
3.1.2 É fácil executar suas funções (Inteligibilidade) & 8 & 0 & 0 \\
3.2.1 É fácil aprender a usar (Apreensibilidade) & 7 & 1 & 0 \\
3.2.2 O software facilita a entrada de dados pelo usuário (Apreensibilidade) & 6 & 2 & 0 \\
3.2.3 O software facilita a saída de dados para o usuário (Apreensibilidade) & 7 & 0 & 1 \\
3.3.1 É fácil de operar e controlar (Operacionalidade) & 8 & 0 & 0 \\
3.3.2 O software fornece ajuda de forma clara (Operacionalidade) & 2 & 5 & 1 \\
\hline
\end{tabular}

A - de Acordo; D - Desacordo; NA - Não se aplica.

A característica Eficiência foi avaliada pelos especialistas em informática por meio de duas subcaracterísticas: tempo e recursos (Tabela 14).

A primeira expressa a adequação do tempo de resposta e de execução de suas funções, enquanto a segunda diz respeito a todos os recursos que se comunicam ao redor do Software-protótipo para Sistematização da Assistência de Enfermagem.

Ambas receberam concordância de sete avaliadores e um considerou não ser possível realizar a avaliação.

Tabela 14 - Validação da Característica Eficiência do Software-protótipo para SAE pelos Especialistas em Informática. Catanduva, SP, 2007.

\begin{tabular}{lccc}
\hline \multicolumn{1}{c}{ EFICIÉNCIA } & A & D & NA \\
\hline 4.1.1 O tempo de resposta do software é adequado (Tempo) & 7 & 0 & 1 \\
4.1.2 O tempo de execução do software é adequado (tempo) & 7 & 0 & 1 \\
4.2.1 Os recursos utilizados são adequados (Recursos) & 7 & 0 & 1 \\
\hline
\end{tabular}

A - de Acordo; D - Desacordo; NA - Não se aplica.

A característica Manutenibilidade apresenta como subcaracterística: analisabilidade, modificabilidade, estabilidade e testabilidade (Tabela 15).

A analisabilidade permite o diagnóstico de deficiência ou causas de falhas sendo avaliada como de acordo por cinco, destes dois justificaram que a falha 
encontrada é mostrada na tela do Software-protótipo para Sistematização da Assistência de Enfermagem e dois consideraram não ser possível a avaliação.

A capacidade de permitir que modificações sejam implementadas resume a modificabilidade, que recebeu o acordo de quatro especialistas, um desacordo e três que julgaram não ser possível a avaliação.

A estabilidade expressa o risco de efeitos inesperados, ocasionados por modificações e foi considerada não aplicável, por quatro especialistas que relataram desconhecer o código-fonte do Software-protótipo em avaliação. Dois avaliadores assinalaram desacordo e dois concordam com esta subcaracterística.

Os atributos que evidenciam o esforço necessário para validar o software modificado definem a testabilidade.

Os resultados demonstraram (Tabela 15) que quatro especialistas consideraram não aplicável, um posicionou-se em desacordo e três como de acordo.

Tabela 15 - Validação da Característica Manutenibilidade do Software-protótipo para SAE pelos Especialistas em Informática. Catanduva, SP, 2007.

\begin{tabular}{lccc}
\hline \multicolumn{1}{c}{ MANUTENIBILIDADE } & A & D & NA \\
\hline 5.1.1 É fácil de encontrar uma falha, quando ocorre (Analisabilidade) & 5 & 1 & 2 \\
5.2.1 É fácil modificar e adaptar (Modificabilidade) & 4 & 1 & 3 \\
5.3.1 Há grande risco quando se faz alterações (Estabilidade) & 2 & 2 & 4 \\
5.4.1 É fácil testar quando se faz alterações (Testabilidade) & 3 & 1 & 4 \\
\hline
\end{tabular}

A - de Acordo; D - Desacordo; NA - Não se aplica

Vale ressaltar que o Software-protótipo para Sistematização da Assistência de Enfermagem sofreu modificações e adaptações em seu código-fonte para sua interação com o dispositivo móvel Pocket PC. Isto foi necessário para que os dados coletados neste equipamento pudessem ser transmitidos ao microcomputador móvel em tempo real através do equipamento de Access Point e também a transmissão e visualização de dados inseridos pelo microcomputador ao dispositivo móvel. 
A característica Portabilidade foi avaliada através de quatro subcaracterísticas: adaptabilidade, capacidade para ser instalado, conformidade e capacidade para substituir (Tabela 16).

A adaptabilidade preconiza a transferência para diferentes ambientes especificados, sem necessidade de aplicação de outras ações ou meios além dos fornecidos pelo software em questão.

Pode-se observar na Tabela 16, que três especialistas concordaram com este item, três discordaram e dois verificaram que não foi possível avaliar.

Tabela 16 - Validação da Característica Portabilidade do Software-protótipo para SAE pelos Especialistas em Informática. Catanduva, SP, 2007.

\begin{tabular}{llll}
\hline \multicolumn{1}{c}{ PORTABILIDADE } & A & D & NA \\
\hline 6.1.2 É fácil adaptar a outros ambientes (Adaptabilidade) & 3 & 3 & 2 \\
6.2.1 É fácil instalar em outros ambientes (Capacidade para ser instalado) & 2 & 4 & 2 \\
6.3.1 Está de acordo com padrões de portabilidade (Conformidade) & 2 & 4 & 2 \\
6.4.1 É fácil usar para substituir outro (Capacidade para substituir) & 3 & 0 & 5 \\
\hline
\end{tabular}

A - de Acordo; D - Desacordo; NA - Não se aplica.

A capacidade para ser instalado em um ambiente especificado resultou em dois especialistas de acordo, quatro não concordaram e dois consideraram que não foi possível avaliar este item.

A conformidade diz respeito à capacidade do produto estar de acordo com normas relacionadas à portabilidade. Esta subcaracterística foi considerada em desacordo por quatro avaliadores; dois consideraram não aplicável e dois apresentaram concordância.

A capacidade para substituir outro produto de software com o mesmo propósito e no mesmo ambiente, foi considerado não aplicável nesta avaliação por cinco especialistas, entretanto, três especialistas apresentaram acordo com este item. 


\subsubsection{Validação dos Docentes e Enfermeiros Hospitais A e B}

A característica Funcionalidade foi avaliada pelos docentes e enfermeiros por meio das subcaracterísticas: adequação, acurácia, interoperabilidade e Segurança de Acesso (Tabela 17).

Com respeito à adequação e acurácia, a Tabela 17 mostra que o software atende essa subcaracterística e dispõe de funções necessárias para sua execução. Um docente acrescentou a observação que o software também oferece agilidade nos resultados do planejamento da Assistência de Enfermagem.

Entretanto, a subcaracterística adequação e acurácia apontam que três docentes, dois enfermeiros do Hospital A e dois enfermeiros do Hospital B, e sete docentes, dois enfermeiros do Hospital A e sete do enfermeiros do Hospital B, respectivamente, discordaram e ressaltaram que a aplicação correta da Sistematização da Assistência de Enfermagem será obtida quando o Softwareprotótipo contemplar o Diagnóstico de Enfermagem. Segundo estes avaliadores a implementação desta fase do Processo de Enfermagem é fundamental para este protótipo ser preciso na execução das funções e na obtenção dos resultados desejados.

A avaliação da subcaracterística interoperabilidade demonstrou ser adequada a interação dos módulos para a aplicação da Sistematização da Assistência de Enfermagem.

Apenas um docente e um enfermeiro do Hospital B discordaram deste aspecto e suas justificativas foram pautadas na ausência do módulo para Diagnóstico de Enfermagem. 
A disponibilidade de segurança de acesso foi evidenciada de acordo por catorze avaliadores. Um docente e dois enfermeiros do Hospital A consideraram desacordo e reivindicaram a necessidade de senha pessoal e dois docentes consideraram que não foi possível avaliar este item.

Tabela 17 - Validação da Característica Funcionalidade do Software-protótipo para SAE pelos Docentes e Enfermeiros dos Hospitais A e B. Catanduva, SP, 2007.

\begin{tabular}{|c|c|c|c|c|c|c|c|c|c|c|c|c|}
\hline \multirow{2}{*}{ FUNCIONALIDADE } & \multicolumn{4}{|c|}{$\mathbf{A}$} & \multicolumn{4}{|c|}{ D } & \multicolumn{4}{|c|}{ NA } \\
\hline & Do & Enf. A & Enf. B & $\mathrm{T}$ & Do & Enf. $A$ & Enf. B & $\mathrm{T}$ & Do & Enf. A & Enf. B & $T$ \\
\hline $\begin{array}{l}\text { 1.1.1 O software atende a aplicação da } \\
\text { Sistematização da Assistência de } \\
\text { Enfermagem (adequação) }\end{array}$ & 6 & 6 & 4 & 16 & 2 & 1 & 0 & 3 & 0 & 0 & 0 & 0 \\
\hline $\begin{array}{l}\text { 1.1.2 O software dispõe de todas as funções } \\
\text { necessárias para a execução da Sistematização da } \\
\text { Assistência de Enfermagem (adequação) } \\
\text { 1.2.1 O software permite a aplicacãa da }\end{array}$ & 7 & 6 & 2 & 15 & 1 & 1 & 2 & 4 & 0 & 0 & 0 & 0 \\
\hline $\begin{array}{l}\text { Sistematização da Assistência de Enfermagem de } \\
\text { forma correta (acurácia) }\end{array}$ & 6 & 6 & 1 & 13 & 2 & 1 & 3 & 6 & 0 & 0 & 0 & 0 \\
\hline $\begin{array}{l}\text { 1.2.2 O software é preciso na execução das funções } \\
\text { da Sistematização da Assistência de Enfermagem } \\
\text { (acurácia) }\end{array}$ & 6 & 7 & 1 & 14 & 2 & 0 & 3 & 5 & 0 & 0 & 0 & 0 \\
\hline $\begin{array}{l}\text { 1.2.3 O software é preciso nos resultados desejados } \\
\text { para a Sistematização da Assistência de } \\
\text { Enfermagem (acurácia) }\end{array}$ & 5 & 6 & 3 & 14 & 3 & 1 & 1 & 5 & 0 & 0 & 0 & 0 \\
\hline $\begin{array}{l}\text { 1.3.1 O software permite ao enfermeiro a adequada } \\
\text { interação dos módulos para a aplicação da } \\
\text { Sistematização da Assistência de Enfermagem } \\
\text { (interoperabilidade) }\end{array}$ & 7 & 7 & 3 & 17 & 1 & 0 & 1 & 2 & 0 & 0 & 0 & 0 \\
\hline $\begin{array}{l}1.5 .1 \text { O software dispõe de segurança de acesso } \\
\text { através de senhas (conformidade) }\end{array}$ & 5 & 5 & 4 & 14 & 1 & 2 & 0 & 3 & 2 & 0 & 0 & 2 \\
\hline
\end{tabular}

Do - Docentes; Enf A - Enfermeiros HEC; Enf B - Enfermeiros HB; T - Total

A - de Acordo; D - Desacordo; NA - Não se aplica.

Os docentes e enfermeiros avaliaram a característica Confiabilidade por meio das subcaracterísticas: maturidade, tolerância a falhas e recuperabilidade (Tabela 18).

A maturidade expressou a freqüência que o software apresentou falhas durante a avaliação e foi considerada como de acordo por um docente, cinco enfermeiros dos Hospital A e três enfermeiros do Hospital B. Devido ao sistema operacional do Software-protótipo apresentar falhas na execução e ser necessário reiniciar durante a avaliação, este item foi considerado em desacordo por cinco docentes, dois enfermeiros do Hospital A e um do Hospital B. Enquanto dois docentes responderam que não foi possível avaliar. 
A Tabela 18 demonstra que a tolerância a falhas recebeu a concordância de catorze avaliadores. Um docente, um enfermeiro do Hospital A e dois enfermeiros do Hospital B discordaram e um docente posicionou não ser aplicável.

A informação de entrada de dados inválida foi evidenciada de acordo por 18 avaliadores e em desacordo por um Enfermeiro do Hospital A.

A recuperabilidade demonstrou a capacidade de recuperação de dados em caso de falhas e recebeu o acordo de 17 avaliadores e dois desacordos, um de Enfermeiro do Hospital A e outro de Enfermeiro do Hospital B

Tabela 18 - Validação da Característica Confiabilidade do Software-protótipo para SAE pelos Docentes e Enfermeiros dos Hospitais A e B. Catanduva, SP, 2007.

\begin{tabular}{|c|c|c|c|c|c|c|c|c|c|c|c|c|}
\hline \multirow{2}{*}{ CONFIABILIDADE } & \multicolumn{4}{|c|}{$\mathbf{A}$} & \multicolumn{4}{|c|}{ D } & \multicolumn{4}{|c|}{ NA } \\
\hline & Do & Enf. $A$ & Enf. B & $\mathrm{T}$ & Do & Enf. & Enf. B & $T$ & Do & Enf. & Enf. B & $T$ \\
\hline $\begin{array}{l}\text { 2.1.1 O software apresenta falhas com freqüência } \\
\text { (maturidade) }\end{array}$ & 1 & 5 & 3 & 9 & 5 & 2 & 1 & 8 & 2 & 0 & 0 & 2 \\
\hline $\begin{array}{l}\text { 2.2.1 O software reage adequadamente quando } \\
\text { ocorre falhas (tolerância a falhas) }\end{array}$ & 6 & 6 & 2 & 14 & 1 & 1 & 2 & 4 & 1 & 0 & 0 & 1 \\
\hline $\begin{array}{l}\text { 2.2.2 O software informa ao usuário a entrada de } \\
\text { dados inválida (tolerância a falhas) }\end{array}$ & 8 & 6 & 4 & 18 & 0 & 1 & 0 & 1 & 0 & 0 & 0 & 0 \\
\hline $\begin{array}{l}\text { 2.3.1 O software é capaz de recuperar dados em } \\
\text { caso de falha (recuperabilidade) }\end{array}$ & 8 & 6 & 3 & 17 & 0 & 1 & 1 & 2 & 0 & 0 & 0 & 0 \\
\hline
\end{tabular}

Do - Docentes; Enf A - Enfermeiros HEC; Enf B - Enfermeiros HB; T - Total

A - de Acordo; D - Desacordo; NA - Não se aplica.

A característica Usabilidade foi avaliada através de suas subcaracterísticas: inteligibilidade, apreensibilidade e operacionalidade (Tabela 19).

A totalidade dos docentes e dos enfermeiros dos hospitais $A$ e $B$ evidenciaram o acordo com a subcaracterística inteligibilidade, significando que o Software-protótipo avaliado apresenta facilidade no entendimento do seu conceito e na sua aplicação. A concordância dos avaliadores foi unânime em relação a apreensibilidade devido à facilidade de inserção e saída das informações e também na operacionalidade representada pelo fácil aprendizado na utilização deste Software-protótipo para SAE. 
Os avaliadores não relataram dificuldade para operar e controlar o Softwareprotótipo e consideraram que o fornecimento de ajuda ocorreu de forma clara. Mesmo concordando com este item, um docente sugeriu a elaboração de um manual explicativo.

Tabela 19 - Validação da Característica Usabilidade do Software-protótipo para SAE pelos Docentes e Enfermeiros dos Hospitais A e B. Catanduva, SP, 2007.

\begin{tabular}{|c|c|c|c|c|c|c|c|c|c|c|c|c|}
\hline USABILIDADE & & $A$ & & & & & $\mathbf{D}$ & & & & & \\
\hline USADILIDADE & Do & Enf. A & Enf. B & $\mathrm{T}$ & Do & Enf. A & Enf. B & $\mathrm{T}$ & Do & Enf. A & Enf. B & $\mathrm{T}$ \\
\hline $\begin{array}{l}\text { 3.1.1 E fácil entender o conceito e a aplicação } \\
\text { (inteligibilidade) }\end{array}$ & 8 & 7 & 4 & 19 & 0 & 0 & 0 & 0 & 0 & 0 & 0 & 0 \\
\hline $\begin{array}{l}\text { 3.1.2 É fácil executar suas funções } \\
\text { (inteligibilidade) }\end{array}$ & 8 & 7 & 4 & 19 & 0 & 0 & 0 & 0 & 0 & 0 & 0 & 0 \\
\hline 3.2.1 É fácil aprender a usar (apreensibilidade) & 8 & 7 & 4 & 19 & 0 & 0 & 0 & 0 & 0 & 0 & 0 & 0 \\
\hline $\begin{array}{l}\text { 3.2.2 O software facilita a entrada de dados pelo } \\
\text { usuário (apreensibilidade) }\end{array}$ & 8 & 7 & 4 & 19 & 0 & 0 & 0 & 0 & 0 & 0 & 0 & 0 \\
\hline $\begin{array}{l}\text { 3.2.3 O software facilita a saída de dados para o } \\
\text { usuário (apreensibilidade) }\end{array}$ & 8 & 7 & 4 & 19 & 0 & 0 & 0 & 0 & 0 & 0 & 0 & 0 \\
\hline $\begin{array}{l}\text { 3.3.1 É fácil de operar e controlar } \\
\text { (operacionalidade) }\end{array}$ & 8 & 7 & 4 & 19 & 0 & 0 & 0 & 0 & 0 & 0 & 0 & 0 \\
\hline $\begin{array}{l}\text { 3.3.2 O software fornece ajuda de forma clara } \\
\text { (operacionalidade) }\end{array}$ & 8 & 7 & 4 & 19 & 0 & 0 & 0 & 0 & 0 & 0 & 0 & 0 \\
\hline
\end{tabular}

A característica Eficiência foi avaliada por meio de suas subcaracterísticas: tempo e recursos (Tabela 20 ).

Os docentes e enfermeiros dos hospitais $A$ e $B$ expressaram sua concordância com a adequação do tempo de resposta e execução do Softwareprotótipo para Sistematização da Assistência de Enfermagem e consideraram adequados os recursos utilizados. Somente um enfermeiro do Hospital B não concordou com o tempo de resposta ser adequado e um enfermeiro deste mesmo hospital respondeu que não se aplica os itens - tempo e recursos. 
Tabela 20 - Validação da Característica Eficiência do Software-protótipo para SAE pelos Docentes e Enfermeiros dos Hospitais A e B. Catanduva, SP, 2007.

\begin{tabular}{|c|c|c|c|c|c|c|c|c|c|c|c|c|}
\hline \multirow{2}{*}{ EFICIÊNCIA } & \multicolumn{4}{|c|}{ A } & \multicolumn{4}{|c|}{ D } & \multicolumn{4}{|c|}{$\mathbf{N A}$} \\
\hline & Do & Enf. A & Enf. B & $\mathrm{T}$ & Do & Enf. $A$ & A Enf. B & $\mathrm{T}$ & Do & Enf. A & Enf. B & $\mathrm{T}$ \\
\hline $\begin{array}{l}\text { 4.1.1 O tempo de resposta do software é adequado } \\
\text { (tempo) }\end{array}$ & 8 & 7 & 3 & 18 & 0 & 0 & 1 & 1 & 0 & 0 & 0 & 0 \\
\hline $\begin{array}{l}\text { 4.1.2 O tempo de execução do software é adequado } \\
\text { (tempo) }\end{array}$ & 8 & 7 & 3 & 18 & 0 & 0 & 0 & 0 & 0 & 0 & 1 & 1 \\
\hline $\begin{array}{l}\text { 4.2.1 Os recursos utilizados são adequados } \\
\text { (recursos) }\end{array}$ & 8 & 7 & 3 & 18 & 0 & 0 & 0 & 0 & 0 & 0 & 1 & 1 \\
\hline
\end{tabular}

Do - Docentes; Enf A - Enfermeiros HEC; Enf B - Enfermeiros HB; T - Total

A - de Acordo; D - Desacordo; NA - Não se aplica.

\subsubsection{Resultados da Validação dos Especialistas em Informática, Docentes e Enfermeiros dos Hospitais A e B}

A ISO/IEC 9126-1 define o modelo de qualidade categorizado em seis características (funcionalidade, confiabilidade, usabilidade, eficiência, manutenibilidade e portabilidade) as quais são subdivididas em subcaracterísticas que são mensuráveis através da medida de seus atributos.

Segundo a ABNT NBR ISO/IEC 14598-6 ainda não existe uma fórmula para a avaliação destes atributos que possibilite a definição de um valor aproximado para as características e subcaracterísticas de qualidade.

Desta forma, este estudo adaptou a escala de avaliação para subcaracterística proposta na ABNT NBR ISO/IEC 14598-6-Anexo C (Informativo) que indica os valores esperados para cada uma das características e subcaracterísticas comparando-as com os valores obtidos na aplicação do Instrumento de Avaliação - Teste de Validação (Anexo II a e Anexo II b) conforme figura abaixo. 


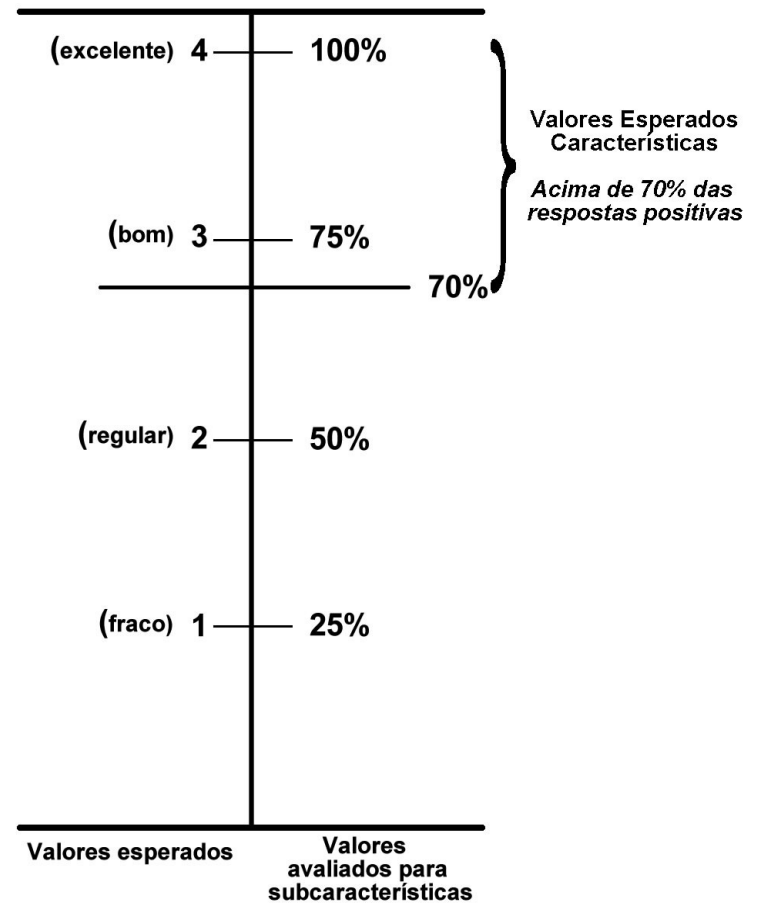

Figura 24 - Valores esperados para Subcaracterísticas e Características adaptados da ABNT NBR ISO/IEC 14598-6-Anexo C (Informativo). Exemplo de um módulo de avaliação Funcionalidade

Para relacionar os percentuais de todas as subcaracterísticas que compõem cada característica e então relacioná-las com o valor esperado, ou seja, mais de $70 \%$ para as respostas positivas (Figura 24), aplicou-se uma equação matemática conhecida como regra de três simples.

\subsubsection{Validação da Funcionalidade do Software-protótipo para Sistematização da Assistência de Enfermagem pelos Especialistas em Informática, Docentes e Enfermeiros dos Hospitais A e B. Catanduva, 2007}

Conforme pode ser observado na Figura 25, a característica Funcionalidade obteve um percentual de $80,5 \%$ de respostas positivas na avaliação dos docentes e enfermeiros e $64,4 \%$ pelos especialistas em informática.

Como o valor esperado para a validação é de mais de $70 \%$ de respostas que apontem concordância com a característica, concluiu-se que a Funcionalidade foi validada por docentes e enfermeiros dos Hospitais A e B. 


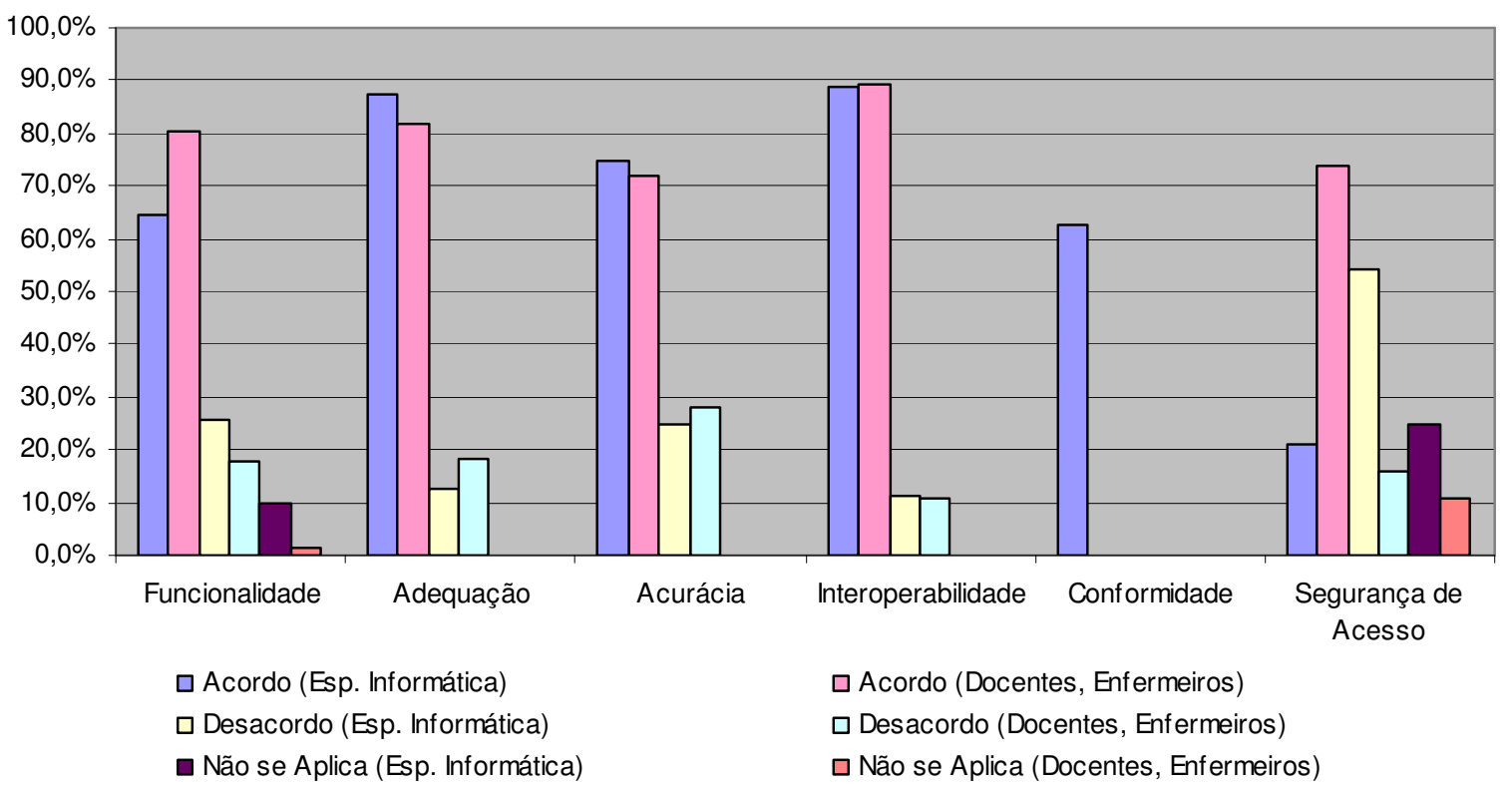

Figura 25 - Validação da Característica Funcionalidade do Software-Protótipo para Sistematização da Assistência de Enfermagem pelos Especialistas em Informática / Docentes / Enfermeiros. Catanduva, SP, 2007.

Entende-se que esta ferramenta computacional atende e permite a aplicação da Sistematização da Assistência de Enfermagem com boa interação entre seus módulos embora os avaliadores docentes e enfermeiros dos Hospitais A e B julguem pertinente a inclusão de um módulo para o diagnóstico de enfermagem.

Cabe ressaltar que a subcaracterística segurança de acesso foi julgada boa dentro do percentual de $73,7 \%$ pelos enfermeiros, enquanto os especialistas em informática concordaram com este item somente em $20,8 \%$.

Para Lakner et al (1997), a segurança no funcionamento de sistemas de informação de saúde é uma necessidade premente, entretanto, este controle de qualidade não é amplamente utilizado. Estes autores utilizaram a norma internacional (ISO/IEC 9126-1) associada a uma nova norma européia CEN/TC 251 para a avaliação da característica Funcionalidade de software de informação médica. Os resultados obtidos foram satisfatórios e poderão ser implementados no processo de acreditação. 
Korth (1995) afirma que dados armazenados em banco de dados precisam ser protegidos contra acessos não-autorizados, destruição ou alteração malintencionada e introdução acidental de inconsistências.

Para este autor, a segurança do banco de dados refere-se à prevenção contra acessos mal-intencionados, enquanto integridade refere-se ao ato de evitar a perda acidental de consistência.

A segurança de um sistema pode ser fornecida a partir de mecanismos que limitem o acesso do usuário apenas aos dados necessários. O Software-protótipo em questão utiliza quatro formas de autorização para efetivar a segurança, dentre elas:

A autorização leitura, que permite ler, mas não modificar os dados. A autorização inserção, que permite inserir novos dados, mas não a modificação de dados existentes. A propriedade de modificar, mas a não remoção de dados é conferida pela autorização atualização e finalmente, a autorização eliminação, que permite a remoção de dados.

Aos enfermeiros usuários deste Software foram conferidos as quatro categorias de autorização nos doze módulos que constituem o modelo informatizado.

Os técnicos e auxiliares de enfermagem obtiveram estas formas de autorização nos módulos: Balanço Hidroeletrolítrico e Sinais Vitais. Para os demais módulos foi disponibilizada somente a autorização leitura.

Observa-se que os recursos para autorização podem não oferecer proteção suficiente para os dados armazenados neste Software em avaliação. Será necessário a elaboração de senhas individualizadas para todos os usuários do 
Software-protótipo somado a concessão de autorização de acordo com a qualificação profissional.

\subsubsection{Validação da Confiabilidade do Software-protótipo para Sistematização da Assistência de Enfermagem pelos Especialistas em Informática, Docentes, Enfermeiros dos Hospitais A e B. Catanduva, 2007}

A análise da Figura 26 demonstrou que nas avaliações dos docentes e enfermeiros, a característica Confiabilidade obteve um percentual de acordo de $74,4 \%$, enquanto para os especialistas em informática, esse item resultou em $31,3 \%$ de acordos.

Conforme os níveis de pontuação estabelecida em mais de $70 \%$, a Confiabilidade mostra-se validada pelos docentes e enfermeiros dos Hospitais A e B e obtido um nível inferior de conformidade pelos especialistas em informática.

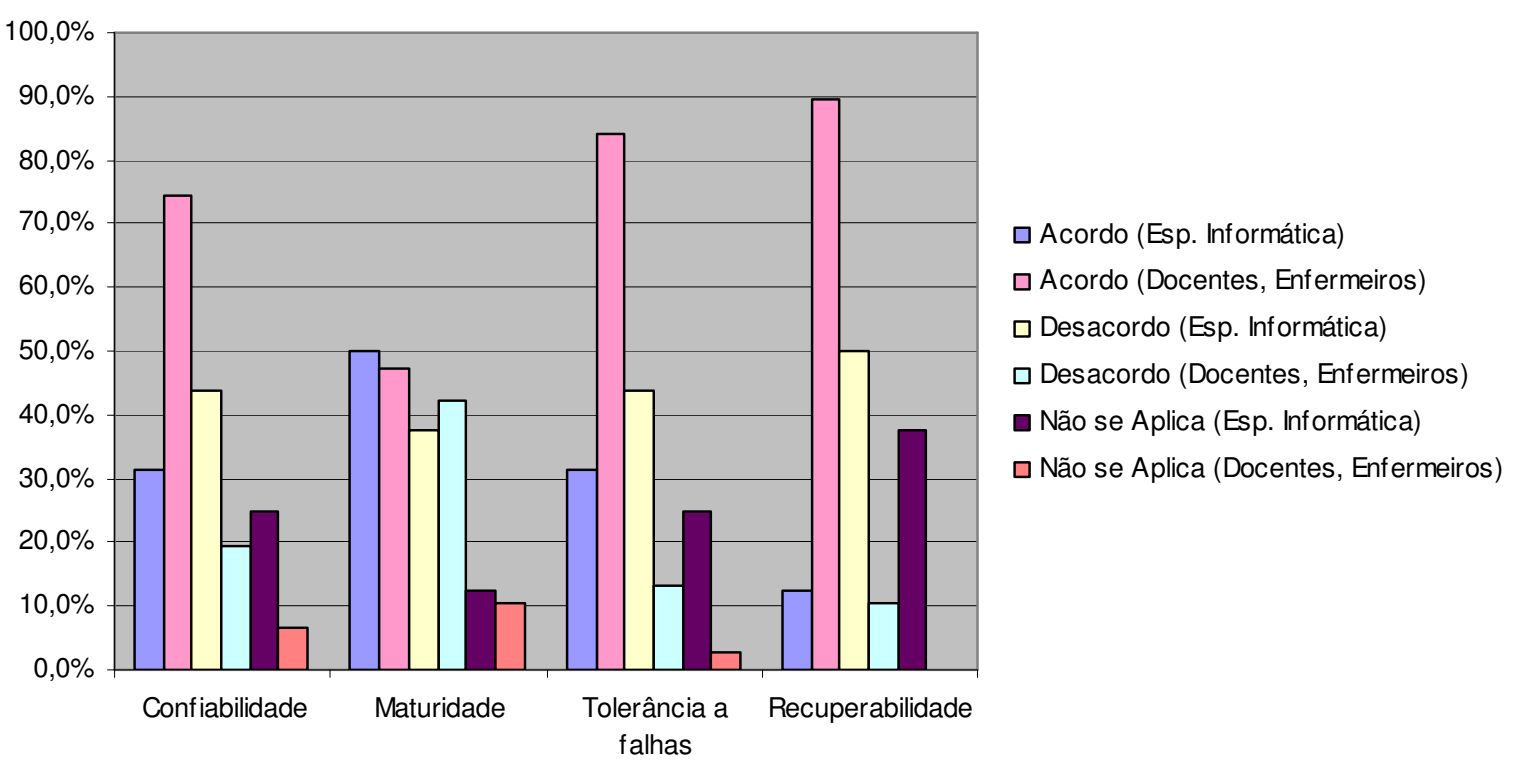

Figura 26 - Validação da Característica Confiabilidade do Software-Protótipo para Sistematização da Assistência de Enfermagem pelos Especialistas em Informática / Docentes / Enfermeiros. Catanduva, SP, 2007.

Palamas et al (2001), com o objetivo de avaliar a característica Confiabilidade do sistema Medical Products Electronic Commerce-MEDICOM, embasado na norma 
internacional ISO/IEC 9126, utilizou no processo de avaliação três diferentes grupos de usuários: usuário final, especialistas em informática e operadores do Portal. Seu propósito era a avaliação completa e representativa dos aspectos do MEDICOM, obtendo sugestões específicas de cada grupo de avaliadores.

A avaliação do Software-protótipo para SAE também foi realizada com a simulação de três distintos contextos de usuários: especialista em informática, docentes e enfermeiros e obteve-se o confronto de respostas nas avaliações das características Funcionalidade e Confiabilidade.

Observa-se que os dois tipos de falhas ocorridos durante o processo de avaliação, são definidos por Korth (1995), como erros lógicos, onde a execução não pode continuar devido a uma condição interna e os erros do sistema que são considerados estados indesejáveis ocasionados como exemplo, um travamento, resultando no impedimento da execução normal.

Este autor afirma ser imperativo a um sistema abranger a recuperação responsável pela detecção de erros e restauração dos dados a um estado de consistência existente antes da ocorrência da mesma.

Esta recuperação é determinada pela identificação nos modos de inconsistências nos dispositivos para armazenamento de dados e também pelas suas implicações que alteram o conteúdo do sistema.

Diante do exposto, torna-se necessária elaboração de algoritmos para assegurar a consistência do banco de dados na ocorrência de falhas para garantir a execução das funções do Software-protótipo para a Sistematização da Assistência de Enfermagem. 


\subsubsection{Validação da Usabilidade do Software-protótipo para Sistematização da Assistência de Enfermagem pelos Especialistas em Informática, Docentes, Enfermeiros dos Hospitais A e B. Catanduva, 2007}

Da Figura 27, depreende-se que o Software-protótipo para a Sistematização da Assistência de Enfermagem apresentou a Característica Usabilidade validada com $100 \%$ de respostas positivas pelos docentes e enfermeiros e em $80,4 \%$ pelos especialistas em informática.

Esta avaliação evidenciou a facilidade de inserir e obter dados. CarpenitoMoyet (2006) explanam que a documentação em enfermagem deve ser objetiva e compreensível e deve dispor de um sistema dinâmico para armazenar mais dados em menor tempo e espaço.

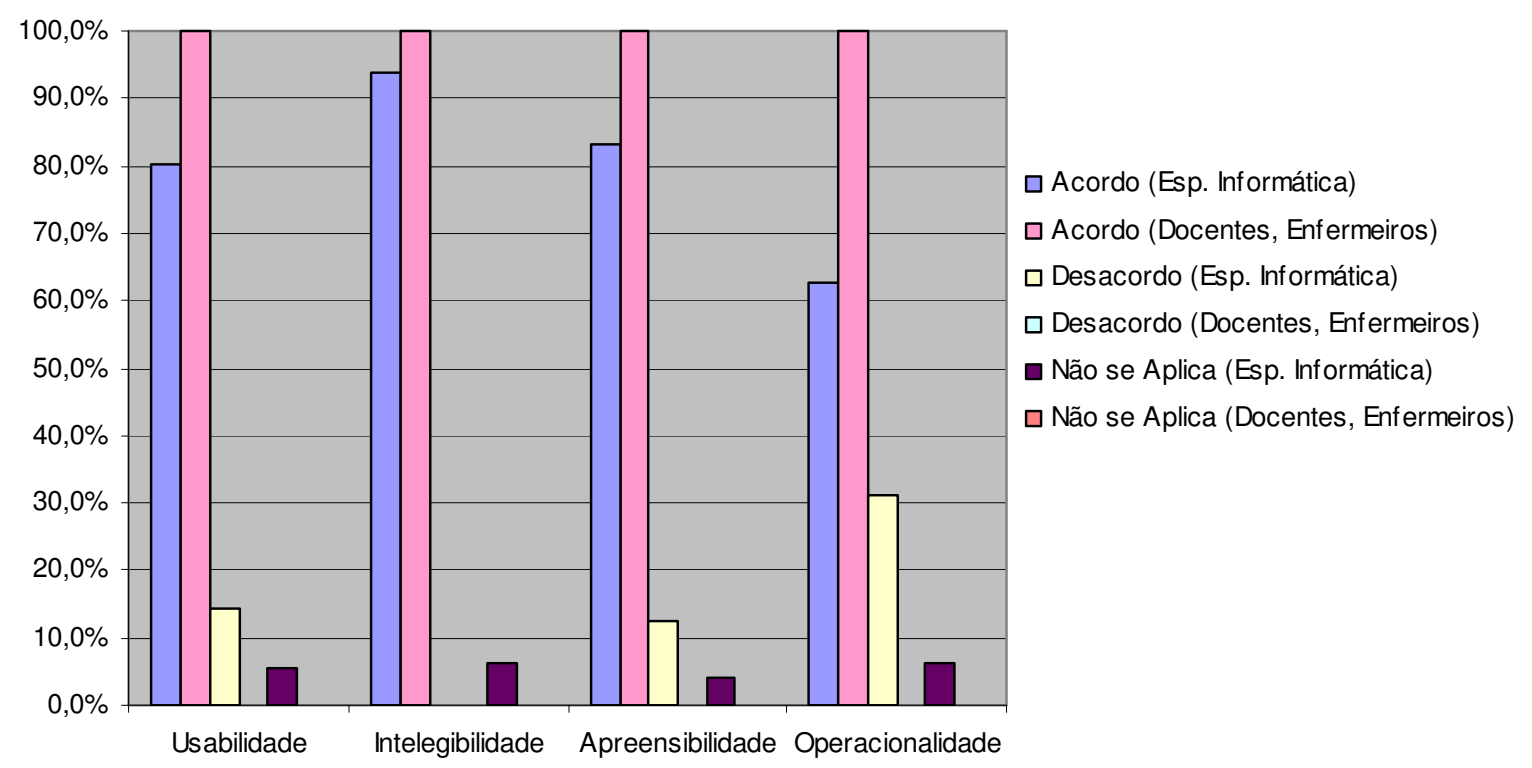

Figura 27 - Validação da Característica Usabilidade do Software-Protótipo para Sistematização da Assistência de Enfermagem pelos Especialistas em Informática / Docentes / Enfermeiros. Catanduva, SP, 2007.

Nielsen (1995) considera a usabilidade como uma das mais importantes características de qualidade de produtos e sistemas de software. Seus benefícios aos sistemas informatizados são observados pelo aumento da produtividade, na 
melhoria de qualidade no trabalho e da satisfação do usuário e também incluem a redução no custo de treinamento e suportes (ISO/IEC 13407, 1999).

O desenvolvimento de sistemas com boa usabilidade é evidenciado por Cybis (2005) como forma dos usuários atingirem com menos esforço e mais satisfação seus objetivos. Para este autor, a usabilidade irá impactar na tarefa no sentido de conferir maior eficiência, eficácia e produtividade na interação usuário-sistema.

Hörsbst e Goebel (2005) explanam que os sistemas de informações de pacientes necessitam ser avaliados de forma integrada e complexa e afirmam que a norma internacional ISO/IEC 9126 oferece um framework para a avaliação da característica usabilidade no desenvolvimento de sistemas, inclusive os que utilizam o serviço de WEB. Estes autores consideram esta norma como um exemplo para a avaliação de sistemas em saúde.

O paradigma que prevaleceu na avaliação do Software-protótipo para a Sistematização da Assistência de Enfermagem foi sua alta qualidade de usabilidade, corroborando com Westphalen e Carraro (2001) que consideram a implementação da Informática no cotidiano da enfermagem como uma forma de contribuir para que a profissão torne-se mais visível.

\subsubsection{Validação da Eficiência do Software-protótipo para Sistematização da Assistência de Enfermagem pelos Especialistas em Informática, Docentes, Enfermeiros dos Hospitais A e B. Catanduva, 2007}

Pode-se observar na Figura 28 que a Característica Eficiência foi aprovada por $87,5 \%$ dos especialistas em informática e $92,3 \%$ dos docentes e enfermeiros, indicando a conformidade com o valor estabelecido em mais de $70 \%$, para a avaliação das características de qualidade deste Software-protótipo. 
Para Santos (2006), a característica Eficiência descrita na ISO/IEC 9126-1 e nos estudos de Nielsen (1995), diz respeito ao sistema fazer a tarefa certa e possibilitar ao usuário realizar as operações atingindo um alto grau de produtividade e desempenho nas suas atividades, acrescentando que a velocidade que o usuário conclui um procedimento também é um ponto fundamental para se avaliar a eficiência do sistema de software.

Os avaliadores concordaram que o tempo de resposta e o tempo de execução são adequados no Software-protótipo para Sistematização da Assistência de Enfermagem.

Palamas et al ( 2001), utilizaram a norma internacional ISO/IEC 9126, para a avaliação da característica Eficiência no sistema Medical Products Electronic Commerc-MEDICOM. Este modelo de qualidade apresentou resultados adequados para a avaliação desta característica e ainda expressou valores representativos superiores neste software a outros similares avaliados neste contexto.

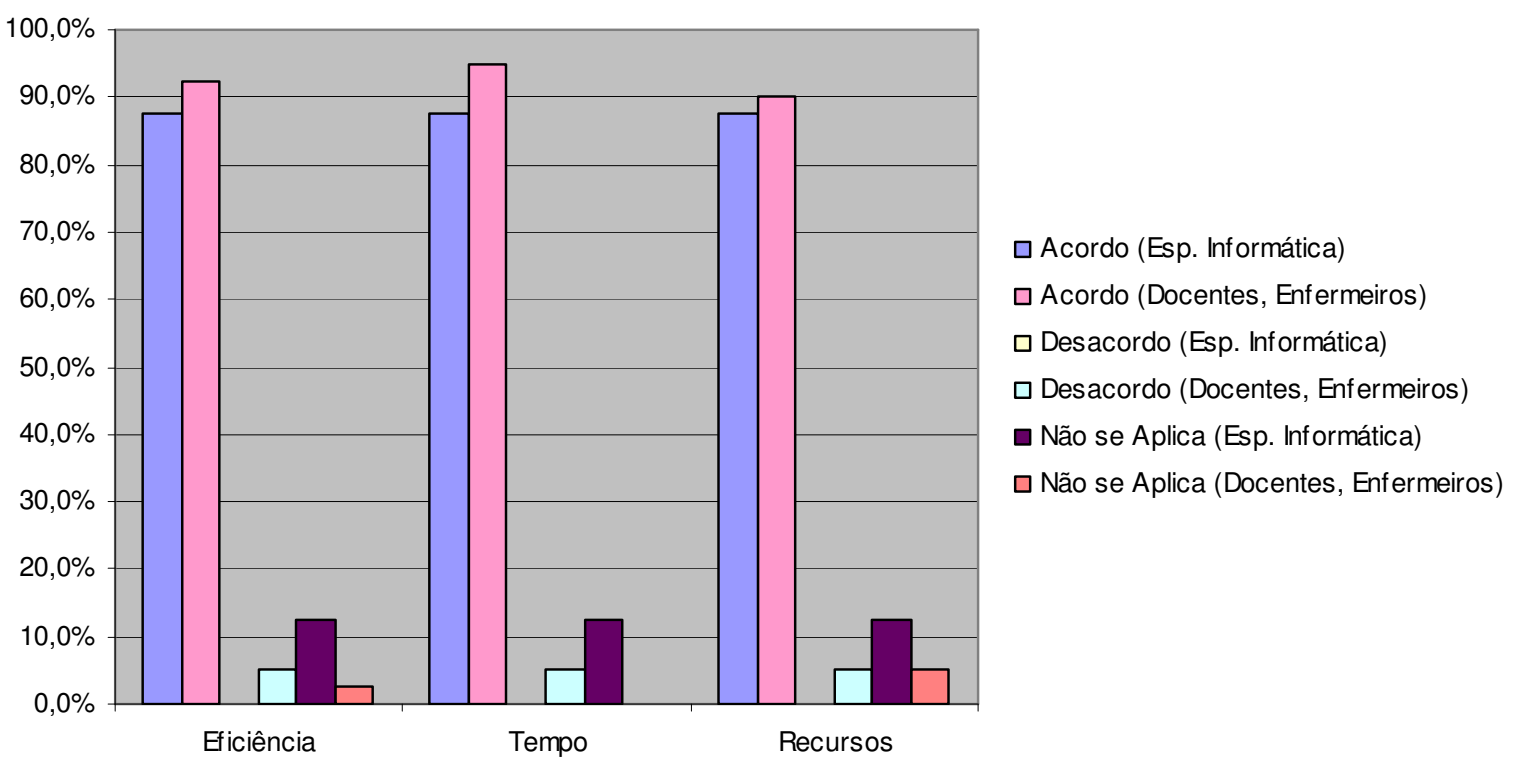

Figura 28 - Validação da Característica Eficiência do Software-Protótipo para Sistematização da Assistência de Enfermagem pelos Especialistas em Informática / Docentes / Enfermeiros. Catanduva, SP, 2007. 
Para Korth (1995), a eficiência das estruturas de dados usadas para a apresentação e capacidade de operação sobre essas estruturas define seu desempenho. Considera ser esta característica, o principal fator na satisfação do usuário em relação a um sistema computacional.

Ainda para o autor anteriormente mencionado, a valorização de um software está relacionada com o menor tempo de resposta para o atendimento de uma requisição.

Alfaro-LeFevre (2005) explicitam que uma das vantagens dos sistemas informatizados é armazenar e processar grandes quantidades de informações e as disponibilizar quando necessárias, muito mais rapidamente do que as pessoas.

Desta forma, para Lunardi Filho et al (1997), à medida que a tecnologia tornase mais utilizadas no atendimento à saúde, o enfermeiro terá mais acesso ao uso do computador e se beneficiará da rapidez na elaboração do planejamento da assistência de enfermagem. Uma vez que a SAE seja informatizada, aumenta o potencial para estes profissionais documentar de forma precisa, completa e contribuindo para as freqüentes necessidades de alterações e recuperação da informação.

\subsubsection{Validação da Manutenibilidade do Software-protótipo para Sistematização da Assistência de Enfermagem pelos Especialistas em Informática. Catanduva, 2007}

$\mathrm{Na}$ Figura 29, são apresentados os resultados da característica Manutenibilidade que foi avaliada somente pelos especialistas em informática com 43,8\% de respostas em concordância. 


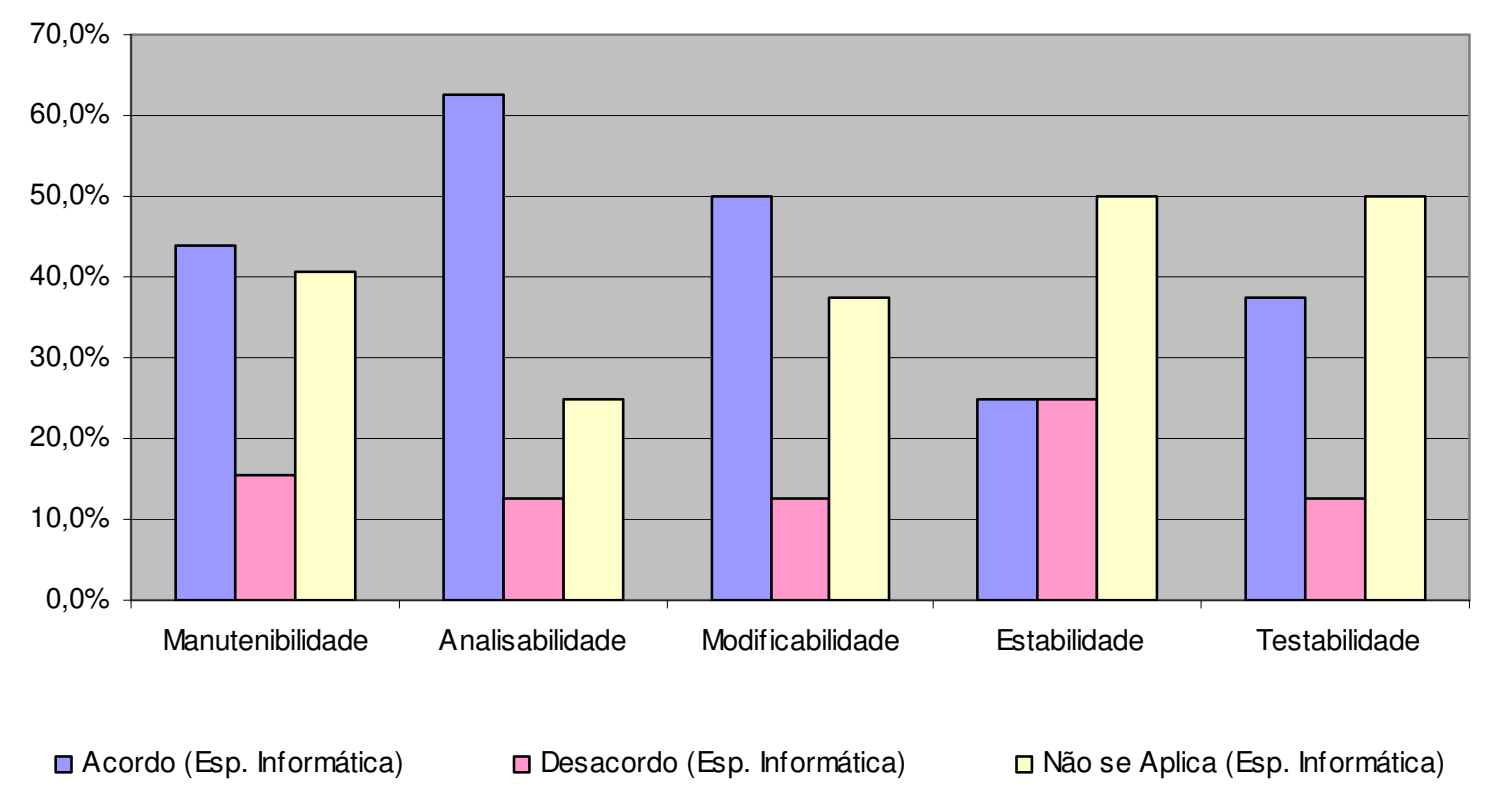

Figura 29 - Validação da Característica Manutenibilidade do Software-Protótipo para Sistematização da Assistência de Enfermagem pelos Especialistas em Informática. Catanduva, SP, 2007.

Este resultado evidencia um nível menor de conformidade desta característica com relação ao índice esperado superior a 70\% neste processo de avaliação.

Segundo Peres (2006), em uma primeira versão de software, é previsto alguns pontos falhos a serem detectados. O primeiro estudo de avaliação tem 0 objetivo de verificar pontos críticos que possam ser melhorados na ferramenta e também na aplicação do processo avaliativo.

Entende-se que nesta pesquisa, o método de avaliação desta característica precisa ser reformulado com a apresentação do código-fonte e com o detalhamento das suas alterações durante o desenvolvimento para facilitar o entendimento e a aplicação deste processo de investigação.

Pressman (2006) também discorre sobre a fase de manutenção concentrar-se nas mudanças que estão associadas à correção de erros e adaptações solicitadas pelo usuário uma vez que ambiente de software evolui e são ampliadas as suas exigências. Três tipos de mudanças comumente ocorrem nesta fase: a manutenção 
corretiva que é efetivada para corrigir defeitos. A manutenção adaptativa que resulta em modificações no software a fim de atender a evolução no seu ambiente e o melhoramento funcional que estende o software além de suas exigências funcionais originais.

A metodologia utilizada para a construção deste software para a Sistematização da Assistência de Enfermagem fundamentou-se no modelo evolucionário de desenvolvimento de sistema, baseando-se no conceito de prototipagem, conforme Pressman (2006).

Considerou-se esta abordagem adequada, uma vez que é caracterizada pela iteratividade, de forma a contemplar a possibilidade de demonstrar aos usuários a implementação de um modelo informatizado que possa ser estendido e refinado gradativamente em conformidade com a avaliação destes profissionais sobre o sistema.

$\mathrm{Na}$ avaliação realizada com base nesta fundamentação metodológica os especialista em informática, docente enfermeiros e enfermeiros exerceram funções chaves na identificação de deficiências e problemas neste Software-protótipo e sugeriram modificações para atender melhor as necessidades reais para a sistematização da assistência.

Desta forma, era esperado que, este estudo apresentasse a necessidade de manutenção corretiva e o melhoramento funcional do Software-protótipo para a Sistematização da Assistência de Enfermagem, a fim de que esta ferramenta evolua e possa ser implantada em unidade de internação hospitalar. 


\subsubsection{Validação da Portabilidade do Software-protótipo para Sistematização da Assistência de Enfermagem pelos Especialistas em Informática. Catanduva, 2007}

Na Figura 30 é apresentado o resultado final da avaliação da característica Portabilidade avaliada somente pelos especialistas em informática. De acordo com os níveis de pontuação obtidos, evidenciou-se o acordo por $31,3 \%$ dos avaliadores.

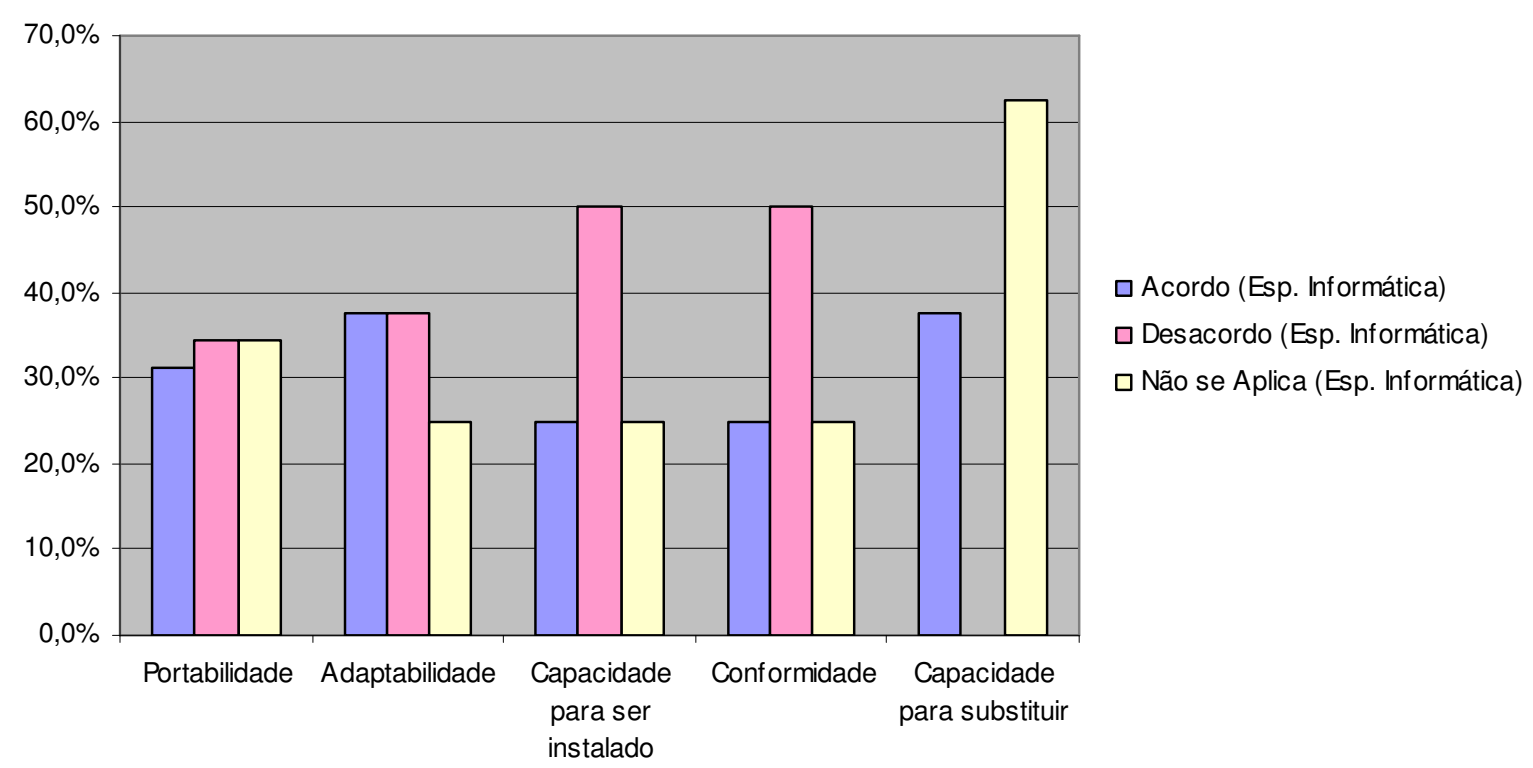

Figura 30 - Validação da Característica Portabilidade do Software-Protótipo para Sistematização da Assistência de Enfermagem pelos Especialistas em Informática. Catanduva, SP, 2007.

O valor encontrado indica que a Portabilidade não está em conformidade com o requisito desejado, ou seja, níveis de respostas acima de $70 \%$.

Este resultado justifica-se, pelo fato do Software-protótipo para SAE ter sua elaboração proposta no Sistema Operacional Windows, plataforma utilizada pela instituição hospitalar A, local em que este estudo foi desenvolvido e também avaliado.

Bertoa (2002) define um conjunto de características de qualidade de software baseado na norma ISO/IEC 9126-1 e não adota para seu modelo a Portabilidade, 
entendendo que esta característica não é aplicável para verificar a qualidade de certos produtos de software.

Simão (2003) considera em sua análise sobre modelo de qualidade para software, baseado na norma ISO/IEC 9126-1, que a portabilidade é uma característica importante e deve ser mantida, pois se refere à capacidade do software ser transferido de um ambiente para outro e para este autor este fato é fundamental em uma aplicação.

Diante do exposto, pode-se inferir que a Portabilidade assume maior grau de importância quando a ferramenta destina-se a aplicações em diferentes instituições, dessa forma, a adequação da conformidade do Software-protótipo para SAE deve ser melhorada quando este produto for disponibilizado para avaliações em diferentes cenários de uso. 


\section{CONSIDERAÇÕES FINAIS}

As etapas envolvidas na avaliação do Software-protótipo para a Sistematização da Assistência de Enfermagem demonstraram que a computação móvel pode ser representada com um novo paradigma computacional que permite ao enfermeiro ampliar a utilização da informática aplicada à profissão.

A incorporação desta tecnologia advinda de rede sem fio e de sistemas distribuídos às atividades assistenciais de enfermagem, tornou-se o estado da arte para a aplicação do Software-protótipo para Sistematização da Assistência de Enfermagem. Este produto possibilitou aos profissionais não só um ambiente com acesso a serviços, independentes de sua localização, mas também mobilidade e comunicação transmitida em tempo real a outros computadores. A comunicação compartilhada com membros da equipe democratizou e aperfeiçoou o processo de informação em enfermagem.

Preliminarmente, esta investigação pretendia disponibilizar como estações de trabalho para o enfermeiro efetuar o planejamento da assistência de enfermagem, computadores com dimensões reduzidas, do tipo Notebook, permitindo o seu transporte apoiado em um suporte com rodízio, oferecendo comodidade e locomoção para todos os leitos da unidade de internação.

Entretanto, o cotidiano das ações assistenciais de enfermagem demanda necessidades de mobilidade com maior agilidade para coletar e documentar informações a beira do leito, assim como acesso aos dados do prontuário do paciente que centraliza o registro sistemático das informações clínicas.

A crescente evolução e popularização de dispositivos computacionais com tamanho bastante reduzido como o Pocket $P C$, apresenta capacidade de processamento e programação, baterias recarregáveis sem a necessidade de 
conexão à rede elétrica, além de integração a rede sem fio, permitiu uma inovação na prática de enfermagem. Com esse equipamento é possível o enfermeiro documentar a beira do leito informações inerentes aos sinais vitais, balanço hidroeletrolítrico, bem como, visualizar os problemas de saúde do paciente e efetivar a etapa de evolução de enfermagem com maior flexibilidade. Acresça-se ainda, a facilidade em consultar a prescrição de enfermagem e após sua execução realizar a checagem individualizada por meio deste dispositivo.

É importante ressaltar que o fato do aparelho móvel utilizado nesta pesquisa ser integrado à rede wireless possibilitou que toda inserção de dados sobre o paciente fosse automaticamente atualizada no banco de dados do Softwareprotótipo instalado no Notebook. Desta forma, a informação acessada nos dois equipamentos computacionais permanece sempre atualizada.

As aplicações da computação móvel na enfermagem proporcionam mobilidade e facilidade para acessar, coletar e documentar informações sobre o paciente em seu próprio leito redundando na diminuição do tempo despendido e na probabilidade de perda das informações, uma vez suprimido as etapas intermediárias do processo de comunicação.

Entretanto, a utilização do Pocket $P C$ na Sistematização da Assistência de Enfermagem implica uma limitação maior na capacidade de memória, assim como no processamento e armazenamento de dados. Acresça-se ainda, o desconforto para digitação de texto livre, pois, a tela é bem pequena e geralmente, a entrada de dados é realizada por meio de uma caneta e um software de reconhecimento de escrita. 
Dessa forma, foi necessário manter as etapas de coleta de dados e elaboração da prescrição de enfermagem para serem realizadas, exclusivamente, através do Notebook.

Para a consolidação desta pesquisa buscou-se a avaliação da qualidade do Software-protótipo para Sistematização da Assistência de Enfermagem (SAE) referendado pela ISO/IEC 9126, Parte 1: Modelo de qualidade, que mensura os atributos de qualidade de software em seis características: funcionalidade, confiabilidade, usabilidade, eficiência, manutenibilidade e portabilidade e também se apropriando de subsídios da NBR ISO/IEC 14598, Partes 1 a 6: Tecnologia de informação - avaliação de produto de software.

De acordo com estes elementos e com os resultados obtidos na avaliação realizada pelos especialistas em informática, docentes e enfermeiros assistenciais nesta pesquisa, o Software-protótipo em questão destacou-se em duas características: usabilidade e eficiência.

Para Nielsen (2000), um sistema com alta qualidade de usabilidade, pode ser considerado fácil de aprender, eficiente e satisfatório para o uso e que não tende a erros.

A usabilidade é significantemente associada com cinco elementos básicos para uma aplicação de software: navegação, tempo de resposta, conteúdo, interatividade e compreensão.

Acredita-se que a estrutura navegacional de Sofware-protótipo proporcionou aos enfermeiros o registro informatizado de forma individualizada, rápida e eficiente.

Esta constatação é evidenciada pela avaliação positiva da característica de qualidade de eficiência do Software-protótipo demonstrando que este armazena, 
processa e disponibiliza informações sobre a SAE de forma mais adequada que a realizada manualmente.

A ISO/IEC 9241-11 define usabilidade como: "Até que ponto um produto pode ser utilizado por usuários específicos para alcançar metas também especificadas com eficácia, eficiência e satisfação em um determinado contexto de uso".

Este conceito contribuiu com um direcionamento para o respaldo e a segurança necessária para o desempenho de Software-protótipo para Sistematização da Assistência de Enfermagem, favorecendo que sua aplicabilidade e visibilidade não findarão com a conclusão desta pesquisa, até porque não se teve essa pretensão, mas sim, de pautá-la para discussão.

Considera-se que a avaliação realizada neste estudo contribuiu sobremaneira com a identificação dos resultados sobre a qualidade deste Software-protótipo, elucidando as atividades de manutenção que deverão ser atendidas para se efetivar as potencialidades desta ferramenta.

A pluralidade deste trabalho coletivo e interdisciplinar mostrou as ambigüidades e diversidades para que esta tecnologia computacional para o planejamento da assistência de enfermagem, possa ser ampliada de forma evolucionária conforme preconizado no processo prescritivo de sistema de prototipação. O resultado evidenciou a organização do registro das atividades pautada no conhecimento técnico e científico.

Ao término desta trajetória de avaliação de qualidade das características internas e externas do Software-protótipo, cabe então, como proposta de estudos futuros, buscar avaliar sua qualidade em uso contemplando a avaliação das três características definidas na ISO/IEC 9126-1 como eficácia, produtividade e satisfação, por meio de metodologia apropriada. 


\section{REFERÊNCIAS BIBLIOGRÁFICAS}

ALFARO-LEFEVRE, R. Aplicação do processo de enfermagem: promoção do cuidado colaborativo. 5. ed. Porto Alegre: Artes Médicas, 2005.

ASSOCIAÇÃO BRASILEIRA DE NORMAS TÉCNICAS. NBR ISO/IEC 8402 - Gestão da qualidade e garantia da qualidade Terminologia. Rio de Janeiro, 1994.

ASSOCIAÇÃO BRASILEIRA DE NORMAS TÉCNICAS. NBR 13596: tecnologia da informação: avaliação de produto de software: características de qualidade e diretrizes para seu uso. Rio de Janeiro, 1996.

ASSOCIAÇÃO BRASILEIRA DE NORMAS TÉCNICAS. NBR ISO/IEC 145981:2001: tecnologia de informação: avaliação de produto de software: parte 1: visão geral. Rio de Janeiro, 2001.

ASSOCIAÇÃO BRASILEIRA DE NORMAS TÉCNICAS. NBR ISO/IEC 145982:2003: engenharia de software: avaliação de produto: parte 2: planejamento e gestão. Rio de Janeiro, 2003.

ASSOCIAÇÃO BRASILEIRA DE NORMAS TÉCNICAS. NBR ISO/IEC 145983:2003: engenharia de software: avaliação de produto: parte 3: processo para desenvolvedores. Rio de Janeiro, 2003.

ASSOCIAÇÃO BRASILEIRA DE NORMAS TÉCNICAS. NBR ISO/IEC 145984:2003: engenharia de software: avaliação de produto: parte 4: processo para adquirentes. Rio de Janeiro, 2003.

ASSOCIAÇÃO BRASILEIRA DE NORMAS TÉCNICAS. NBR ISO/IEC 145985:2001: tecnologia de informação: avaliação de produto de software: parte 5: processo para avaliadores. Rio de Janeiro, 2001.

ASSOCIAÇÃO BRASILEIRA DE NORMAS TÉCNICAS. NBR ISO/IEC 145986:2004: engenharia de software: avaliação de produto: parte 6: documentação de módulos de avaliação. Rio de Janeiro, 2004.

ASSOCIAÇÃO BRASILEIRA DE NORMAS TÉCNICAS. NBR ISO/IEC 9126-1:2003: engenharia de software: qualidade de produto: parte 1: modelo de qualidade. Rio de Janeiro, 2003.

ASSOCIAÇÃO BRASILEIRA DE NORMAS TÉCNICAS. NBR ISO/IEC 924111:2000: requisitos ergonômicos para trabalho de escritórios com computadores: parte 11: orientações sobre usabilidade. Rio de Janeiro, 2000.

BARRETO JÚNIOR, J. Qualidade de software. Disponível em: <http://www.barreto.com.br/qualidade>. Acesso em: 2 set. 1997.

BERTOA, M.; VALLECILLO, A. Quality atributes for COTS components. In: Proceedings of the $6^{\text {th }}$ ECOOP Workshop on Quantitatives Approaches in Object Oriented Software Engineering (QAOOSE); 2002; Spain. 
BRASIL. Ministério da Saúde. Secretaria de Atenção à Saúde. CNESNet. Cadastro Nacional dos Estabelecimentos de Saúde. DATASUS. Ficha estabelecimento: módulo básico. Disponível em:

$<\mathrm{http}$ ://cnes.datasus.gov.br/cabecalho_reduzido.asp?VCod_Unidade $=351110208933$ 5>. Acesso em: 22 maio 2008.

CARPENITO, L. J. Diagnóstico de enfermagem: aplicação à prática clínica. 6 . ed. Porto Alegre: Artes Médicas, 2000.

CARPENITO-MOYET, L. J. Documentação dos cuidados de enfermagem. In: Planos de cuidados de enfermagem e documentação: diagnósticos de enfermagem e problemas colaborativos. 4. ed. Porto alegre: Artmed, 2006. p. 27-45.

CASSIANI, S. H. C. A coleta de dados nas pesquisas em enfermagem: estratégias, validade e confiabilidade. 1987. Dissertação (Mestrado em Enfermagem Fundamental) - Escola de Enfermagem de Ribeirão Preto, Universidade de São Paulo, USP.

CROSBY, P. B. Qualidade é investimento. 6. ed. Rio de Janeiro: Olympio, 1988.

CYBIS, W. A. Engenharia de usabilidade: uma abordagem ergonômica. Disponível em: <http://www.labiutil.inf.ufsc.br/hiperdocumento/conteudo.html>. Acesso em: 23 abr. 2008.

COFEN, Conselho Federal de Enfermagem.Brasil. Resolução COFEN-272/2002. Disponível em: $<$ http://www.portalcofen.gov.br/2007/section.asp?sectionParentID=34\&sectionID=30 $>$. Acesso em: 16 jun. 2008.

DEMING, W. E. Qualidade: a revolução da administração. Rio de Janeiro: Brasport, 1990.

ÉVORA, Y. D. M. Processo de informatização em enfermagem: orientações básicas. São Paulo: EPU, 1995.

ÉVORA, Y. D. M.; DALRI, M. C. B. O uso do computador como ferramenta para a implantação do processo de enfermagem. Rev. Bras. Enferm., Brasília, v. 55, n. 6, p. 709-713, nov./dez. 2002.

FEIGENBAUM, A. V. Total quality control. New York: McGraw-Hill, 1994. v. 1.

GERLACK, A. C. Análise da gestão da qualidade na indústria da carne bovina do Estado de São Paulo. 2001. Dissertação (Mestrado em Engenharia de Produção) - Universidade Federal de São Carlos, UFSCAR.

HERBERT, J. S.; PRICE, A. M. A. Métodos para avaliação da qualidade de software. Porto Alegre: Instituto de Informática da UFRGS, 1995.

HÖRBST, A. ; FINK, K. ;GOEBEL, G. The ISO/IEC 9126-1 as a supporting means for the system development process of a patient information web service. Stud. Health Technol. Inform., v. 116, p. 967-970, 2005. 
HORTA, V. A. Processo de enfermagem. São Paulo: EPU, 1979.

INTERNATIONAL ORGANIZATION FOR STANDARDIZATION. ISO/IEC 9126: Information technology: software product evaluation: quality characteristics and guidelines for their use. [S.I.], 1991.

INTERNATIONAL ORGANIZATION FOR STANDARDIZATION. ISO/IEC:13407 Human-centred design processes for interactive systems, 1999.

JURAN, J. M. Planejamento para a qualidade. São Paulo: Pioneira, 1990.

KORTH, H. F.; SILBERSCHATZ, A. Sistema de bancos de dados. 2. ed. rev. São Paulo: Makron Books, 1995.

LAKNER, G. et al. Quality of healthcare related software applications: setting up an accreditation system in Hungary. Stud Health Technol. Inform., 1997.v. 43, pt. B, p. 791-795.

LAUDON, K. C.; LAUDON, J. P. Telecomunicações e redes. In: de informação gerenciais: administrando a empresa digital. 5. ed. São Paulo: Pearson Prentice Hall, 2004. p. 255-282.

LOBIONDO-WOOD, G.; HABER, J. Pesquisa em enfermagem: métodos, avaliação crítica e utilização. 4. ed. Rio de Janeiro: Guanabara-Koogan, 2001.

LOPES, M. J. M. Quando a voz e a palavra são atos terapêuticos: a interação individual e coletiva nas palavras cotidianas do trabalho de enfermagem. In: WALDOW, V. R.; LOPES, M. L. M.; MEYER, D. E. M. Maneiras de cuidar, maneiras de ensinar. Porto Alegre: Artes Médicas, 1995. p. 182-185.

LUNARDI FILHO, W. D.; LUNARDI, G. L.; PAULITSCH, F. S. A prescrição de enfermagem computadorizada como instrumento de comunicação nas relações multiprofissionais e intra equipe de enfermagem:relato de experiência. Rev.

Latino-am. Enfermagem, Ribeirão Preto, v. 5, n. 3, p. 63-69, jul. 1997.

MARIN, H. F. Informática em enfermagem. São Paulo: EPU, 1995.

MATEUS, G. R.; LOUREIRO, A. A. F. Introdução à computação móvel.Minas Gerais:UFMG,2004 Disponível em:

<http://homepages.dcc.ufmg.br/ loureiro/cm/docs/cm_livro_1e.pdf>. Acesso em: 20 jun. 2008.

MENDES, I. A. C. et al. O uso do computador como ferramenta para a implantação do processo de enfermagem. Rev. Bras. Enferm., Brasília, v. 55, n. 6, p. 709-713, nov./dez. 2002.

MICROSOFT CORPORATION. Visão geral dos recursos do Visual Studio: NET 2003: Professional. Disponível em:

<http://www.microsoft.com/brasil/msdn/produtos/VisualStudio/RecursosVS2003Pro/D efault.mspx>. Acesso em: 22 maio 2008. 
NIELSEN, J. Applying discount usability engineering. IEEE Software, v. 12, n. 1, p. 98-100, Jan. 1995.

NIELSEN, J. Designing web usability: the practice of simplicity. Indianapolis, Indiana, USA: New Riders Publishing, 2000.

OLIVEIRA, A. A. A. C. P. Qualidade de software. Campinas: Pontifícia Universidade Católica de Campinas/SP, 1996.

PALAMAS, S. et al. Design and Implementation of a portal for the medical equipment market: MEDICOM. J. Med. Internet Res., v. 3, n. 4, Oct./Dec. 2001.

PERES, D. R. Modelo de qualidade para componentes de software. 2006.

Dissertação (Mestrado em Ciências da Computação e Matemática

Computacional) - Instituto de Ciências Matemáticas e de Computação,

Universidade de São Paulo, USP.

POLLONI, E. G. E. Sistemas de Informação. São Paulo: Futura, 2000.

POTTER, P. A.; PERRY, A. G. Implementação do processo de enfermagem. In: . Grande tratado de enfermagem prática: clínica e prática hospitalar. 3. ed. São Paulo: Santos Livraria, 1998. p. 101-125.

PRESSMAN, R. S. Engenharia de software. 6. ed. São Paulo: McGraw-Hill, 2006.

ROCHA, A. R. C. Análise e projeto estruturado de sistemas. Rio de Janeiro: Makron Books, 1992.

SANTOS, R. C. dos. Desenvolvimento de uma metodologia para avaliação de usabilidade de sistemas utilizando a lógica Fuzzy baseado na ISO . 2006. Dissertação (Mestrado Profissionalizante em Administração) - Faculdade de Economia e Finanças, IBMEC.

SIMÃO, R. P. S; BELCHIOR, A. Quality characteristics for software components: hierarchy and quality guides. Component based software quality: methods and techiniques, lecture notes in computer science (LNCS). Springer Verlag, n. 2693, p. 188-211, 2003.

SPERANDIO, D. J. Sistematização da assistência de enfermagem: proposta de um software-protótipo. 2002. Dissertação (Mestrado em Enfermagem Fundamental) - Escola de Enfermagem de Ribeirão Preto, Universidade de São Paulo, USP.

TOLEDO, J.C. Gestão da qualidade na agroindústria. In: BATALHA, M. O. (Org.). Gestão Agroindustrial. São Carlos: Atlas, 1997. p. 437-487.

WEISER, M. The computer for $21^{\text {st }}$ century. 1991.Disponível em: <http://www.ubiq.com/hypertext/weiser/SciAmDraft3.html>. Acesso em: 20 jun. 2008

WESTPHALEN, M. E. A.; CARRARO, T. E. (Org.). Metodologias pra a assistência de enfermagem: teorizações, modelos e subsídios para a prática. Goiânia: $A B$, 2001. 


\section{ANEXO I \\ INSTRUMENTO DE AVALIAÇÃO DE SOFTWARE-PROTÓTIPO TESTE DE UNIDADE MODULAR \\ ENFERMEIROS DOCENTES, ENFERMEIROS E ESPECIALISTA EM INFORMÁTICA}

Nome do software: Software-protótipo para sistematização da assistência de enfermagem Nome do avaliador:

Data:

\begin{tabular}{|c|c|c|c|}
\hline Módulo & $\begin{array}{c}\text { Aceito } \\
\text { como } \\
\text { está }\end{array}$ & $\begin{array}{l}\text { Não } \\
\text { aceito }\end{array}$ & $\begin{array}{c}\text { Necessita de modificações } \\
\text { Quais? }\end{array}$ \\
\hline \multicolumn{4}{|l|}{$\begin{array}{c}\text { Ficha de } \\
\text { identificação }\end{array}$} \\
\hline \multicolumn{4}{|l|}{ Dados clínicos } \\
\hline \multicolumn{4}{|l|}{ Internações } \\
\hline \multicolumn{4}{|l|}{$\begin{array}{c}\text { Informações } \\
\text { adicionais }\end{array}$} \\
\hline \multicolumn{4}{|l|}{ Entrevista } \\
\hline \multicolumn{4}{|l|}{ Coleta de dados } \\
\hline \multicolumn{4}{|l|}{ Lista de problemas } \\
\hline \multicolumn{4}{|l|}{$\begin{array}{l}\text { Prescrição de } \\
\text { Enfermagem }\end{array}$} \\
\hline \multicolumn{4}{|l|}{$\begin{array}{l}\text { Evolução de } \\
\text { enfermagem }\end{array}$} \\
\hline \multicolumn{4}{|l|}{ Sinais vitais } \\
\hline \multicolumn{4}{|l|}{$\begin{array}{c}\text { Balanço } \\
\text { hidroeletrolítrico }\end{array}$} \\
\hline $\begin{array}{c}\text { Telas para } \\
\text { cadastramento }\end{array}$ & & & \\
\hline
\end{tabular}

Comentários Gerais: 


\section{ANEXO II a \\ INSTRUMENTO DE AVALIAÇÃO DE SOFTWARE-PROTÓTIPO TESTE DE VALIDAÇ̃̃O ESPECIALISTA EM INFORMÁTICA}

Nome do software: Software-protótipo para sistematização da assistência de enfermagem Nome do avaliador:

Data:

VALORAÇÃO: A: de Acordo; D: Desacordo; NA: Não se aplica.

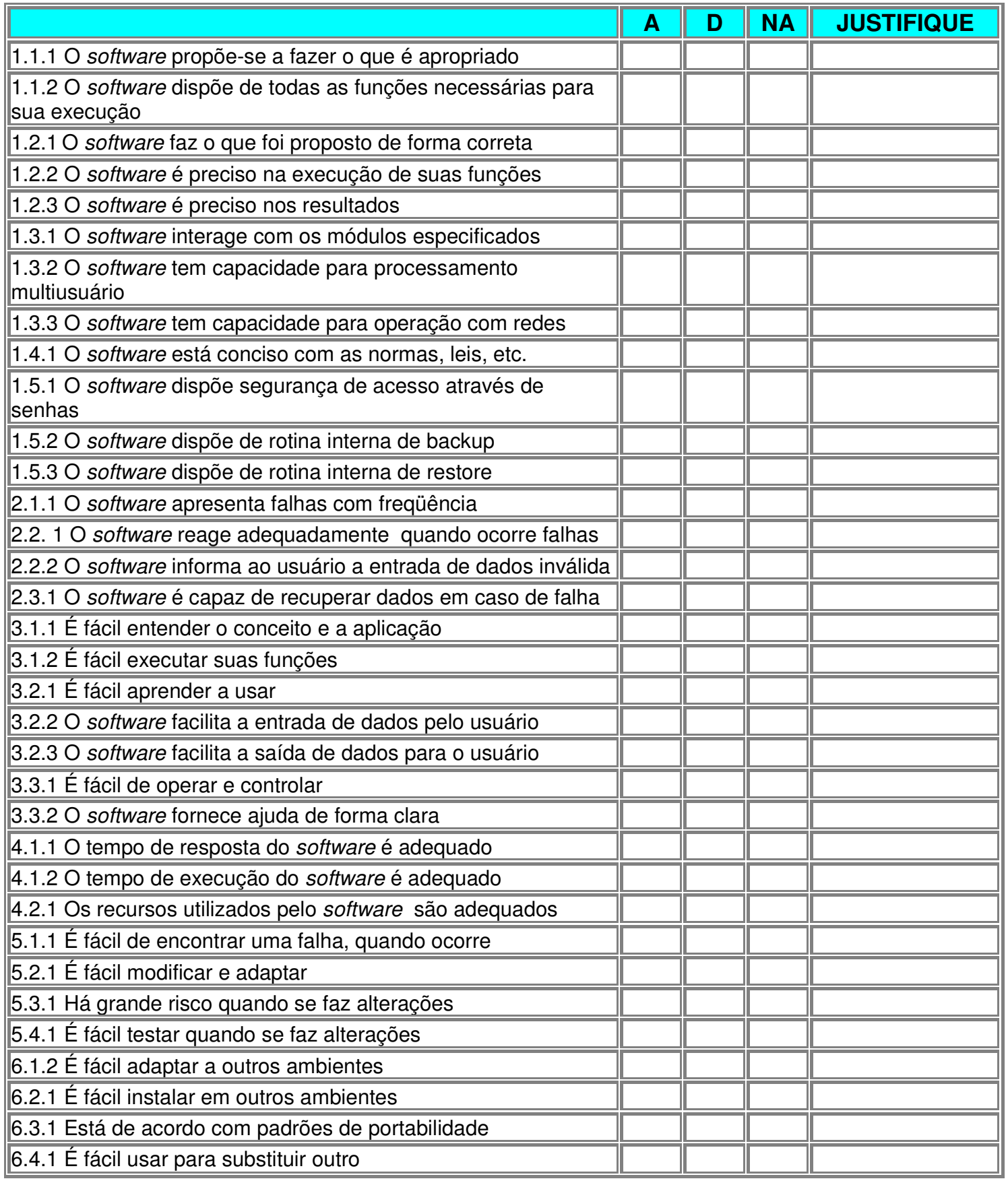

\section{COMENTÁRIOS GERAIS:}




\section{ANEXO II $b$ \\ INSTRUMENTO DE AVALIAÇÃO DE SOFTWARE-PROTÓTIPO TESTE DE VALIDAÇÃO ENFERMEIROS DOCENTES E ENFERMEIROS}

Nome do software: Software-protótipo para sistematização da assistência de enfermagem Nome do avaliador:

Data:

VALORAÇÃO: A: de Acordo;D: Desacordo; NA: Não se aplica.

\begin{tabular}{|c|c|c|c|c|}
\hline \multirow{2}{*}{$\begin{array}{l}\text { 1.1.1 O software atende a aplicação da Sistematização da } \\
\text { Assistência de Enfermagem }\end{array}$} & A & D & NA & JUSTUFIQUE \\
\hline & & & & \\
\hline \multicolumn{5}{|l|}{$\begin{array}{l}\text { 1.1.2 O software dispõe de todas as funções necessárias } \\
\text { para a execução da Sistematização da Assistência de } \\
\text { Enfermagem }\end{array}$} \\
\hline \multicolumn{5}{|l|}{$\begin{array}{l}\text { 1.2.1 O software permite a aplicação da Sistematização } \\
\text { da Assistência de Enfermagem de forma correta }\end{array}$} \\
\hline \multicolumn{5}{|l|}{$\begin{array}{l}\text { 1.2.2 O software é preciso na execução das funções da } \\
\text { Sistematização da Assistência de Enfermagem }\end{array}$} \\
\hline \multicolumn{5}{|l|}{$\begin{array}{l}\text { 1.2.3 O software é preciso nos resultados desejados para } \\
\text { a Sistematização da Assistência de Enfermagem }\end{array}$} \\
\hline \multicolumn{5}{|l|}{$\begin{array}{l}\text { 1.3.1 O software permite ao enfermeiro a adequada } \\
\text { interação dos módulos para a aplicação da } \\
\text { Sistematização da Assistência de Enfermagem }\end{array}$} \\
\hline \multicolumn{5}{|l|}{$\begin{array}{l}\text { 1.5.1 O software dispõe de segurança de acesso através } \\
\text { de senhas }\end{array}$} \\
\hline \multicolumn{5}{|l|}{ 2.1.1 O software apresenta falhas com freqüência } \\
\hline \multicolumn{5}{|l|}{$\begin{array}{l}\text { 2.2.1 O software reage adequadamente quando ocorre } \\
\text { falhas }\end{array}$} \\
\hline \multicolumn{5}{|l|}{$\begin{array}{l}\text { 2.2.2 O software informa ao usuário a entrada de dados } \\
\text { inválida }\end{array}$} \\
\hline \multicolumn{5}{|l|}{$\begin{array}{l}\text { 2.3.1 O software é capaz de recuperar dados em caso de } \\
\text { falha }\end{array}$} \\
\hline \multicolumn{5}{|l|}{ 3.1.1 É fácil entender o conceito e a aplicação } \\
\hline \multicolumn{5}{|l|}{ 3.1.2 É fácil executar suas funções } \\
\hline \multicolumn{5}{|l|}{ 3.2.1 É fácil aprender a usar } \\
\hline \multicolumn{5}{|l|}{ 3.2.2 O software facilita a entrada de dados pelo usuário } \\
\hline \multicolumn{5}{|l|}{ 3.2.3 O software facilita a saída de dados para o usuário } \\
\hline \multicolumn{5}{|l|}{ 3.3.1 O software é fácil de operar e controlar } \\
\hline \multicolumn{5}{|l|}{ 3.3.2 O software fornece ajuda de forma clara } \\
\hline \multicolumn{5}{|l|}{ 4.1.1 O tempo de resposta do software é adequado } \\
\hline \multicolumn{5}{|l|}{ 4.1.2 O tempo de execução do software é adequado } \\
\hline 4.2.1 Os recursos utilizados pelo software são adequados & & & & \\
\hline
\end{tabular}

COMENTÁRIOS GERAIS: 


\section{ANEXO III \\ TERMO DE CONSENTIMENTO LIVRE E ESCLARECIDO}

Prezado Colega,

Estamos realizando uma pesquisa intitulada "A Tecnologia Computacional Móvel na Sistematização da Assistência de Enfermagem: Avaliação de um Software-protótipo".

A fundamentação deste estudo caracteriza-se na utilização do Modelo do Processo de Avaliação segundo ISO 9126-1 para a avaliação da qualidade de um Software-protótipo para a sistematização da assistência de enfermagem junto a enfermeiros e especialistas em informática. Este modelo informatizado, com 12 módulos, referentes ao processo de planejamento da assistência de enfermagem é alicerçado nas considerações do Processo de Enfermagem segundo Wanda Horta (1979) e nas intervenções de enfermagem descritas por Carpenito (2000).

$>$ Tem por objetivo geral:- Avaliar a o desempenho funcional e a qualidade técnica de um Software-protótipo desenvolvido para a Sistematização da Assistência de Enfermagem utilizando-se do Modelo do Processo de Avaliação segundo a norma ISO/IEC 9126-1.

\section{Objetivos Específicos:}

- Avaliar junto a especialistas em Informática a qualidade técnica do software em questão.

- Avaliar junto a enfermeiros docentes e enfermeiros o desempenho funcional deste software à beira do leito.

Sendo assim, solicitamos a permissão para procedermos a avaliação deste Softwareprotótipo, assegurando que a pesquisa não trará custos, serão mantidos o sigilo e anonimato das informações e os participantes poderão se retirar a qualquer momento da pesquisa, sem qualquer prejuízo para os mesmos.

Desde já contamos com a sua colaboração e agradecemos a sua atenção.

Assinatura do entrevistado

Assinatura do entrevistador 


\section{ANEXO IV \\ TERMO DE CONSENTIMENTO PÓS-ESCLARECIMENTO}

Titulo da Pesquisa : A Tecnologia Computacional Móvel na Sistematização da Assistência de Enfermagem: Avaliação de um Software-protótipo".

Responsável pelo Projeto : Profa. Ms. Dircelene Jussara Sperandio

Instituição : Faculdade de Enfermagem de Catanduva

$\mathrm{Eu}$,

$R G$ n. $\stackrel{\circ}{ }$ abaixo assinado, concordo em participar deste estudo, tendo recebido informações sobre os objetivos, justificativas e procedimentos que serão adotados durante a sua realização, assim como, recebi orientação de que não haverá riscos de danos à dimensão física , psíquica ou moral dos participantes, em qualquer fase da pesquisa.

Autorizo a publicação das informações por mim oferecidas com a segurança de que não serei identificado e de que será mantido o caráter confidencial da informação relacionada com a minha privacidade.

Tendo ciência do exposto acima, assino esse termo de consentimento.

Data:

Assinatura do Pesquisado

Assinatura do Pesquisador 
Catanduva, 17 de outubro de 2005.

\section{Oficio $n^{\circ} 53 / 05$}

CEP/trbm

Ref.: Registro de Projeto de Trabalho Aprovado no CEP-FAMECA.

Prezado(a) Senhor(a):

Vimos informar Vossa Senhoria que o Projeto do Trabalho de Pesquisa intitulado "Avaliação de Software-Protótipo para a Sister atização da Assistência de Enfermagem", foi avaliado por este Comitê de Ética e Pesquisa a considerado aprovado, de acordo com as exigêr.cias das Resoluções Nacionais 196/96 e 251/97 da CONEP.

O registro de aprovação do referido Piojeto no Comitê de Ética em Pesquisa da Faculdade de Medicina de Catanduva é sob nº $\mathbf{4 1 / 0 5 .}$

Sendo o que temos a informar, subscrevemo-nos.

Atenciosamente.

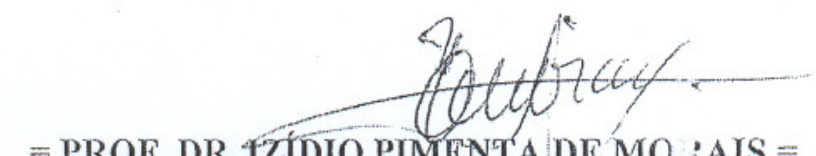

$=$ PROF. DR. 1ZIDIO PIMENTA DE MO.:AIS =
Coordenador do Comitê de Ética em Pesquisa d: FAMECA

Ilmo(a). Sr(a).

Dircelene Jussara Sperandio

Pesquisador(a) Responsável 